\title{
DDE-MURR Status Report of Conceptual Design Activities
}

N.E. Woolstenhulme

R.B. Nielson

M.H. Sprenger

G.K. Housley

September 2012

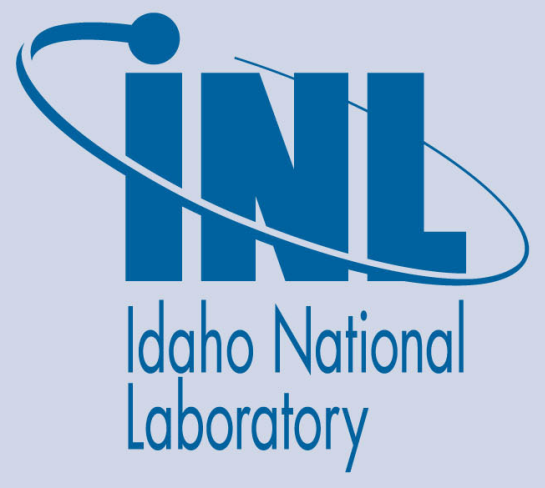

The INL is a U.S. Department of Energy National Laboratory operated by Battelle Energy Alliance 


\section{DISCLAIMER}

This information was prepared as an account of work sponsored by an agency of the U.S. Government. Neither the U.S. Government nor any agency thereof, nor any of their employees, makes any warranty, expressed or implied, or assumes any legal liability or responsibility for the accuracy, completeness, or usefulness, of any information, apparatus, product, or process disclosed, or represents that its use would not infringe privately owned rights. References herein to any specific commercial product, process, or service by trade name, trade mark, manufacturer, or otherwise, does not necessarily constitute or imply its endorsement, recommendation, or favoring by the U.S. Government or any agency thereof. The views and opinions of authors expressed herein do not necessarily state or reflect those of the U.S. Government or any agency thereof. 


\title{
DDE-MURR Status Report of Conceptual Design Activities
}

\author{
N.E. Woolstenhulme \\ R.B. Nielson \\ M.H. Sprenger \\ G.K. Housley
}

September 2012

Idaho National Laboratory Idaho Falls, Idaho 83415

http://www.inl.gov

\author{
Prepared for the
}

U.S. Department of Energy

Office of National Nuclear Security Administration

Under DOE Idaho Operations Office

Contract DE-AC07-05ID14517 


\section{DDE-MURR Status Report of Conceptual Design Activities}

INL/EXT-12-27078

N.E. Woolstenhulme

R.B. Nielson

M.H. Sprenger

G.K. Housley

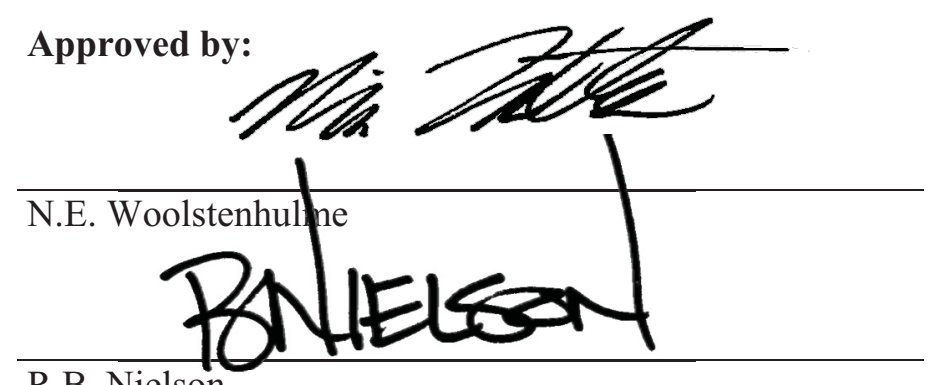

R.B. Nielson

$9-20-2012$

Date

$9-20-2012$

Date 


\section{CONTENTS}

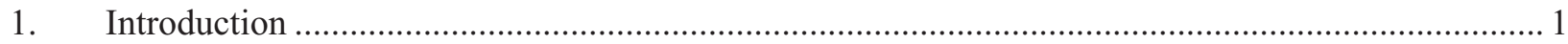

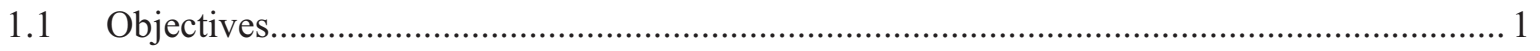

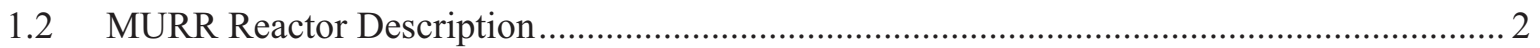

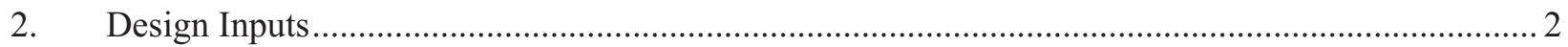

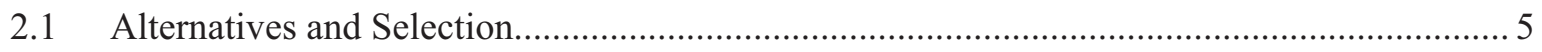

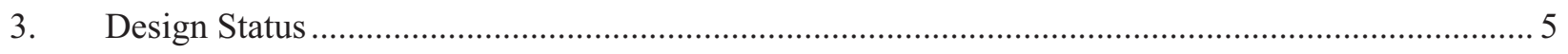

3.1 Experiment Design and Physics Analysis................................................................... 7

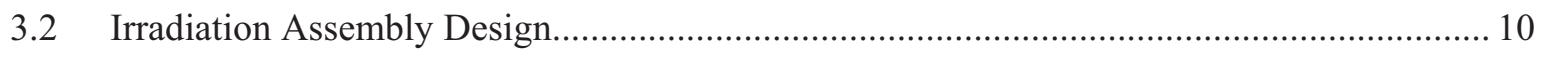

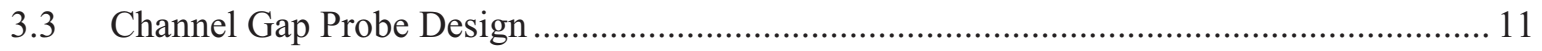

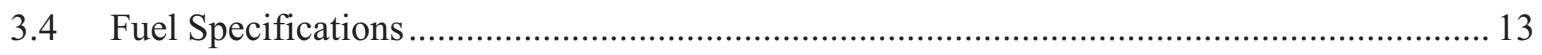

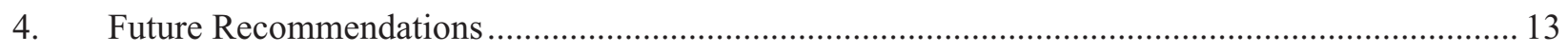

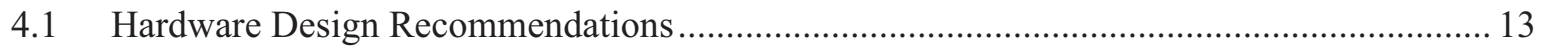

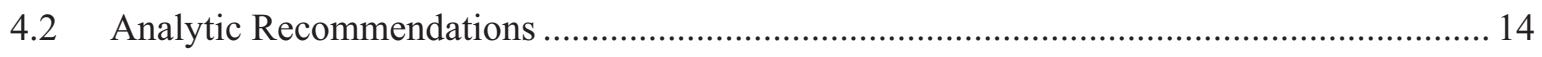

4.3 Design and Engineering Process Recommendations ........................................................ 15

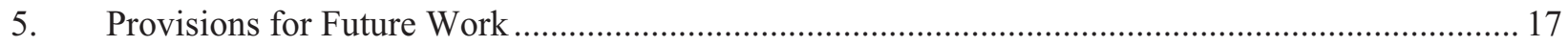

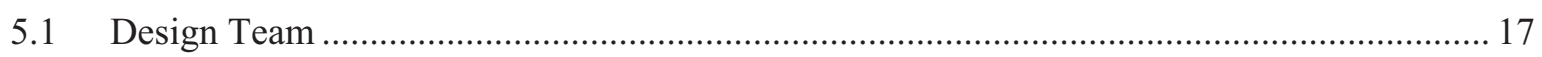

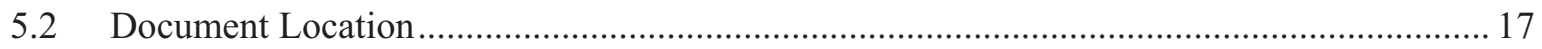

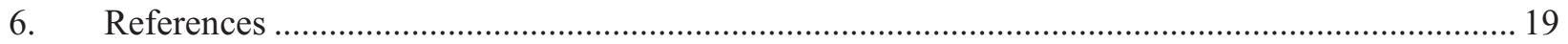




\section{Abstract}

The Design Demonstration Experiment for the University of Missouri Research Reactor (DDE-MURR) is intended to facilitate Low Enriched Uranium (LEU) conversion of the MURR by demonstrating the performance and fabrication of the LEU fuel element design through an irradiation test in a $200 \mathrm{~mm}$ channel at the Belgium Reactor 2. At the time this report was prepared the resources for furthering DDE design work were expected to be postponed. As such, the conceptual design effort to date is summarized herein in order to provide the status of key objectives, notable results, and provisions for future design work. These demonstrate that the DDE-MURR design effort is well on the path to producing a suitable irradiation experiment. This report also exhibits several recommendations in order to facilitate success of the irradiation campaign. 


\section{DDE-MURR Status Report of Conceptual Design Activities}

\section{Introduction}

The National Nuclear Security Agency Global Threat Reduction Initiative Convert (GTRI-Convert) program employs the Reduced Enrichment for Research and Test Reactors (RERTR) Fuel Development (FD) pillar to facilitate maturation of Low Enriched Uranium (LEU) fuel technology in order to enable conversion of High Power Research Reactors (HPRR) to these fuels. The RERTR FD pillar has overseen design, fabrication, irradiation, and examination of numerous tests on small to medium sized specimens containing these fuels. To enable three HPRR conversions, including the Massachusetts Institutes of Technology Reactor (MITR), University of Missouri Research Reactor (MURR), and National Bureau of Standard Reactor (NBSR), the FD pillar is currently focused on qualification of the "Base Monolithic Design". The Base Monolithic Design consists of uranium-10 wt\% molybdenum alloy (U-10Mo) in the form of a monolithic foil, with thin zirconium interlayers, clad in aluminum by hot isostatic press as seen in Figure 1. ${ }^{[1][2][3]}$

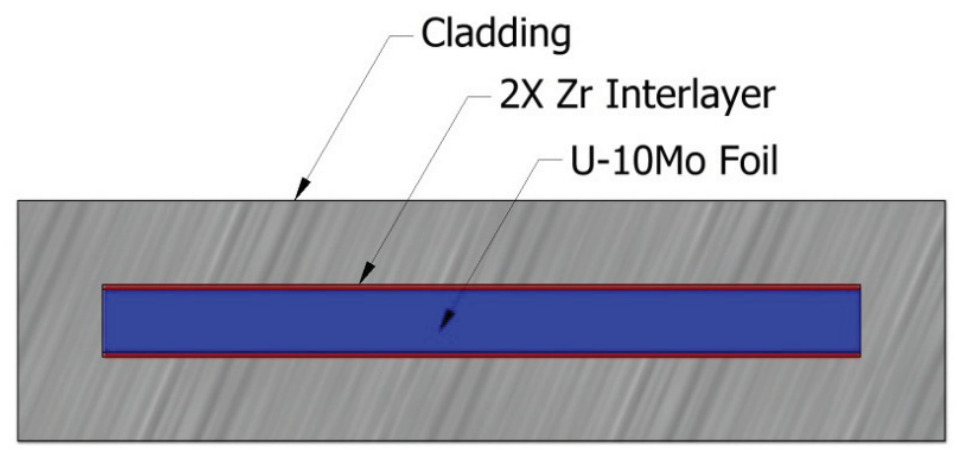

Figure 1: Base Monolithic Design

The licensing basis of the three aforementioned HPRR's restricts them from testing lead test elements of their respective LEU fuel element designs ${ }^{[4]}$. In lieu of the lead test assembly methodology, one Design Demonstration Experiment (DDE) for each of the three NRC licensed reactors will be irradiated elsewhere using prototypic fuel plate geometries under prototypic conditions (i.e. "end use application" in a "design environment" ${ }^{[5]}$ ). In terms of the technology life cycle, execution of the DDE campaign will represent a significant level of maturity as a "Development Work" activity and will be subject to all pertinent "Part I and applicable Part II" quality assurance requirements ${ }^{[6]}$.

\subsection{Objectives}

While absolute prototypic conditions may not be achievable in any reactor except the one for which the LEU element is designed, the DDE campaign is intended to accomplish several critical functions. The following list constitutes the core goals for the DDE campaign:

-Confirm Performance under stringent prototypic parameters (e.g. heat flux, fission density)

-Show Resistance to worrisome failure modes (e.g. fission gradients, thin-clad structural stability)

-Demonstrate Fabrication by producing the plates/elements as demonstration products ${ }^{[7]}$

- Give Confidence in the LEU fuel designs prior to conversion 


\subsection{MURR Reactor Description}

The MURR is a multi-disciplinary research and education facility providing a broad range of analytical and irradiation services. The MURR is a pressurized reactor which is both cooled and moderated by light water. The reactor core assembly is located eccentrically within a cylindrically-shaped, aluminum-lined pool as seen in Figure 2. The fuel region has a fixed geometry consisting of eight fuel elements having identical physical dimensions placed vertically around an annulus in between two cylindrical aluminum reactor pressure vessels ${ }^{[8]}$.

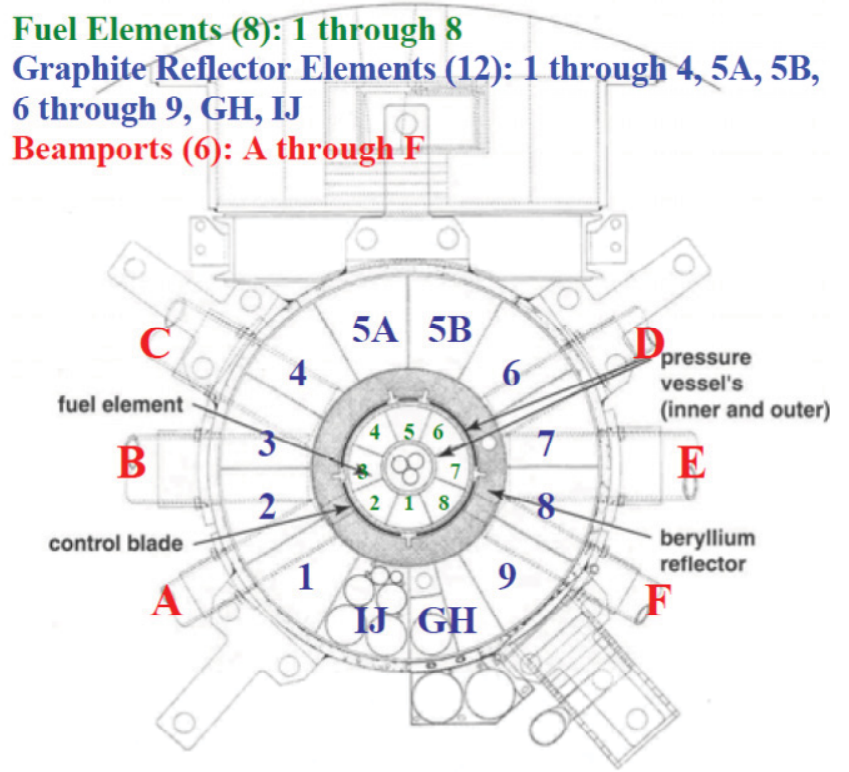

Figure 2: MURR Core Layout (reference [8])

\section{Design Inputs}

MURR critical geometry and irradiation parameters were established based on forthcoming conversion analyses provided by the GTRI-Convert Reactor Conversion (RC) pillar. The LEU fuel assembly will be comprised of 23 circumferential plates as seen in Figure 3. Nominal LEU fuel plate dimensions can be seen in Figure 4, Figure 5, Figure 6, and Table 1. Irradiation parameters are summarized in Table 2. 


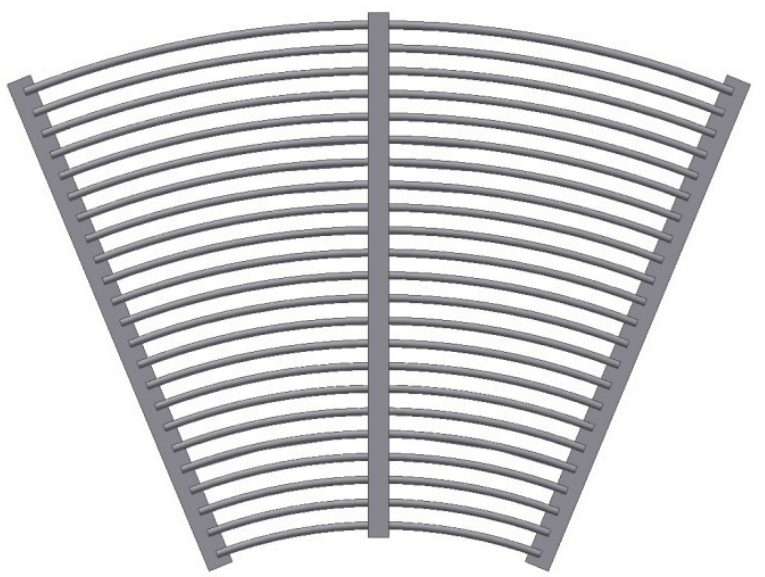

Figure 3: LEU MURR Fuel Element Design

MURR LEU Plate 1

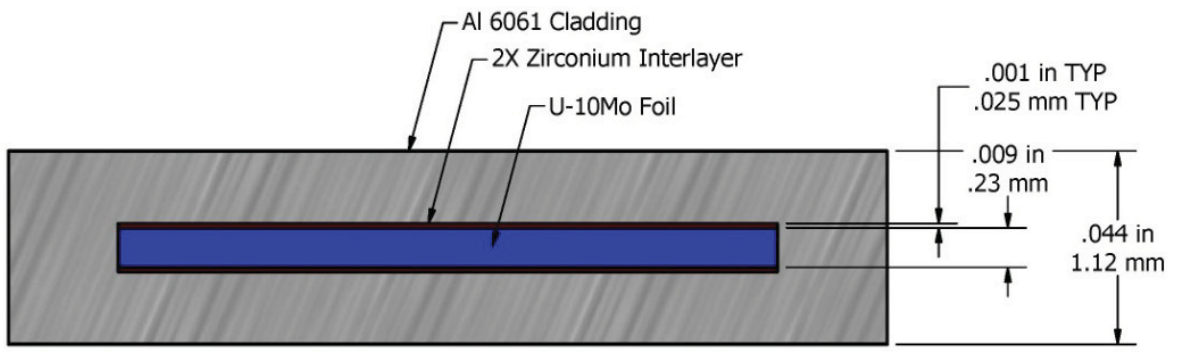

MURR LEU Plate 2

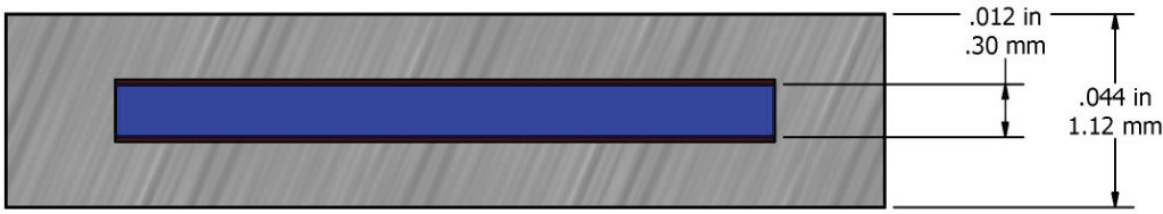

MURR LEU Plate 3

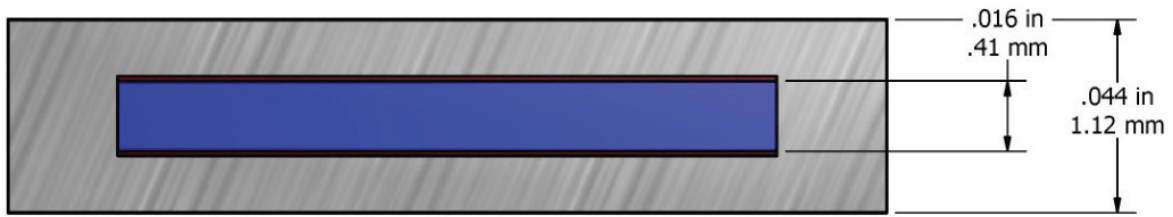

MURR LEU Plate 4 - 22
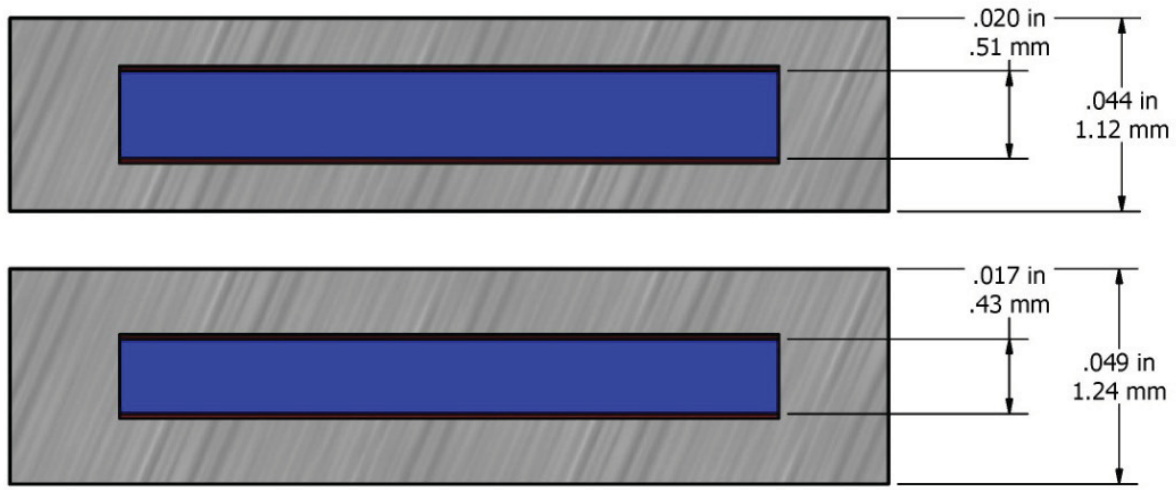

Figure 4: MURR LEU Fuel Plate Nominal Cross Sections 


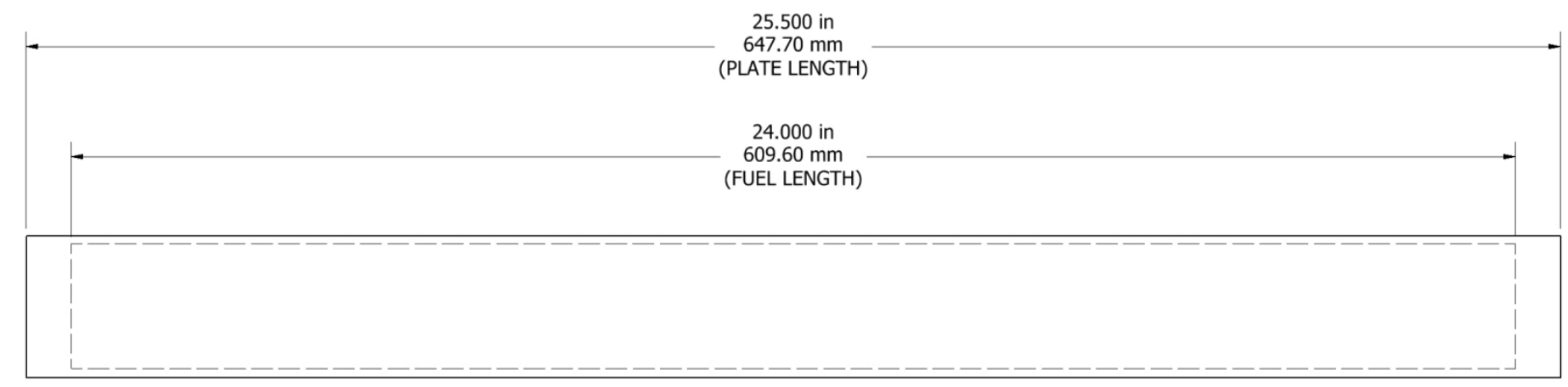

Figure 5: MURR LEU Fuel Plate Nominal Lengths

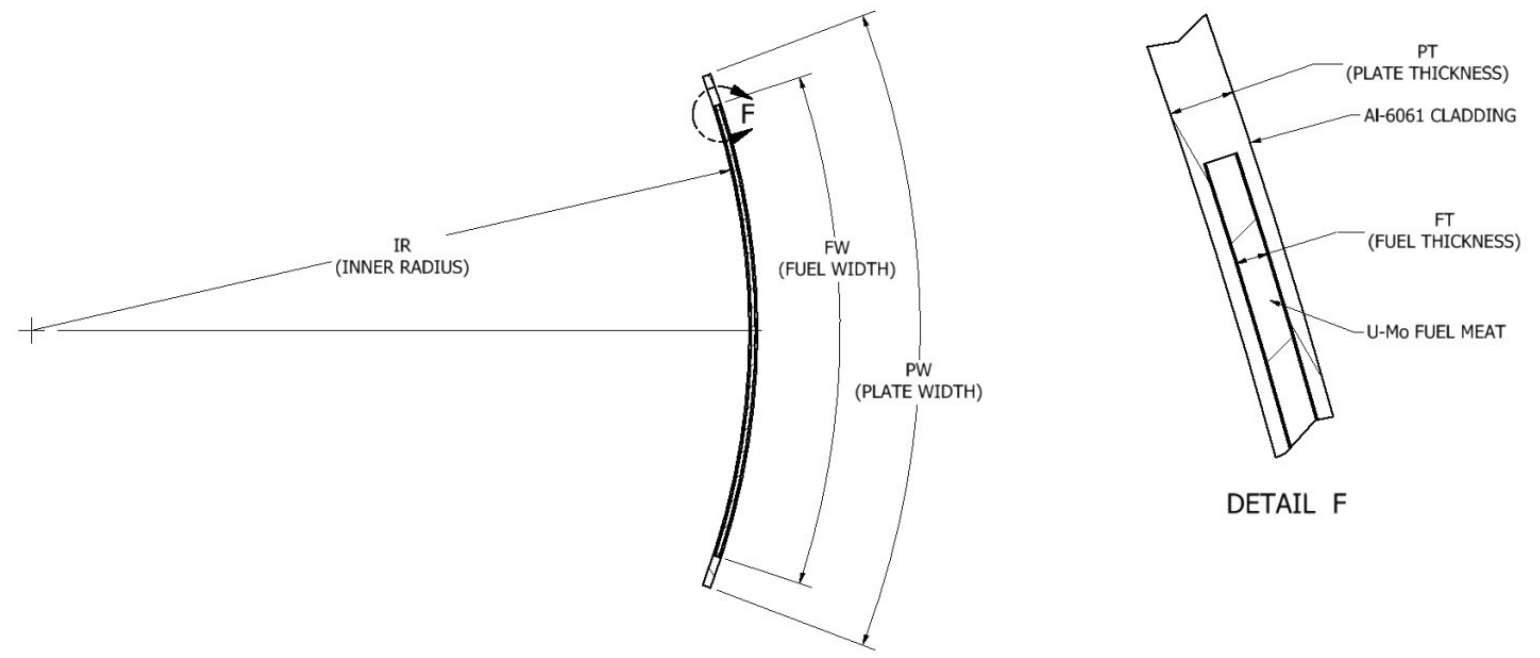

Figure 6: MURR LEU Fuel Plate Widths and Radii Sketch (see Table 1)

Table 1: MURR LEU Fuel Plate Nominal Dimensions

\begin{tabular}{|c|cc|cc|cc|cc|cc|}
\hline \multirow{2}{*}{ Plate } & \multicolumn{2}{|c|}{$\begin{array}{c}\text { Inner Radius } \\
\text { in }\end{array}$} & \multicolumn{2}{|c|}{ Fuel Width } & \multicolumn{2}{|c|}{ Plate Width } & \multicolumn{2}{c|}{ Plate Thickness } & \multicolumn{2}{c|}{ Fuel Thickness } \\
in & $\mathbf{m m}$ & in & mm & in & mm & in & mm \\
\hline $\mathbf{1}$ & 2.7555 & 69.99 & 1.690 & 42.93 & 1.980 & 50.29 & 0.044 & 1.12 & 0.009 & 0.23 \\
\hline $\mathbf{2}$ & 2.8925 & 73.47 & 1.797 & 45.64 & 2.087 & 53.01 & 0.044 & 1.12 & 0.012 & 0.30 \\
\hline $\mathbf{3}$ & 3.0295 & 76.95 & 1.905 & 48.39 & 2.195 & 55.75 & 0.044 & 1.12 & 0.016 & 0.41 \\
\hline $\mathbf{4}$ & 3.1665 & 80.43 & 2.012 & 51.10 & 2.302 & 58.47 & 0.044 & 1.12 & 0.020 & 0.51 \\
\hline $\mathbf{5}$ & 3.3035 & 83.91 & 2.120 & 53.85 & 2.410 & 61.21 & 0.044 & 1.12 & 0.020 & 0.51 \\
\hline $\mathbf{6}$ & 3.4395 & 87.36 & 2.227 & 56.57 & 2.517 & 63.93 & 0.044 & 1.12 & 0.020 & 0.51 \\
\hline $\mathbf{7}$ & 3.5755 & 90.82 & 2.334 & 59.28 & 2.624 & 66.65 & 0.044 & 1.12 & 0.020 & 0.51 \\
\hline $\mathbf{8}$ & 3.7115 & 94.27 & 2.440 & 61.98 & 2.730 & 69.34 & 0.044 & 1.12 & 0.020 & 0.51 \\
\hline $\mathbf{9}$ & 3.8475 & 97.73 & 2.547 & 64.69 & 2.837 & 72.06 & 0.044 & 1.12 & 0.020 & 0.51 \\
\hline $\mathbf{1 0}$ & 3.9835 & 101.18 & 2.654 & 67.41 & 2.944 & 74.78 & 0.044 & 1.12 & 0.020 & 0.51 \\
\hline $\mathbf{1 1}$ & 4.1195 & 104.64 & 2.761 & 70.13 & 3.051 & 77.50 & 0.044 & 1.12 & 0.020 & 0.51 \\
\hline $\mathbf{1 2}$ & 4.2555 & 108.09 & 2.868 & 72.85 & 3.158 & 80.21 & 0.044 & 1.12 & 0.020 & 0.51 \\
\hline $\mathbf{1 3}$ & 4.3915 & 111.54 & 2.974 & 75.54 & 3.264 & 82.91 & 0.044 & 1.12 & 0.020 & 0.51 \\
\hline $\mathbf{1 4}$ & 4.5275 & 115.00 & 3.081 & 78.26 & 3.371 & 85.62 & 0.044 & 1.12 & 0.020 & 0.51 \\
\hline $\mathbf{1 5}$ & 4.6635 & 118.45 & 3.188 & 80.98 & 3.478 & 88.34 & 0.044 & 1.12 & 0.020 & 0.51 \\
\hline
\end{tabular}




\begin{tabular}{|l|ll|ll|ll|ll|ll|}
$\mathbf{1 6}$ & 4.7995 & 121.91 & 3.295 & 83.69 & 3.585 & 91.06 & 0.044 & 1.12 & 0.020 & 0.51 \\
\hline $\mathbf{1 7}$ & 4.9355 & 125.36 & 3.402 & 86.41 & 3.692 & 93.78 & 0.044 & 1.12 & 0.020 & 0.51 \\
\hline $\mathbf{1 8}$ & 5.0715 & 128.82 & 3.508 & 89.10 & 3.798 & 96.47 & 0.044 & 1.12 & 0.020 & 0.51 \\
\hline $\mathbf{1 9}$ & 5.2075 & 132.27 & 3.615 & 91.82 & 3.905 & 99.19 & 0.044 & 1.12 & 0.020 & 0.51 \\
\hline $\mathbf{2 0}$ & 5.3445 & 135.75 & 3.723 & 94.56 & 4.013 & 101.93 & 0.044 & 1.12 & 0.020 & 0.51 \\
\hline $\mathbf{2 1}$ & 5.4815 & 139.23 & 3.830 & 97.28 & 4.120 & 104.65 & 0.044 & 1.12 & 0.020 & 0.51 \\
\hline $\mathbf{2 2}$ & 5.6185 & 142.71 & 3.938 & 100.03 & 4.228 & 107.39 & 0.044 & 1.12 & 0.020 & 0.51 \\
\hline $\mathbf{2 3}$ & 5.7555 & 146.19 & 4.048 & 102.82 & 4.338 & 110.19 & 0.049 & 1.24 & 0.017 & 0.43 \\
\hline
\end{tabular}

Table 2: MURR Operating Conditions and Reactor Parameters

\begin{tabular}{|c|c|c|}
\hline Parameter & LEU Core Nominal & DDE Target \\
\hline Average Coolant Velocity $(\mathrm{m} / \mathrm{s})^{[9]}$ & 7.0 & $\sim 7.0$ \\
\hline Beginning of Life Element Power $(\mathrm{MW})^{[9]}$ & 1.58 & $>1.58$ \\
\hline Peak Local Heat Flux $\left(\mathrm{W} / \mathrm{cm}^{2}\right)^{[9]}$ & $215^{*}$ & $>215$ \\
\hline Peak Plate Surface Temp $\left({ }^{\circ} \mathrm{C}\right)^{[10]}$ & 114 & $\sim 114$ \\
\hline Peak Fuel Meat Centerline Temp $\left({ }^{\circ} \mathrm{C}\right)^{[10]}$ & 140 & $\sim 140$ \\
\hline Peak Fission Density (fissions/cc $)^{[9]}$ & $4.0 \mathrm{E}+21^{\dagger}$ & $>4.0 \mathrm{E}+21$ \\
\hline
\end{tabular}

${ }^{*}$ Peak local heat flux occurs on plate 23

${ }^{\dagger}$ Peak fission density occurs in plate 1

While the above geometries and parameters were subject to change, they were assumed based on the best information available at the onset of the DDE-MURR effort and were used for scoping analysis activities. A formalized submission of the experiment's critical characteristics was requested from the RC pillar with the intent of including these, among other requirements, in a Functional and Operational Requirements (F\&OR) document. Receipt of this submittal was delayed. As a result, the above parameters were also assumed as the key inputs for the conceptual design work. The F\&OR document was not approved as a final document, but the draft document is included in this report for reference purposes and can be seen in Appendix A.

\subsection{Alternatives and Selection}

Several irradiation locations were considered and it was determined that DDE-MURR would be best suited for irradiation in one of the $200 \mathrm{~mm}$ " $\mathrm{H}$ " positions of the Belgium Reactor 2 (BR2). This is documented elsewhere ${ }^{[11]}$.

\section{Design Status}

The DDE design effort was commenced in mid 2010 for three distinct campaigns; one for each MITR, MURR, and NBSR. This was premised around the original proposal to irradiate each in an Advanced Test Reactor (ATR) Medium I position. As a result, the efforts primarily concerned designing an experiment, consisting of LEU fuel meat, which would fit in to the Medium I position geometry, which can accommodate just over three inches of useable test geometry with the existing liner cans removed ${ }^{[12]}$, while meeting the ATR TSR requirement of $<365 \mathrm{~g} \mathrm{U}-235$ per experiment position ${ }^{[13]}$. 
Resources for designers and analysts were difficult to ascertain until the effort was better funded in Fiscal Year 2011 (FY11). It was at this point that analysts identified that the low fluence of ATR I positions gave fission rates which failed to approach the irradiation conditions of each reactor. Budget cuts in March of 2011 caused suspension of further investigations until June of that year when a small budget was allocated to evaluate DDE designs with increased fuel meat enrichment (i.e. HEU). While scoping analysis indicated that HEU fuel meat could give fission rates representative of the MITR, these efforts were unsuccessful for the DDE-MURR and DDE-NBSR experiments. As a result, alternate experiment positions were evaluated and one of the $200 \mathrm{~mm}$ " $\mathrm{H}$ " positions of the Belgium Reactor 2 (BR2) was selected for DDE-MURR ${ }^{[8]}$.

The DDE work languished somewhat due to inadequate funding in FY11, but was revived in FY12 with meaningful funding and allocation of personnel. This is the general timeframe when the conceptual design work is considered to have been commenced. Design efforts for DDE-MITR and DDE-NBSR (both planned for irradiation in ATR) were aggressive in early FY12 in order to accommodate an HPRR conversion schedule which would require completion of these DDE's irradiation around 2015 while DDE-MURR represented a different schedule strategy due to irradiation in BR2. Efforts were undertaken to mature this schedule in collaboration with BR2 personnel. Experiment plans were drafted and called for formal submission of the aforementioned Critical Characteristics, as well as another set of inputs referred to as the Technical Tolerances, from the RC pillar in mid FY12. These were intended to facilitate further design work and production of specifications for the DDE U-Mo coupons and fuel elements. This planning effort also identified the need for design and engineering of a new Channel Gap Probe (CGP) to be installed at BR2 to support characterization of the DDE-MURR element coolant channels before, during, and after irradiation. INL held regular conference calls with key personnel from the RC and Fuel Fabrication Capability (FFC) pillars as well as representatives from the each reactor in order to define experiment parameters, discuss design options, and foster communication between the design team and stakeholders.

Formal submission of both the Critical Characteristics and Technical Tolerances was postponed due to reprioritization of GTRI-Convert personnel resources which was caused, to some extent, caused by emergent PIE blister threshold results from the RERTR-12 and AFIP-4 campaigns ${ }^{[14]}$. These prompted reduction of the DDE funding level in mid FY12 with the intent to complete less design work than originally intended. Regardless, the aforementioned specifications were produced for each DDE design, but are considered to be inadequately mature for fabrication of final DDE products, are discussed in greater detail in section 3.4, and are included in Appendices B and C for reference purposes. While these were not required as INL milestones as were the same for DDE-MITR and DDE-NBSR, completion of the DDE-MURR draft specifications was undertaken in the interest of good documentation as it only required minimal modification of those produced for the other DDE campaigns.

Due to difficulties in arranging onsite meetings (i.e. at BR2), which eventually proved to be paramount in defining the scope, schedule, roles, and responsibilities of both GTRI and BR2 personnel, the status of the DDE-MURR design work trailed that of DDE-MITR and DDE-NBSR slightly. However, the DDEMURR conceptual design work saw meaningful acceleration in the second half of FY12. Personnel from the RC pillar were instrumental in providing the majority of the needed information, prior to official submittal of the Critical Characteristics document in late FY12, in a detailed presentation on the emergent MURR "CD-35" design with the new 23 plate LEU element geometric scheme and the corresponding irradiation conditions ${ }^{[9]}$. This material was presented at the initial BR2 onsite meeting in April of 2012 and enabled BR2 personnel to proceed with more detail physics analysis ${ }^{[15]}$. The initial onsite meeting also revealed that BR2 did not have adequate personnel to support the design of the irradiation vehicle and CGP and requested that INL provide design, engineering, drafting, and fabrication services in this regard. A second design meeting with BR2 in June of 2012 saw significant maturation of the design needs and preferred concepts for the irradiation vehicle and CGP as summarized in sections 3.2 and 3.3, respectively. 
Toward the latter end of FY12 several factors drove a new HPRR conversion schedule to be proposed. This invalidated some the original DDE design assumptions, particularly those pertaining to schedule constraints, and also gave way to a suspension of DDE-related funding in FY13. As a result, the DDE design team endeavored to use the remaining FY12 resources to finalize a few important activities and document the results in preparation for a hiatus in DDE design work; resulting in the preparation of this document. However, funding overruns in another project which shared the DDE control account forced abandonment of some critical DDE design activities. These, in combination with the already trailing design work, gave way to a conceptual design status that was not considered entirely complete at the time this report was prepared. Recommendations, concerns, risk, incomplete activities, and other useful information are presented in section 4 for the purpose of facilitating future DDE design work.

\subsection{Experiment Design and Physics Analysis}

The DDE-MURR experiment was designed to accommodate a full size MURR fuel element in accordance with the objective to irradiate prototypic plate geometry. This geometry could fit within a $200 \mathrm{~mm}$ channel in the BR2. In order to accommodate international shipping considerations, design options such as $>20 \%$ fuel meat enrichment were not explored as a means of tailoring the fission rates within the experiment design. Constituent compositions of the LEU fuel plates can be seen in Table 3.

Table 3: DDE-MURR Nominal Plate Volumes and Masses

\begin{tabular}{|c|c|c|c|c|c|c|c|c|c|}
\hline \multirow[b]{3}{*}{ Plate } & \multicolumn{3}{|c|}{ Constituent Volumes } & \multicolumn{6}{|c|}{ Constituents Masses } \\
\hline & \multirow{2}{*}{$\begin{array}{c}\begin{array}{c}\text { Fuel } \\
\text { Core }\end{array} \\
\begin{array}{c}\text { U-Mo } \\
\text { Volume } \\
\left(\mathbf{c m}^{3}\right)\end{array}\end{array}$} & \multirow{2}{*}{$\begin{array}{c}\text { Interlayer } \\
\begin{array}{c}\mathrm{Zr} \\
\text { Volume } \\
\left(\mathrm{cm}^{3}\right)\end{array}\end{array}$} & \multirow{2}{*}{$\begin{array}{c}\text { Cladding } \\
\text { Al-6061 } \\
\text { Volume } \\
\left(\mathrm{cm}^{3}\right)\end{array}$} & \multicolumn{4}{|c|}{ Fuel Core } & \multirow{2}{*}{$\begin{array}{c}\text { Interlayer } \\
\text { Zr Mass } \\
\text { (g) }\end{array}$} & \multirow{2}{*}{$\begin{array}{l}\text { Cladding } \\
\text { Al-6061 } \\
\text { Mass (g) }\end{array}$} \\
\hline & & & & $\begin{array}{c}\text { U-Mo } \\
\text { Mass } \\
\text { (g) }\end{array}$ & $\begin{array}{c}\text { Total U } \\
\text { Mass (g) }\end{array}$ & $\begin{array}{c}\text { U-235 } \\
\text { Mass } \\
\text { (g) }\end{array}$ & $\begin{array}{c}\text { Mo Mass } \\
\text { (g) }\end{array}$ & & \\
\hline 1 & 5.98 & 1.33 & 29.09 & 101.81 & 91.63 & 18.10 & 10.18 & 8.68 & 78.55 \\
\hline 2 & 8.48 & 1.41 & 28.48 & 144.34 & 129.91 & 25.66 & 14.43 & 9.23 & 76.89 \\
\hline 3 & 11.99 & 1.50 & 26.87 & 204.03 & 183.62 & 36.27 & 20.40 & 9.78 & 72.55 \\
\hline 4 & 15.83 & 1.58 & 24.92 & 269.36 & 242.42 & 47.88 & 26.94 & 10.33 & 67.27 \\
\hline 5 & 16.68 & 1.67 & 25.97 & 283.82 & 255.43 & 50.45 & 28.38 & 10.89 & 70.11 \\
\hline 6 & 17.52 & 1.75 & 27.01 & 298.14 & 268.33 & 52.99 & 29.81 & 11.44 & 72.93 \\
\hline 7 & 18.36 & 1.84 & 28.05 & 312.47 & 281.22 & 55.54 & 31.25 & 11.99 & 75.74 \\
\hline 8 & 19.19 & 1.92 & 29.08 & 326.66 & 293.99 & 58.06 & 32.67 & 12.53 & 78.52 \\
\hline 9 & 20.03 & 2.00 & 30.12 & 340.98 & 306.88 & 60.61 & 34.10 & 13.08 & 81.34 \\
\hline 10 & 20.88 & 2.09 & 31.17 & 355.31 & 319.78 & 63.16 & 35.53 & 13.63 & 84.15 \\
\hline 11 & 21.72 & 2.17 & 32.21 & 369.63 & 332.67 & 65.70 & 36.96 & 14.18 & 86.96 \\
\hline 12 & 22.56 & 2.26 & 33.25 & 383.96 & 345.56 & 68.25 & 38.40 & 14.73 & 89.77 \\
\hline 13 & 23.39 & 2.34 & 34.28 & 398.15 & 358.33 & 70.77 & 39.81 & 15.28 & 92.56 \\
\hline 14 & 24.23 & 2.42 & 35.32 & 412.47 & 371.22 & 73.32 & 41.25 & 15.83 & 95.37 \\
\hline 15 & 25.08 & 2.51 & 36.36 & 426.80 & 384.12 & 75.86 & 42.68 & 16.37 & 98.18 \\
\hline 16 & 25.92 & 2.59 & 37.41 & 441.12 & 397.01 & 78.41 & 44.11 & 16.92 & 100.99 \\
\hline 17 & 26.76 & 2.68 & 38.45 & 455.45 & 409.90 & 80.96 & 45.54 & 17.47 & 103.81 \\
\hline 18 & 27.59 & 2.76 & 39.48 & 469.64 & 422.67 & 83.48 & 46.96 & 18.02 & 106.59 \\
\hline 19 & 28.43 & 2.84 & 40.52 & 483.96 & 435.56 & 86.02 & 48.40 & 18.57 & 109.40 \\
\hline 20 & 29.28 & 2.93 & 41.57 & 498.42 & 448.58 & 88.59 & 49.84 & 19.12 & 112.24 \\
\hline 21 & 30.13 & 3.01 & 42.61 & 512.74 & 461.47 & 91.14 & 51.27 & 19.67 & 115.05 \\
\hline 22 & 30.98 & 3.10 & 43.66 & 527.20 & 474.48 & 93.71 & 52.72 & 20.23 & 117.89 \\
\hline 23 & 27.06 & 3.18 & 58.57 & 460.64 & 414.58 & 81.88 & 46.06 & 20.79 & 158.15 \\
\hline \multicolumn{4}{|c|}{ Mass Totals (g) } & 8477.08 & 7629.37 & 1506.80 & 847.71 & 338.78 & 2145.04 \\
\hline
\end{tabular}


Physics analysis of a $20 \%$ enriched DDE-MURR design in a peripheral (i.e. not center) $200 \mathrm{~mm}$ " $\mathrm{H}$ " channel, combined with BR2's "flexible" core loading schemes, showed that prototypic fission rates were achievable in the BR2. The physics analysis assumed the experiment to be fixtured within two aluminum "plugs", the larger outer plug containing an eccentric hole for the smaller inner plug with the inner plug containing a cavity for the DDE-MURR element. This was evaluated in the BR2 H5, H4, and H3 channels as seen in Figure 7.
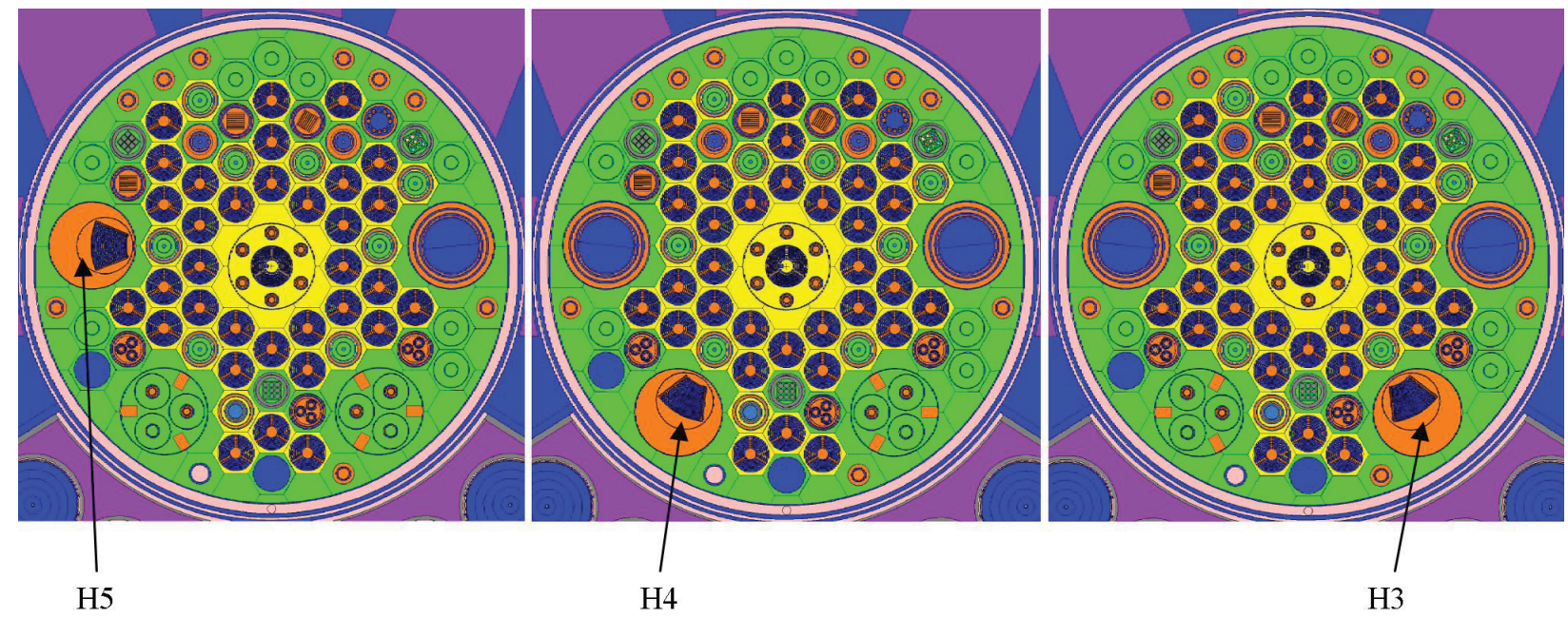

Figure 7: DDE-MURR in Various 200mm H Channels

The target peak heat flux for DDE-MURR was $215 \mathrm{~W} / \mathrm{cm}^{2}$ occurring on plate 23. MCNPX was used to model and evaluate these configurations ${ }^{[15]}$ and showed a peak Beginning of Life (BOL) heat flux of 238 $\mathrm{W} / \mathrm{cm}^{2}, 211 \mathrm{~W} / \mathrm{cm}^{2}$, and $219 \mathrm{~W} / \mathrm{cm}^{2}$ in the $\mathrm{H} 5, \mathrm{H} 4$, and $\mathrm{H} 3$ channels, respectively. A final determination regarding which $\mathrm{H}$ channel to use was not made during this phase of the design, but all seemed to be fair matches for the MURR heat flux. This determination should be made when the future DDE-MURR and BR2 schedules become more mature and will likely include considerations of other BR2 irradiation users.

These calculations included axially and azimuthally resolved cells to account for edge peaking. Unlike the projected LEU MURR design, however, these peaks occurred on those plates with full-thickness fuel which were nearest the core center (i.e. plates 3 and 4). In general, the plate-to-plate power profiles exhibited more suppressed powers on the trailing plates than would be expected in the LEU MURR design as seen in Figure 8 and Figure 9. 


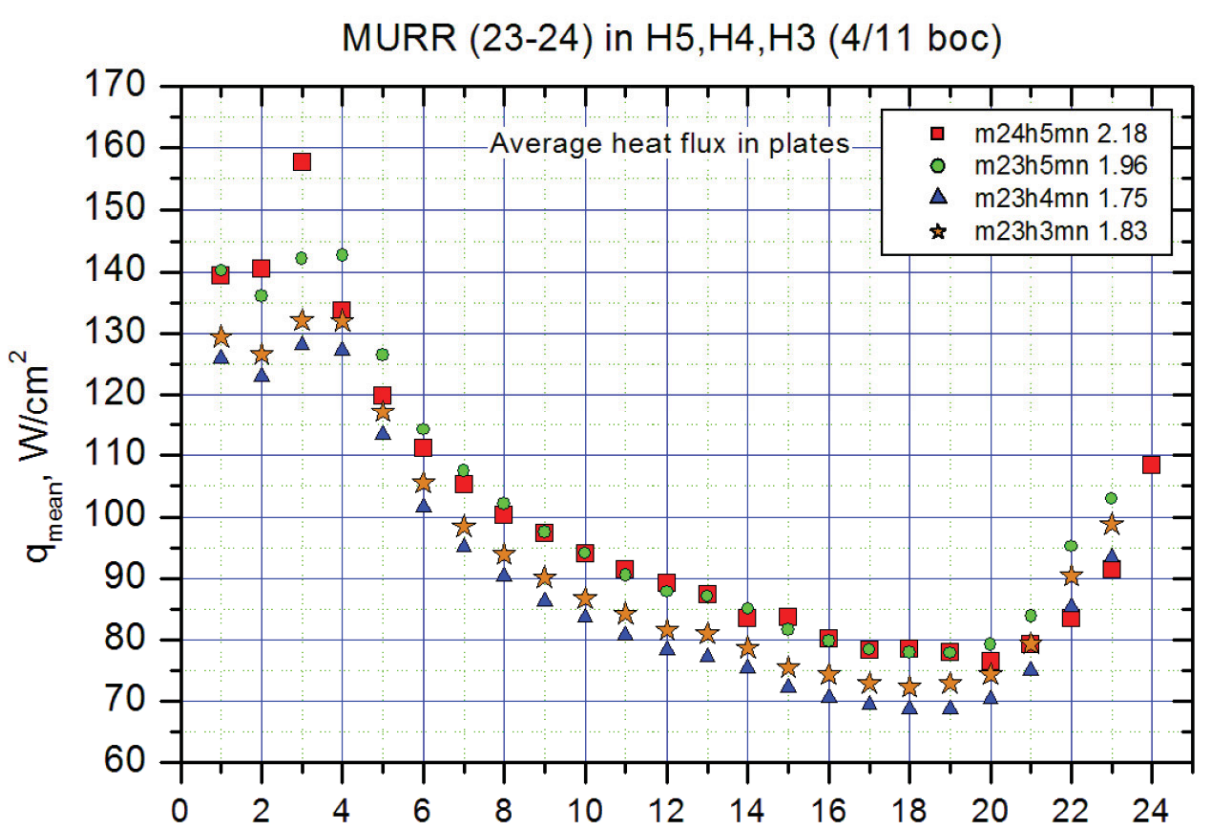

Figure 8: DDE-MURR Plate-to-Plate Average BOL Heat Flux Plot with Plate 1 Leading (LEU 24 plate design also plotted in red)

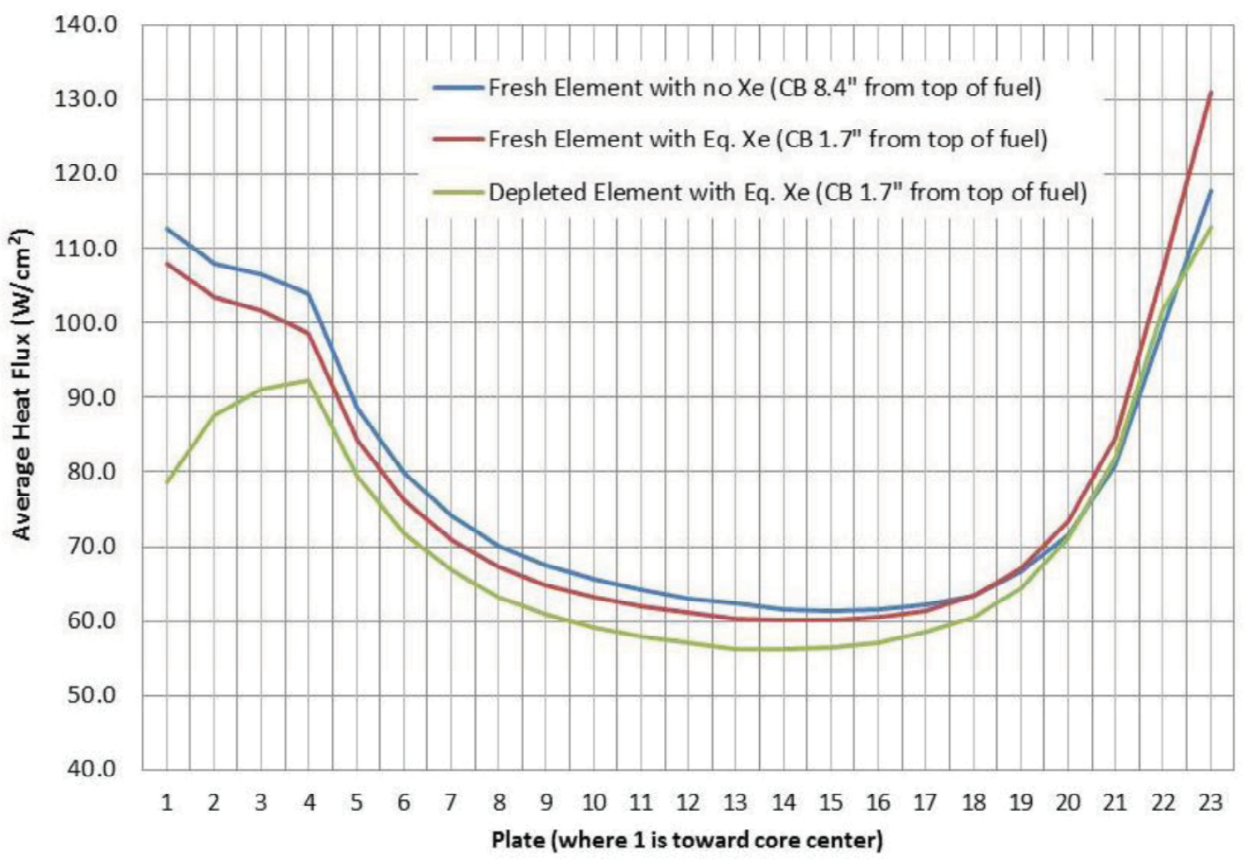

Figure 9: MURR Plate-to-Plate Average Heat Flux Plot (reference [16])

These behaviors are due to inherent differences in the spatial distribution of the thermal flux profiles within the MURR and BR2 reactors. However, design options which include cycle-to-cycle $180^{\circ}$ rotation of the DDE-MURR inner plug were suggested in order to orient plate 23 as the "leading" plate during some cycles to achieve peak heat fluxes targets on the correct plate, while orienting plate 1 as the "leading" plate during other cycles in order to achieve peak fission density targets on the correct plate. These should be investigated in greater detail in the future. 
While detailed depletion analyses were not performed, an assumption of linearly decreasing plate fission rates estimated achievement of the fission density goal $(4.0 \mathrm{E}+21$ fissions/cc in plate 1$)$ in $\sim 130$ full power days where plate 1 is configured nearest the core center for every cycle. Alternating rotational schemes, while not yet investigated in detail, would somewhat extend the time required to achieve this goal in plate 1 as they would orient plate 1 furthest from the core center during some cycles, but would likely induce a more prototypic plate-to-plate burnup profile in the final irradiated element.

More detailed physics analyses, thermal hydraulic analyses, and structural evaluations were not accomplished during this phase of the design. The intent was to design an irradiation vehicle which throttles flowrates to match those of the project LEU MURR core. This design feature was thought to require additional thermal analysis for flow coastdown and reversal in the BR2. Irradiation vehicle and CGP design efforts were also undertaken in some measure. These are summarized in sections 3.2 and 3.3.

\subsection{Irradiation Assembly Design}

Layouts of the hardware designs can be found in Appendix D. Functional and Operational Requirements document FOR-118 was initiated to capture the requirements for the DDE-MURR design. This design incorporated the requirements to be irradiated in the BR2 reactor and was design with the following fundamental features, see also Figure 10: DDE-MURR Irradiation Assembly:

- BR2 Outer Pressure Boundary: This outer tube is approximately $7.7 \mathrm{~m}$ (25.5 feet) long and slightly smaller than the $200 \mathrm{~mm}$ diameter of the BR2 H position irradiation tube. The boundary tube incorporates an upper lifting bail and lower catcher. The catcher will contain the fuel if there is a meltdown condition. The irradiation zone contains the vehicle portion which is comprised primarily of aluminum and serves the purpose of holding the fuel element and displacing water between the cylindrical channel and element. The eccentric inner plug concept, as seen in Figure 7 , was not investigated during this initial concept generation.

- The Irradiation Vehicle: The irradiation vehicle is approximately 26 inches $(660 \mathrm{~mm})$ in length and 6 inches in $(150 \mathrm{~mm})$ diameter. It is designed to contain the MURR LEU 23 plate fuel during the irradiation process. This portion includes orientation slots at $90^{\circ}$ to facilitate alternate orientation schemes as discussed in section 3.1 (e.g. 180 cycle-to-cycle rotation).

- The E-FUTURE style Grapple: This grapple is designed to provide the irradiation vehicle's handling interface. The grapple will also have the typical MURR End Box attached so that it will be part of the irradiation process but will be removed after placement in the Channel Gap Probe basket.

- Upper Sealing Plug: This plug seals the reactor channels during the irradiation process. This design also allows the entire assembly to be lifted out or for removal of just the irradiation vehicle with the BR2 lift bail. 


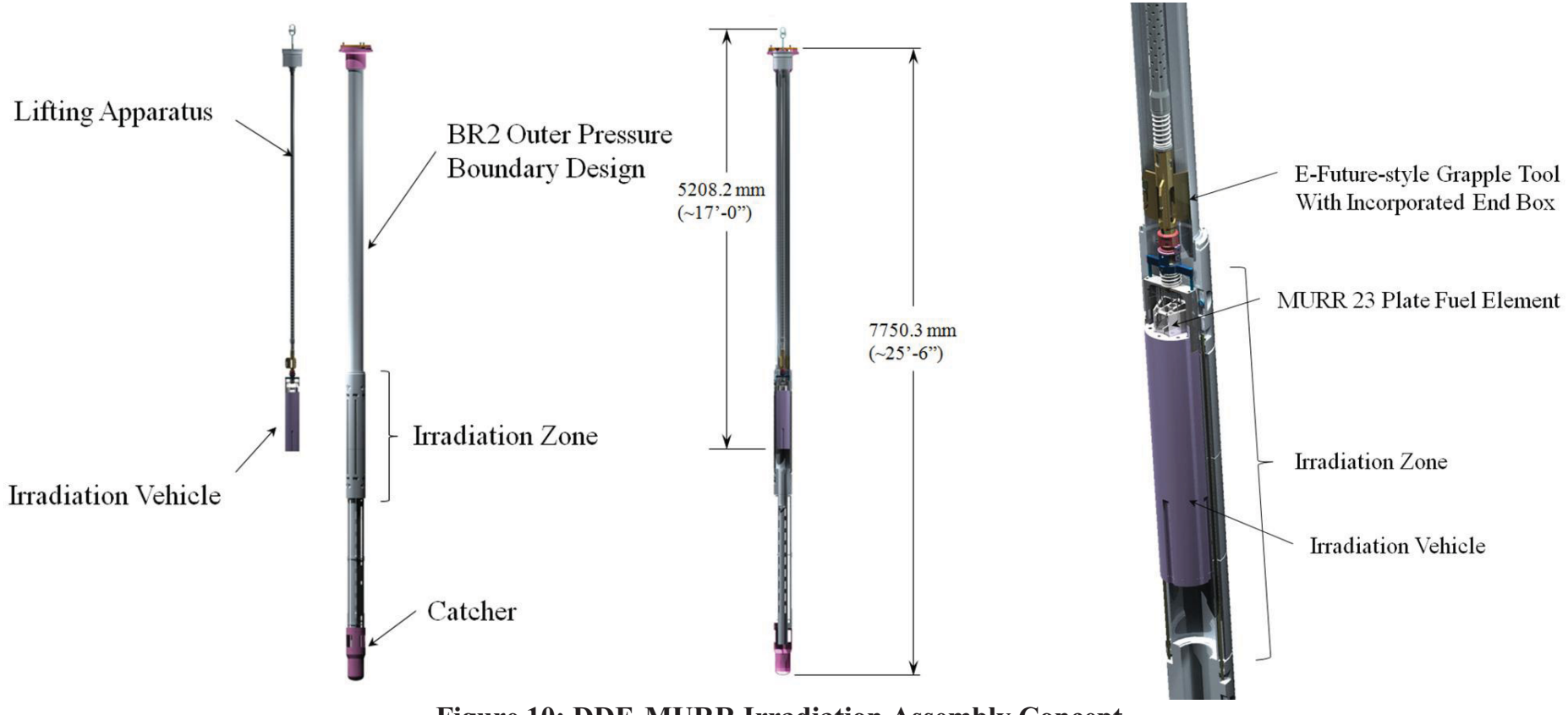

Figure 10: DDE-MURR Irradiation Assembly Concept

Overall, the irradiation vehicle design was just beginning to emerge at the time that the DDE funding was suspended. Further design maturation will be needed upon resumption of the DDE-MURR effort. Future recommendations are detailed in section 4.1.

\subsection{Channel Gap Probe Design}

Layouts of the Channel Gap Probe (CGP) hardware designs can be found in Appendix E. Functional and Operational Requirements document FOR-118 was initiated to capture the requirements for the DDEMURR design, including the CGP. The Channel Gap Probe measurements taken before, during, and after irradiation are key to the DDE-MURR mission. As BR2 did not have this capability existing, a BR2specific CGP design was conceptualized with the following key features (see also Figure 11):

- Basket Frame Assembly: This outer frame is approximately 16 feet $(4.9 \mathrm{~m})$ long and 2 feet by 2 feet $(0.6 \mathrm{~m}$ by $0.6 \mathrm{~m})$. It holds the Irradiation Vehicle that contains the DDE-MURR fuel element. It mates with the probe frame using alignment pins corresponding to the E-Future grapple. The basket Frame Assembly stays in the canal for the entire fuel irradiation campaign.

- CGP to Fuel Alignment Assembly - This assembly consists of a plate that is 2 feet by 2 feet $(0.6 \mathrm{~m}$ by $0.6 \mathrm{~m})$ and a precisely located guide block (mimics the fuel shape) that aligns the fuel to the above Channel Gap Probe using alignment pins. This Guide Block aids the operators in inserting the probe in the correct spot without damage to the delicate probe.

- The Channel Gap Probe (CGP) Frame: This frame is approximately 16 feet $(4.9 \mathrm{~m})$ long and 2 feet by 2 feet $(0.6 \mathrm{~m}$ by $0.6 \mathrm{~m})$. This frame mates with the Basket Frame Assembly using the CGP to Fuel Alignment Assembly. The framework is removed from the canal following the completion of each fuel gap measurement.

- Probe movements: The probe is approximately 0.5 inch $(12 \mathrm{~mm})$ wide, 0.05 inch $(1.2 \mathrm{~mm})$ thick, and 4 feet $(1200 \mathrm{~mm})$ in length. The probe is capable of being moved in the $\mathrm{X}$ and $\mathrm{Y}$ planes, up and down $(Z)$, and rotated about the Z-axis. A system of gears enables these movements.

- Calibration Block: The probe passes through a calibration block before insertion into the MURR fuel to ensure consistent and accurate measurements. 


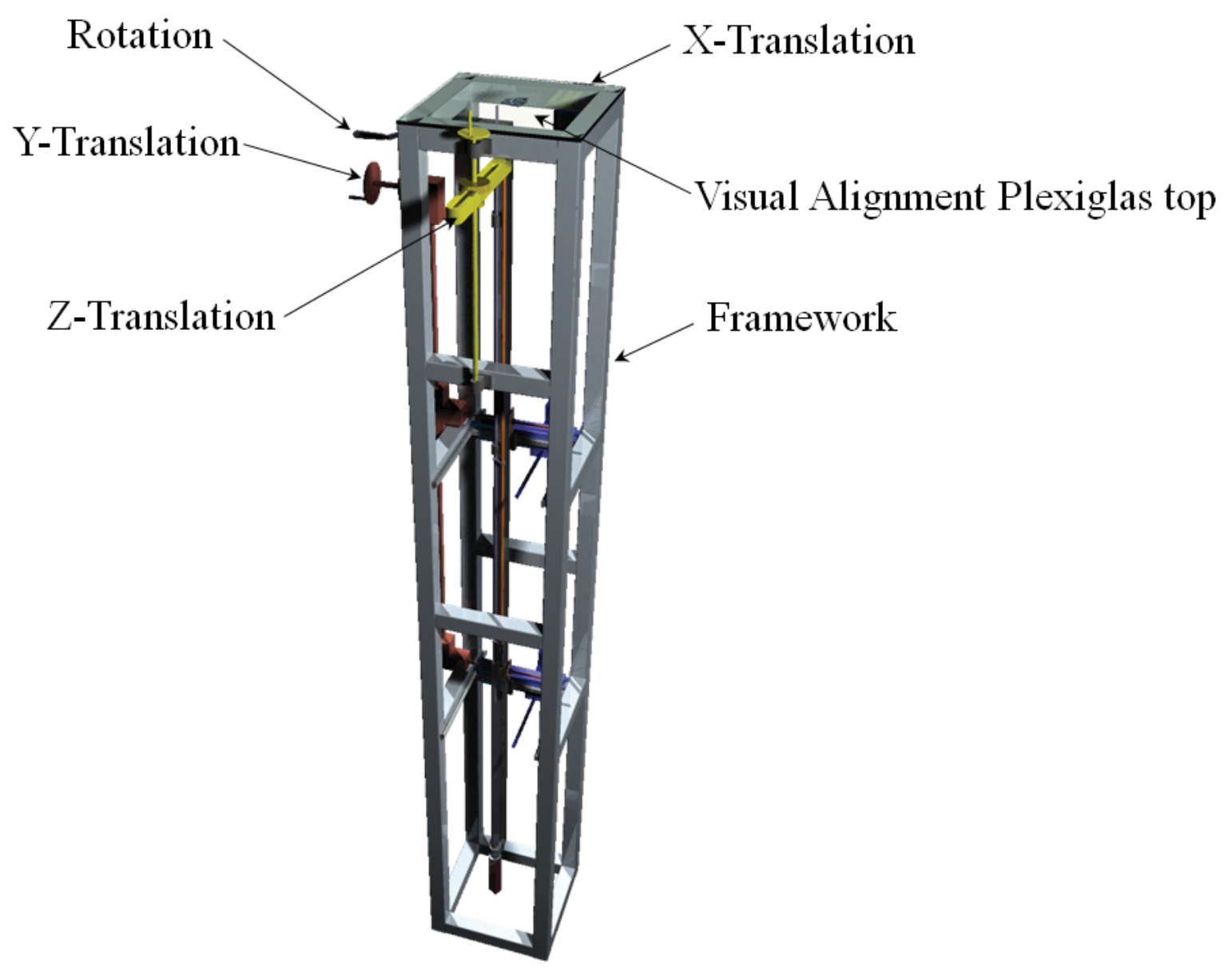

Figure 11: BR2 Channel Gap Probe

The following items need further design consideration in regard to the Channel Gap Probe design:

- Interface with the Irradiation Vehicle: Both designs need to incorporate alignment features for both in the reactor and in the CGP. Alignment pins have been designed generally, but actual length, position, and shape need to be looked at more closely.

- Guide Block: The Guide Block is an intricately machined part that matches the nominal dimensions of the MURR fuel. There will need to be tapered features incorporated into the design so that it will give alignment of the CGP to the fuel assembly.

- Probe: This probe has a T-shaped feature at the top side that allows the probe to be slid through a support channel. Whether this probe and channel system will work as assumed needs further investigation.

- The CGP shows the probe being able to move in 4 directions as described in above. The mechanisms and functionality of these concepts needs to be developed more so that the probe can be precisely located over the guide block repeatedly.

- Basket Frame Assembly attachment to the wall of the BR2 Reactor also needs development. 


\subsection{Fuel Specifications}

As discussed in section 3, draft specifications were produced for the DDE-MURR U-Mo coupons and fuel element and can be seen in Appendices B and C, respectively. These specifications represent a design maturity level commensurate with conceptual design only and are considered to be inadequately mature for fabrication of final DDE products. The element specification corresponds with fuel element assembly drawing 603455, as seen in Appendix F. This element drawing represents the in-progress drawing for the actual LEU MURR design. While the final DDE-MURR element drawing may differ slightly (e.g. end box attachment design) and eventually require a distinct drawing, this drawing was used for the conceptual design specification work.

These specifications were based, to the level possible, upon a quality control and quality assurance requirements in existing specifications. The chemical and isotopic requirements of U-Mo materials were based upon existing standards for HEU metal ${ }^{[17]}$, Y-12 specifications for LEU metal ${ }^{[18]}$ and LEU-Mo ${ }^{[19]}$, ASTM standards for LEU-metal ${ }^{[20]}$, and U-Mo foil specifications for the RERTR-FE campaign ${ }^{[21]}$. These were tabulated and the appropriate compositional limits were selected. Equivalent Boron Content (EBC) limits were derived by comparing the sum total max EBC of each plate constituent in the existing HEU designs to the proposed EBC limit for U-Mo. These limits were compared to historical analyses of U-Mo materials. These tabulations, calculations, and comparisons can be found in the Coupon Specification Composition Worksheet as denoted in Table 4 of section 5.2.

The composition and isotopic limits explained above were specified based primarily on existing requirements and equivalency to currently accepted designs and/or standards. Consequently, these limits represent a proposed base for nuclear safety and LEU reactor operation of the MITR, MURR, and NBSR, but do not represent any requirements that the manufacturer wish to impose in order to facilitate greater yield rates or ease in fabrication. Intermediate product specifications ${ }^{[22]}$, sampling plans, manufacturing procedures, etc. should be incorporated into the DDE coupon specifications, or related documents, as their effects on fabrication processes becomes known during the FFC pillar's ongoing fabrication studies.

Like the coupon specifications, DDE element specifications were based, to the level possible, on existing specifications and standards. Specifically, the MITR HEU ${ }^{[23]}$ element and MURR HEU ${ }^{[24]}$ element specifications were chosen as "templates" to work from. These were selected based on their succinct structure and experience base with the fuel procurement group at the INL who currently procures HEU fuel elements for MURR. This was intended to facilitate one of the core DDE goals to demonstrate fabrication by providing a prototypic procurement structure.

Other specification adaptations include differences innate to the MURR LEU design such as the plate/element U-235 limits based on a 23 plate $20 \%$ enriched design and boehmite prefilm treatment. Requirements that were based on upon the precedent HEU dispersion fuel (e.g. stray fuel particles and provisions for "dogbones") were eliminated or modified. Additional inspections and requirements which pertain to the monolithic base fuel design and respective fabrication process are also included such as bend testing of clad croppings and zirconium interlayer thickness inspection. Finally, some specification adaptations were necessary based on the DDE's end use such as referencing to the MURR as the "stakeholder" rather than the "user".

\section{Future Recommendations}

\subsection{Hardware Design Recommendations}

The following items need further design consideration in regard to the Irradiation Vehicle: 
- Interface with the Channel Gap Probe: Both designs need to incorporate alignment features for both in the reactor and in the CGP. Alignment pins have been designed generally, but actual length, position, and shape need to be looked at more closely.

- The irradiation vehicle needs to be modified to include flow inlet and outlet path features with input from thermal calculations. This will also include design of the orifice at the bottom of the irradiation vehicle which needs to operate in normal and flow coastdown and reversal conditions.

- The detailed E-Future Grapple design with removable end box is anticipated to be a difficult endeavor. Future investigations should include evaluations of simpler designs and their propensity to meet design requirements. This should include a detailed design work in regards to tolerance stack-up and the exterior coolant channel gap (i.e. channels 1 and 24) and their means of being determined/located within the irradiation vehicle.

- The detailed design of inner plug eccentricity in outer plug features is also anticipated to be a difficult endeavor. Future investigations should include evaluations "centered" design options and their propensity to meet design requirements.

- Detailed evaluations of the feasibility of simple instrumentation (e.g. thermocouples) in the irradiation test vehicle.

The following items need further design consideration in regard to the Channel Gap Probe:

- More detailed design and drafting of the irradiation vehicle and CGP should be accomplished as a continuation of the fruitful collaboration which is already in place with BR2 engineers. This also should include a channel gap probe sensor which can measure channel gap distance and water temperature concurrently.

Other design considerations should include:

- An effort intended to fabricate full-size mock-ups of the DDE-MURR irradiation assembly for the purpose of functional handling in the BR2 vessel, handling pools, channel gap probe, and other applicable handling evolutions should be commenced. This should substantially reduce the risk of hardware based failure in providing "hands-on" experience regarding fabrication of the hardware, ability to assemble underwater and perform channel gap measurements, and likelihood of damage during handling. Completion of this work is strongly recommended.

- Development of any special purpose tooling for handling such as storage buckets, handling tools, and fixturing. These should also be fabricated and handled in a prototypic effort as described above early enough in the design process to facilitate modifications if necessary. Storage buckets and similar fixtures should also endeavor to allow for natural circulation removal of decay heat.

- Design of a suitable location in the irradiation assembly and selection of an appropriate dosimetry material (e.g. flux wires) for the purpose of benchmarking cycle-to-cycle as-run depletion analysis in order to reduce the risk of "over-burning" or "under-shooting" the actual experiment during irradiation.

\subsection{Analytic Recommendations}

Several analytic efforts were not completed due cancellation of the FY13 scope for DDE-MURR. Their maturation is recommended for future efforts. These include: 
- Upon ascertainment of a more mature design schedule and selection of the appropriate $200 \mathrm{~mm}$ channel, a full suite of analyses should be performed and reviewed by the appropriate personnel.

- Physics: $180^{\circ}$ inner plug rotational scheme, detailed depletion, source term

- Thermal: Flow coastdown and reversal analysis for throttled irradiation vehicle design, BR2 recommended that Argonne National Laboratory perform this based their familiarity with the BR2 coolant system.

- Structural based on more mature inputs from the thermal analysis and all anticipated loading modes

- Further design analyses should include:

- An analysis "round robin" where the DDE-MURR heat loads, flow rates, etc. would be provided to the RC team for input into their MURR LEU models and vice-versa for the purpose of comparing analytic results between the DDE-MURR and MURR LEU methods, models, codes, etc.

- Since the DDE experiments, compared to previous RERTR-FD irradiations, have more specific fission density goals which must be confidently met prior to post irradiation shipment, as-built equivalent boron content of non-fueled components (e.g. aluminum stock used to fabricate the irradiation vehicle) should be investigated for it contribution to the final fission densities via physics analyses.

- Fluid Structure Interaction (FSI) analysis performed in order to evaluate the risks for flow induced failure modes. This should be performed in conjunction with physical flow testing of dummy hardware. This flow testing should be performed far in advance of the final "acceptance" flow testing that BR2 must perform on the delivered final element and vehicle.

- Analysis to determine the risk for an oxide spallation failure. Since the DDE-MURR experiment will reside in BR2 storage pools under decay heat conditions for greater lengths of time than previous RERTR-FD fuel development experiments these calculations should also consider including "pool-time", if significant, in the oxide spallation analysis.

- Analysis regarding fuel plate performance and its impact on potential failure modes. This should be done with the most pertinent tools, including multiphysics codes where applicable, to evaluate effect of fuel swelling, material properties evolution, fuel creep, thermal conductivity degradation, and other pertinent and predictable fuel performance phenomena.

\subsection{Design and Engineering Process Recommendations}

\section{A Process Focused on Risk and Failure Modes}

The DDE-MURR campaign is considered an engineering scale demonstration test with significant maturity in the technology life cycle. As such, this campaign constitutes less of a "scientific" interest compared to other GTRI-FD irradiations (e.g. RERTR and AFIP series tests) where fuel is often driven to extreme conditions in order to amplify fuel performance phenomena. Rather, DDE-MURR constitutes a demonstration of engineering design scale performance. As a result, the campaign is likely to have lower 
probability of scientific-scale type failures, but constitutes a large consequence of failure in precluding regulatory approval of reactor conversion.

Consequently, the campaign should be treated as a high risk effort and handled appropriately. This should include design efforts strongly focused on failure modes in regards to concept generation, analysis, evaluations, design reviews, and other pertinent arenas. Furthermore, project management strategies should work to this end through use of campaign-focused risk management plans and an emphasis on stable funding in order to foster design team continuity and propensity to identify failure modes. In this regard, stable "modest" funding should be considered superior to sporadic "aggressive" funding.

\section{A Process Founded in Structured Design-Phases}

In the context of the original assumptions, the DDE-MURR design concept is a sound strategy. However, some of the original schedule assumptions have already been invalidated. Combined with the possibilities of a redefined base fuel design (driven largely by emergent PIE results), the potential for design modifications of the proposed final LEU conversion element, and prospective design modifications based on forthcoming FFC fabrication studies, it is apparent that the existing DDE-MURR design concept should be evaluated and updated for their applicability at such time as the design work is recommenced. This should include:

- Final approval of the rev 0 Functional and Operational Requirements document with the Critical Characteristics incorporated

- More detailed hardware design work, as described in section 4.1, with production of detailed engineering drawings

- Updating and final approval of rev 0 Experiment Control Plan complete with plan details regarding design control, quality level determination, and quality assurance measures for the overall design campaign.

- Producing a detailed DDE-MURR schedule, project execution plan, and other deliverables needed for project management. As the experience and knowledge base of key personnel from the BR2 facility were crucial in commencing this work these planning bases should include provisions for on-site collaboration with the BR2.

- Evaluate, in the context of the new schedule constraints, the severity of the risk that BR2 operation will be terminated prior to DDE-MURR completion and identify, if needed, a suitable back-up plan and irradiation location.

- Performance of a conceptual design evaluation with key stakeholders from the GTRI-Convert program to ensure that the concept is appropriately engineered to meet the campaign objectives

- Approval of the conceptual design package by the BR2's Committee for Examination of Experiments (CEE)

Completion of the conceptual design work should give way to completion of the more detailed preliminary work per the experiment control plan and should include the following recommendations:

- Completion and approval of the Technical and Functional Requirements with updating of the F\&OR as needed

- Flow testing of a physical mock-up irradiation assembly combined with FSI structural analysis to experimentally determine flowrates and potential for flow induced failure modes. This flow testing should be performed far in advance of the final "acceptance" flow testing that BR2 must perform on the delivered final element and vehicle. 
- Functional handling and operation of a physical mock-up irradiation assembly in BR2 facility. These should verify that the assembly can be manipulated underwater through all expected handling evolutions including characterization in the channel gap probe.

- Performance of the full suite of safety analyses required for physics, thermal, structural, and oxide growth/spallation calculations

- Receipt of the official Technical Tolerances submittal and finalization of the coupon and element specifications

- PIE design activities

- Evaluation of the emerging design in the context of potential failure modes and effects

- Performance of a preliminary design evaluation with key stakeholders from the GTRIConvert program to ensure that the concept is appropriately engineered to meet the campaign objectives

- Approval of the preliminary design package by the CEE

Completion of the preliminary design work should give way to completion of final design per the experiment control plan and should include the following recommendations:

- Finalization of all engineering deliverables

- Fabrication of the final DDE-MURR irradiation vehicle hardware, fuel element, CGP, and ancillary tools/fixtures with the appropriate quality assurance measures and incorporation of any as-built features, if needed, into the original engineering deliverables

- Compilation and approval of the final design and analyses package for the CEE

- Performance of a final design evaluation with key stakeholders from the GTRI-Convert program to ensure that the concept is appropriately engineered to meet the campaign objectives

\section{Provisions for Future Work \\ 5.1 Design Team}

The following personnel made up the INL portion of the DDE-MURR conceptual design team:

- Bruce Nielson - Experiment Manager

- Nicolas Woolstenhulme - Irradiation Testing Lead and Specification Author

- Michael Sprenger - Irradiation Assembly Designer

- Greg Housley - Channel Gap Probe Designer

Additionally, a communication plan was compiled in collaboration with BR2. This provides personnel functions and contact information of the RC, FD, and BR2 team member. This is available in the location shown in section 5.2.

\subsection{Document Location}

The following items were produced during this design campaign and, at the time this report was prepared, were stored as seen in Table 4. 
Table 4: Document Location

\begin{tabular}{|c|c|c|}
\hline Item & Status & Location \\
\hline $\begin{array}{l}\text { DDE Design Status Report Nov } \\
2011\end{array}$ & Final rev 0 & $\begin{array}{l}\text { INL external report INL/EXT-11- } \\
23991\end{array}$ \\
\hline Fuel Element Drawings & Draft INL drawing 603455 & $\begin{array}{l}\text { Appendix F of this report } \\
\text { CAD and solid model files reside } \\
\text { with ATR Experiment Drafting and } \\
\text { are stored on their server }\end{array}$ \\
\hline $\begin{array}{l}\text { Irradiation Vehicle and CGP Solid } \\
\text { Models }\end{array}$ & In-Progress & $\begin{array}{l}\text { Original model files stored in Wind- } \\
\text { chill database management system } \\
\text { Exported model on DDE design file } \\
\text { path }(\backslash \backslash \text { fserob } 1 \backslash \text { projects } \backslash \text { rertr } \backslash \text { Design } \\
\text { Demonstration Experiments } \backslash D D E- \\
\text { MURR) }\end{array}$ \\
\hline Experiment Control Plan & Draft & $\begin{array}{l}\text { DDE design file path } \\
(\backslash \backslash \text { fserob } 1 \backslash \text { projects } \backslash \text { rertr } \backslash \text { Design } \\
\text { Demonstration Experiments } \backslash \text { DDE- } \\
\text { MURR) }\end{array}$ \\
\hline Fuel Specifications & $\begin{array}{l}\text { Draft, awaiting Technical } \\
\text { Tolerances submittal and } \\
\text { Preliminary Design work }\end{array}$ & $\begin{array}{l}\text { Appendices B and } \mathrm{C} \text { of this report } \\
\text { DDE design file path } \\
(\backslash \backslash \text { fserob } 1 \backslash \text { projects } \backslash \text { rertr } \backslash \text { Design } \\
\text { Demonstration Experiments } \backslash \text { DDE- } \\
\text { MURR) }\end{array}$ \\
\hline $\begin{array}{l}\text { Coupon Specification Composition } \\
\text { Worksheet }\end{array}$ & $\begin{array}{l}\text { In-process worksheet "Origin of } \\
\text { DDE Coupon Spec Limits.xlsx" }\end{array}$ & $\begin{array}{l}\text { DDE design file path } \\
(\backslash \backslash \text { fserob } 1 \backslash \text { projects } \backslash \text { rertr } \backslash \text { Design } \\
\text { Demonstration Experiments } \backslash \text { DDE- } \\
\text { MURR) }\end{array}$ \\
\hline $\mathrm{F} \& \mathrm{OR}$ & Draft & $\begin{array}{l}\text { Appendix A of this report } \\
\text { DDE design file path } \\
\text { ( (\fserob } 1 \backslash \text { projects } \backslash \text { rertr } \backslash \text { Design } \\
\text { Demonstration Experiments } \backslash D D E- \\
\text { MURR) }\end{array}$ \\
\hline Critical Characteristics Submittal & Final Received & $\begin{array}{l}\text { DDE design file path } \\
(\backslash \backslash \text { fserob } 1 \backslash \text { projects } \backslash \text { rertr } \backslash \text { Design } \\
\text { Demonstration Experiments } \backslash \text { DDE- } \\
\text { MURR) }\end{array}$ \\
\hline Technical Tolerances Submittal & $\begin{array}{l}\text { Not yet received } \\
\text { Requested information outlined in } \\
\text { experiment control plan }\end{array}$ & $\mathrm{n} / \mathrm{a}$ \\
\hline $\begin{array}{l}\text { DDE-MURR presentation given at } \\
\text { BR2 initial meeting "Irradiation } \\
\text { Characteristics of MURR LEU Fuel } \\
\text { Design" [9] }\end{array}$ & Received & $\begin{array}{l}\text { DDE design file path } \\
(\backslash \backslash \text { fserob } 1 \backslash \text { projects } \backslash \text { rertr } \backslash \text { Design } \\
\text { Demonstration Experiments } \backslash \text { DDE- } \\
\text { MURR) }\end{array}$ \\
\hline
\end{tabular}




\begin{tabular}{|c|c|c|}
\hline $\begin{array}{l}\text { Physics analysis report "DDE- } \\
\text { MURR assembly: Provisional heat } \\
\text { fluxes in channels H5, H4, H3" "[15] }\end{array}$ & Received & $\begin{array}{l}\text { DDE design file path } \\
(\backslash \backslash \text { fserob1\projects } \backslash \text { rertr } \backslash \text { Design } \\
\text { Demonstration Experiments\DDE- } \\
\text { MURR })\end{array}$ \\
\hline DDE-MURR Communication Plan & Living Document & $\begin{array}{l}\text { DDE design file path } \\
\text { ( } \backslash \text { fserob1\projects } \backslash \text { rertr\Design } \\
\text { Demonstration Experiments\DDE- } \\
\text { MURR) }\end{array}$ \\
\hline $\begin{array}{l}\text { INL/BR2 action item list from June } \\
2012 \text { on-site visit }\end{array}$ & Living Document & $\begin{array}{l}\text { DDE design file path } \\
\text { ( } \backslash \text { fserob1\projects } \backslash \text { rertr } \backslash \text { Design } \\
\text { Demonstration Experiments } \backslash \text { DDE- } \\
\text { MURR) }\end{array}$ \\
\hline
\end{tabular}

\section{References}

[1] N.E. Woolstenhulme, D.M. Wachs, and M.K. Meyer, "Design and Testing of Prototypic Elements Containing Monolithic Fuel", Proceedings of the RERTR-2011 International Conference, Santiago Chile, October 23-27, 2011.

[2] D.M. Wachs, "RERTR Fuel Development and Qualification Plan", rev 5, 07/05/2011, INL external report INL/EXT-05-01017.

[3] A.B. Robinson et al., "Irradiation Performance of U-Mo Alloy Based 'Monolithic' Plate-Type Fuel - Design Selection”, INL external report INL/EXT-09-16807, Aug. 2009.

[4] M.K. Meyer and R.B. Nielsen, "Utilization of the Center Flux Trap for Irradiation During Cycles 157A - 160B", draft white paper 11/17/11.

[5] "Applying Quality Assurance Requirements to Research and Development Activities", rev 3, 8/12/2010, INL Document LWP-13016.

[6] "Quality Assurance Requirements for Nuclear Facility Applications", ASME NQA-1-2008, Part IV, Subpart 4.2.

[7] D.E. Burkes, "Overview of the GTRI Fuel Fabrication Capability (FFC) Project", presentation given at High Power Research Reactor Working Group Meeting, Cambridge Massachusetts, July 26-27, 2011.

[8] J.C. McKibben, et. al, "Progress Made on the University of Missouri Research Reactor HEU to LEU Fuel Conversion Feasibility Study", proceedings of the RERTR-2007 International Conference, Prague, Czech Republic, Sep 23-27, 2007.

[9] J. Stevens to N. Woolstenhulme, "MURR DDE Critocal [sic] Characteristics ppt from BR2 Visit", email 5/9/2012, attachment "Stevens_MURR_DDE_Element_Requirements_ 120417rev1.ppt"

[10] E. Feldman to N. Woolstenhulme, "Temperatures and Heat Fluxes for MURR LEU core", email 9-28-11, attachment "Temps_Fluxes_LEU_092711jgs.xls"

[11] N.E. Woolstenhulme, R.B. Nielson, "DDE Design Status Report Nov 2011", November 2011, INL/EXT-11-23991.

[12] INL Drawing 419609, “ATR Beryllium Reflector Blocks Mark IV”, 7-11-1984.

[13] INL Document TSR-186, “ATR Complex-ATR Nuclear Safety Basis - Technical Safety Requirements".

[14] INL External Report INL/EXT-12-26500, "Investigation Of The Cause Of Low Blister Threshold Temperatures In The RERTR-12 And AFIP-4 Experiments", rev 0, 06/28/2012

[15] V. Kuzminov to S. Van Dyck and E. Koonen, "DDE-MURR assembly: Provisional heat fluxes in channels H5, H4, H3", technical note 06/18/2012. 
[16] J. Stillman et. al, ANL/RERTR/TM-12-38 "Conceptual Design Parameters for MURR LEU UMo Fuel Conversion Design Demonstration Experiment", pre-print copy September 2012.

[17] INL Document SPC-324, "Specification for Enriched U-Metal", 03/27/2007.

[18] Y-12 Document Y/GNSS/05-05, "The Y-12 Standard Specification Low Enriched Uranium Metal Supply to Research and Test Reactors", rev 2, August 2007.

[19] Y-12 Document Y/GNSS/07-02, "Standard Specification Low Enriched Uranium Molybdenum Alloy for RERTR Fuel Development Program”, rev 2, April 2008.

[20] ASTM C 1462-00 (Reapproved 2008), "Standard Specification for Uranium Metal Enriched to More than $15 \%$ and Less Than $20 \%{ }^{235} \mathrm{U}$ ".

[21] INL Document SPC-1167, "Specification for U-Mo Monolithic Foils", rev 3, 08/16/2011.

[22] J.D. Sease to N.E. Woolstenhulme, "FW: Intermediate LEU Foil Product Specification White Paper", e-mail 04/23/2012.

[23] INL Document TRTR-3, "Specification TRTR-3 for Massachusetts Institute of Technology Fuel Elements", rev 1, 04/13/1990.

[24] INL Document TRTR-4, "Specification TRTR-4 for University of Missouri-Columbia Fuel Elements Assembled for University of Missouri Research Reactor”, rev 4, 06/08/1994. 


\section{Functional and Operational Requirements}

\section{DDE-MURR Irradiation in the BR2}

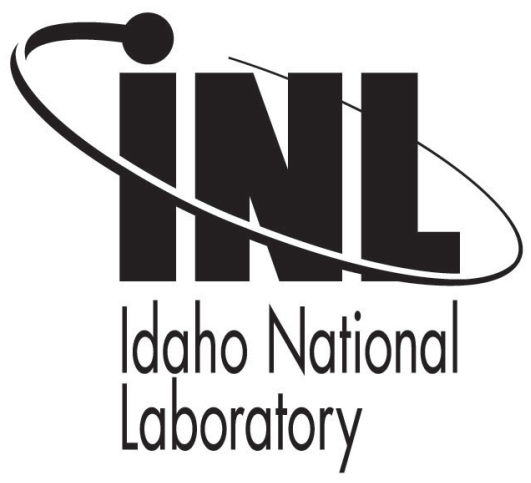

The INL is a U.S. Department of Energy National Laboratory operated by Battelle Energy Alliance. 


\section{Appendix A (Draft F\&OR)}

\begin{tabular}{|l|lll|}
\hline \multirow{2}{*}{ DDE-MURR IRRADIATION IN THE BR2 } & Identifier: & FOR- 118 & \\
& Revision: & 0 (DRAFT) \\
Effective Date: & XX/XX/XX & Page: 2 of 12 \\
\hline
\end{tabular}

\begin{tabular}{|l|l|l|l|}
\hline Applicability: Laboratory-wide & Functional and Operational Requirements & & eCR Number: XXXXXX \\
\hline
\end{tabular}

Management System: Engineering

\section{CONTENTS}

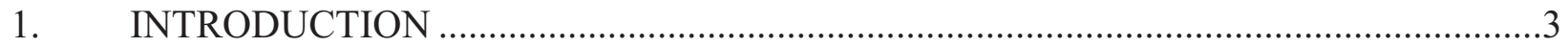

1.1 Description of Engineering Task ...............................................................

1.2 Description of the End-Use for the Engineered Item or Activity .........................

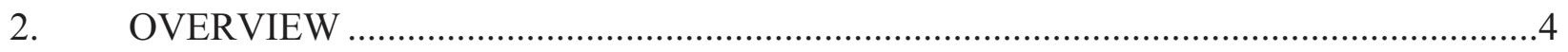

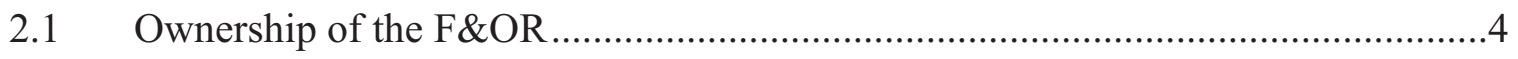

2.2 End-User of Engineered Item or Activity ....................................................4

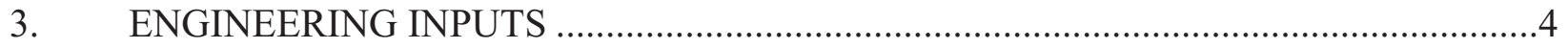

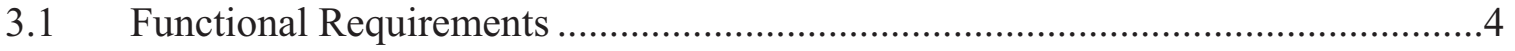

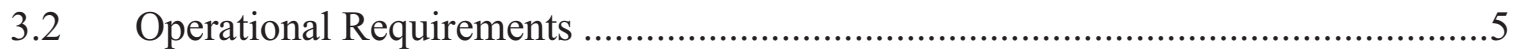

3.3 Owner Specified Technical Requirements...............................................

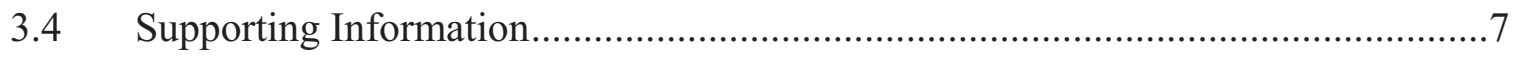

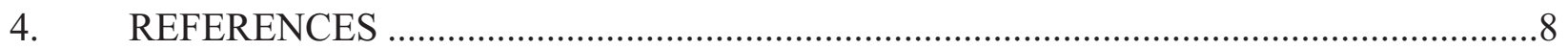




\section{Appendix A (Draft F\&OR)}

\begin{tabular}{|l|lll|}
\hline \multirow{2}{*}{ DDE-MURR IRRADIATION IN THE BR2 } & Identifier: & FOR- 118 & \\
& Revision: & 0 (DRAFT) & \\
& Effective Date: & XX/XX/XX & Page: 3 of 12 \\
\hline
\end{tabular}

\section{INTRODUCTION}

\subsection{Description of Engineering Task}

This engineering task will facilitate maturation of Low Enriched Uranium (LEU) fuel technology in order to enable conversion of High Power Research Reactors. To enable conversion of the University of Missouri Research Reactor (MURR), whose licensing basis restricts them from testing lead test elements of its LEU fuel element design ${ }^{[1]}$, a Design Demonstration Experiment (DDE) will be irradiated elsewhere using prototypic fuel plate geometries under prototypic conditions (i.e. "end use application" in a "design environment" ${ }^{[2]}$ ) in lieu of the lead test element methodology. MURR intends to convert using the Base Monolithic Design which consists of uranium-10 wt\% molybdenum alloy (U$10 \mathrm{Mo}$ ) in the form of a monolithic foil, with thin zirconium interlayers, clad in aluminum by hot isostatic press as seen in Figure 1. ${ }^{[3]}$ [4] [5] $^{[5}$

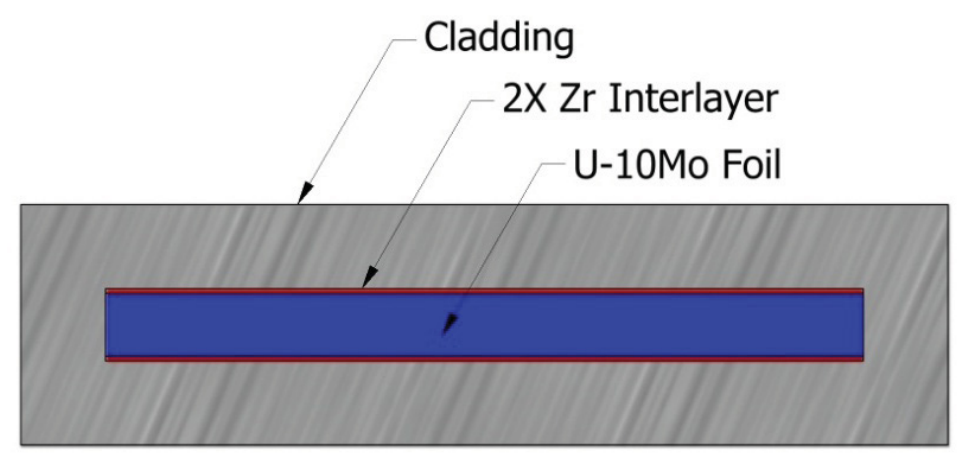

Figure 1: Base Monolithic Design

\subsection{Description of the End-Use for the Engineered Item or Activity}

The following list constitutes the core goals for the DDE campaign:

- Confirm Performance under stringent prototypic parameters (e.g. heat flux, fission density)

- Show Resistance to worrisome failure modes (e.g. fission gradients, thin-clad structural stability)

- Demonstrate Fabrication by producing the plates/elements as demonstration products ${ }^{[6]}$

- Give Confidence in the LEU fuel design prior to conversion

This design is intended for irradiation in the Belgium Reactor 2 (BR2) and channel gap measurements in the BR2 pool area (hereafter referred to as pool). The majority of the scientific information gathered is planned to occur in Post Irradiation Examination (PIE) activities at the BR2 Facility. 


\section{Appendix A (Draft F\&OR)}

\begin{tabular}{|l|lll|}
\hline \multirow{2}{*}{ DDE-MURR IRRADIATION IN THE BR2 } & Identifier: & FOR-118 & \\
& Revision: & 0 (DRAFT) \\
Effective Date: & XX/XX/XX & Page: 4 of $\mathbf{1 2}$ \\
\hline
\end{tabular}

\section{OVERVIEW}

\subsection{Ownership of the F\&OR}

This F\&OR is owned by the Irradiation Testing Lead for the Global Threat Reduction Initiative-Convert (GTRI-Convert) Fuel Development (FD) program. The GTRI-Convert program experiment working group is also responsible for identification of the requirements found in this document.

\subsection{End-User of Engineered Item or Activity}

End users of this design will include:

- Fuel Fabrication Capability (FFC) pillar fabrication group

- FD characterization group

- BR2 operations

- LHMA post irradiation examination (PIE) group

- Channel gap probe user team

- INL experiment design and analysis group

- MURR stakeholders (who will submit the final data to the Nuclear Regulatory Commission as part of the licensing request to operate with LEU fuel)

\section{ENGINEERING INPUTS}

\subsection{Functional Requirements}

3.1.1 The DDE-MURR experiment shall be designed to irradiate fuel specimens which include prototypic MURR LEU fuel plate geometry under representative irradiation conditions as defined in the DDE-MURR experiment critical characteristics in Appendix A.

3.1.2 The DDE-MURR experiment shall be designed with features which enable irradiation in BR2 for several irradiation cycles.

3.1.3 The DDE-MURR experiment shall be designed with fuel plate coolant channel gaps which can be characterized via the channel gap probe.

3.1.4 The DDE-MURR experiment should be designed to accommodate dosimeters to enable cycle to cycle as-run benchmarking of burn-up analysis.

3.1.5 The DDE-MURR experiment shall be designed to be easily removable and re-installable in the BR2 during routine outages. 


\section{Appendix A (Draft F\&OR)}

\begin{tabular}{|l|lll|}
\hline \multirow{2}{*}{ DDE-MURR IRRADIATION IN THE BR2 } & Identifier: & FOR- 118 \\
& Revision: & 0 (DRAFT) \\
Effective Date: & XX/XX/XX & Page: 5 of $\mathbf{1 2}$ \\
\hline
\end{tabular}

3.1.6 The DDE-MURR experiment shall fit within existing fresh and spent fuel shipping containers.

3.1.7 The DDE-MURR experiment shall be designed to be characterized by channel gap probe before irradiation, between each cycle (during outage) and after irradiation.

3.1.8 The DDE-MURR experiment shall be designed to mitigate the risk of fuel plate damage (e.g. scratches).

3.1.9 DDE-MURR components and other extra-reactor handling equipment shall be designed to allow decay heat removal via low-impedance freeconvection pathways.

3.1.10 The DDE-MURR element side plates of the experiment must enable the fabricator (i.e. Babcock and Wilcox) to "swage" the fuel plates.

\subsection{Operational Requirements}

3.2.1 The DDE-MURR element shall be designed to provide adequate flow and cooling during flow coastdown and reversal conditions.

3.2.2 The DDE-MURR experiment shall be designed so that moving part interfaces resist binding, galling, galvanic corrosion, and other phenomena which may cause the assembly to be inoperable.

3.2.3 The DDE-MURR experiment shall be designed to be disassembled at the LHMA hot cell faciliti with minimal redesign of PIE equipment and risk of damaging the fuel plate specimens.

3.2.4 The DDE-MURR experiment shall be designed to be capable of 180 degree rotation of the element following each irradiation cycle.

3.2.5 The DDE-MURR experiment shall be designed so that duplicate components can be identified with unique features (e.g. identification markings) that are present in locations where the risk for damage or obliteration of such features is minimized.

3.2.6 The DDE-MURR experiment shall be easy to handle remotely and must be very robust to mitigate unintended separation of components in the reactor.

3.2.7 All materials shall meet BR2 primary coolant system requirements.

3.2.8 The DDE-MURR experiment shall be designed for in-core service lifetime of at least \#\# BR2 cycles 


\section{Appendix A (Draft F\&OR)}

\begin{tabular}{|l|lll|}
\hline \multirow{2}{*}{ DDE-MURR IRRADIATION IN THE BR2 } & Identifier: & FOR- 118 \\
& Revision: & 0 (DRAFT) \\
& Effective Date: & XX/XX/XX & Page: 6 of $\mathbf{1 2}$ \\
\hline
\end{tabular}

3.2.9 The DDE-MURR experiment shall be designed to allow decay removal adequate to prevent melting of the aluminum cladding in the event that the irradiated assembly is dropped horizontal in water during handling.

3.2.10 The DDE-MURR experiment shall minimize the use of difficult or high risk welds, especially thin-to-thick section or small throat aluminum welds.

3.2.11 The DDE-MURR experiment shall be designed to provide structural integrity through use of simple and robust components which remain intact during irradiation/handling and alleviate the risk of damaging the fuel plate specimens.

3.2.12 The DDE-MURR experiment shall be designed so that the position of the fuel plate specimens/element and all other components remains fixed during reactor operation.

3.2.13 The DDE-MURR irradiation test assemblies shall allow for test element fabrication/assembly at the commercial facilities within the fabrication process to be established by the FFC pillar.

3.2.14 The DDE-MURR irradiation test assemblies shall allow for non-fueled hardware fabrication/assembly at the commercial facilities within the existing capabilities of facilities at the INL complex.

3.2.15 The DDE-MURR irradiation test assemblies shall be designed so that no more than two operators and two handling tools are required concurrently for a given handling evolution (e.g. vessel to pool transport, channel gap examination, reconfiguration, etc.).

3.2.16 The DDE-MURR channel gap probe shall be designed to be removable from the pool and stored on the deck or rack.

3.2.17 The DDE-MURR irradiation test assemblies shall be designed to facilitate timely accomplishment of outage work so that the specimen extraction, characterizations, and experiment reconfiguration, for one irradiation assembly, can be accomplishment in one normal working day.

3.2.18 The DDE-MURR channel gap probe shall be designed to move in 3 directions: radial, linear, and up and down.

3.2.19 The DDE-MURR channel gap probe shall be designed to include cameras to aid in alignment and insertion of probe.

3.2.20 The DDE-MURR channel gap probe shall be designed to always have a minimum of 3 meters of water coverage over MURR fuel. 


\section{Appendix A (Draft F\&OR)}

\begin{tabular}{|l|lll|}
\hline \multirow{2}{*}{ DDE-MURR IRRADIATION IN THE BR2 } & Identifier: & FOR-118 & \\
& Revision: & 0 (DRAFT) & \\
& Effective Date: & XX/XX/XX & Page: 7 of 12 \\
\hline
\end{tabular}

3.2.21 The DDE-MURR channel gap probe shall be designed to include a guide block or alignment fixture that will aid the operator in inserting the probe into the MURR fuel.

\subsection{Owner Specified Technical Requirements}

3.3.1 The DDE-MURR experiment should be designed to minimize the acquisition of additional PIE equipment by accommodating with the existing fabrication and PIE infrastructure at the LHMA (e.g. machine tools, PIE measurement bench, etc.).

3.3.2 The DDE-MURR irradiation test assemblies shall be designed to satisfy all BR2 safety requirements and to prohibit operational failure modes. The specific requirements relating to this shall be recorded in a Technical and Functional Requirements (TFR) document.

\subsection{Supporting Information}

\subsubsection{Quality Level of Engineered Item or Activity}

Those activities needed to perform this engineering task for which graded application is applicable include:

- Calculations and Analysis - QLX per QLD\#XXXX rev 0

- Design Control - QLX per QLD\#XXXX rev 0

- Configuration Management - QLX per QLD\#XXXX rev 0

- Material Acquisitions - QLX per QLD\#XXXX rev 0

- Fabrication - QLX per QLD\#XXXX rev 0

\subsubsection{Need for Configuration Management}

Configuration management shall be needed for this engineering activity.

\subsubsection{Sensitive Information}

This engineering activity is not expected to include or produce information of a sensitive nature.

\subsubsection{Need for Engineering Change Control}

Engineering change control shall be needed for this engineering activity.

\subsubsection{Level of Verification Needed}




\section{Appendix A (Draft F\&OR)}

\begin{tabular}{|l|lll|}
\hline \multirow{2}{*}{ DDE-MURR IRRADIATION IN THE BR2 } & Identifier: & FOR- 118 \\
& Revision: & 0 (DRAFT) \\
& Effective Date: & XX/XX/XX & Page: 8 of $\mathbf{1 2}$ \\
\hline
\end{tabular}

The engineering deliverables associated with this design shall be verified by way of design review per the applicable INL procedure. Additionally, the GTRI-Convert program experiment working group will review the design and ensure that it is adequately engineered to meet the programmatic experiment objectives. These design reviews shall each take place upon completion of the conceptual, preliminary, and final design phases of the DDE-MURR experimental campaign.

\subsubsection{Technical Integrator}

The technical integrator is the Experiment Manager for the DDE-MURR irradiation campaign.

\section{REFERENCES}

[1] M.K. Meyer and R.B. Nielsen, "Utilization of the Center Flux Trap for Irradiation During Cycles 157A - 160B”, draft white paper 11/17/11.

[2] "Applying Quality Assurance Requirements to Research and Development Activities", rev 3, 8/12/2010, INL Document LWP-13016.

[3] N.E. Woolstenhulme, D.M. Wachs, and M.K. Meyer, "Design and Testing of Prototypic Elements Containing Monolithic Fuel”, Proceedings of the RERTR-2011 International Conference, Santiago Chile, October 23-27, 2011.

[4] D.M. Wachs, "RERTR Fuel Development and Qualification Plan", rev 5, 07/05/2011, INL external report INL/EXT-05-01017.

[5] A.B. Robinson et al., "Irradiation Performance of U-Mo Alloy Based 'Monolithic' Plate-Type Fuel - Design Selection”, INL external report INL/EXT-09-16807, Aug. 2009.

[6] D.E. Burkes, "Overview of the GTRI Fuel Fabrication Capability (FFC) Project", presentation given at High Power Research Reactor Working Group Meeting, Cambridge Massachusetts, July 26-27, 2011. 


\section{Appendix A (Draft F\&OR)}

\begin{tabular}{|l|lll|}
\hline \multirow{2}{*}{ DDE-MURR IRRADIATION IN THE BR2 } & Identifier: & FOR- 118 \\
& Revision: & 0 (DRAFT) \\
& Effective Date: & XX/XX/XX & Page: 9 of 12 \\
\hline
\end{tabular}

\section{Appendix A}

\section{Critical Characteristics Submittal for DDE-MURR}

J. Stevens

RC National Technical Lead

C. McKibben

MURR Director

E. Wilson

RC Analysis Lead

\section{Date}

\section{Date}

Date

\section{Introduction}

The University of Missouri Research Reactor (MURR) is slated for conversion to Low Enriched Uranium (LEU) using a monolithic Uranium Molybdenum (U-Mo) alloy base fuel design which is currently under development by the Fuel Development (FD) pillar of the Agency Global Threat Reduction Initiative Convert (GTRI-Convert) program. The MURR licensing basis restricts them from testing their own LEU lead test elements. Consequently, a Design Demonstration Experiment campaign (DDE-MURR) will be performed with irradiation of MURR prototypic LEU fuel plates/assemblies in the Best Reactor 2 (BR2) located in Belgium in the chosen $\mathrm{H}$ position.

As set forth in INL document PLN-4060, the DDE-MURR campaign will be executed primarily by the FD pillar. Scoping design and feasibility studies have shown that this irradiation campaign can likely achieve the experiment objectives. The FD pillar is ready to enter a formalized engineering process, beginning with conceptual design, and requires further explication of experiment objectives from the Reactor Conversion (RC) pillar of the GTRI-Convert program. This submittal is referred to as the Critical Characteristics of the experiment. The sections below constitute submittal of the requested Critical Characteristics. 


\section{Appendix A (Draft F\&OR)}

\begin{tabular}{|l|lll|}
\hline \multirow{2}{*}{ DDE-MURR IRRADIATION IN THE BR2 } & Identifier: & FOR- 118 \\
& Revision: & 0 (DRAFT) \\
Effective Date: & XX/XX/XX $\quad$ Page: 10 of 12 \\
\hline
\end{tabular}

\section{Nominal Fuel Element Design}

Table 1: Nominal Element Characteristics

\begin{tabular}{|c|c|}
\hline Plates & Interior \\
Per & Channel \\
Element & Spacing \\
\hline & \\
\hline
\end{tabular}

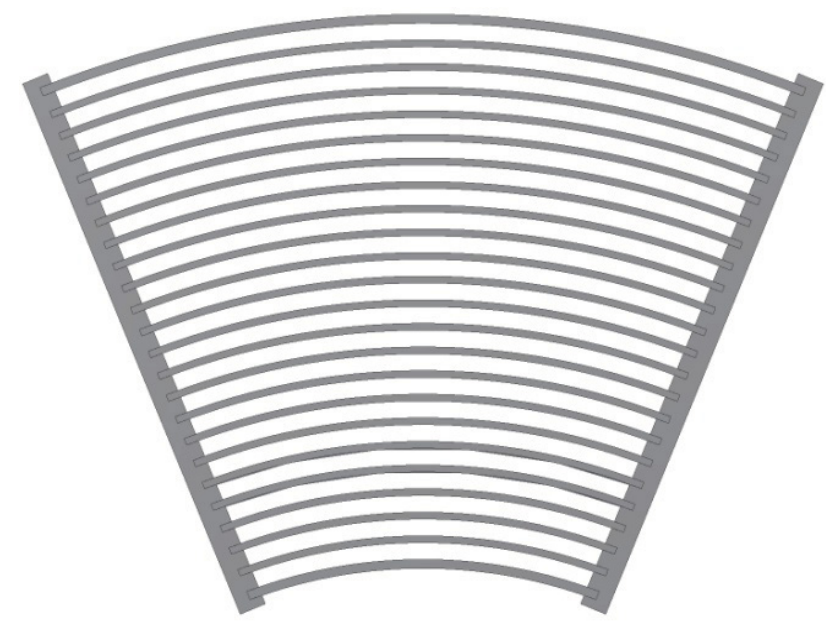

Table 2: Nominal Plate Dimensions

\begin{tabular}{|c|c|c|c|c|c|c|c|}
\hline $\begin{array}{l}\text { Plate } \\
\text { Number }\end{array}$ & $\begin{array}{l}\text { Plate } \\
\text { Length }\end{array}$ & $\begin{array}{l}\text { Plate } \\
\text { Width }\end{array}$ & $\begin{array}{c}\text { Plate } \\
\text { Total } \\
\text { Thickness }\end{array}$ & $\begin{array}{l}\text { Plate } \\
\text { Radius }\end{array}$ & $\begin{array}{l}\text { Fuel } \\
\text { Length }\end{array}$ & $\begin{array}{c}\text { Fuel } \\
\text { Width }\end{array}$ & $\begin{array}{c}\text { Fuel } \\
\text { Thickness } \\
\text { (U-Mo) }\end{array}$ \\
\hline & & & & & & & \\
\hline & & & & & & & \\
\hline & & & & & & & \\
\hline & & & & & & & \\
\hline & & & & & & & \\
\hline & & & & & & & \\
\hline & & & & & & & \\
\hline & & & & & & & \\
\hline & & & & & & & \\
\hline & & & & & & & \\
\hline & & & & & & & \\
\hline & & & & & & & \\
\hline & & & & & & & \\
\hline & & & & & & & \\
\hline & & & & & & & \\
\hline
\end{tabular}




\section{Appendix A (Draft F\&OR)}

\begin{tabular}{|l|lll|}
\hline \multirow{2}{*}{ DDE-MURR IRRADIATION IN THE BR2 } & Identifier: & FOR- 118 \\
& Revision: & 0 (DRAFT) \\
Effective Date: & XX/XX/XX $\quad$ Page: 11 of 12 \\
\hline
\end{tabular}

Table 3: Plate Constituents

\begin{tabular}{|c|c|c|c|c|}
\hline $\begin{array}{c}\text { Plate } \\
\text { Number }\end{array}$ & $\begin{array}{c}\text { U-Mo } \\
\text { Mass }\end{array}$ & $\begin{array}{c}\text { U-235 } \\
\text { Mass }\end{array}$ & Zr Mass & $\begin{array}{c}\text { Al-6061 } \\
\text { Mass }\end{array}$ \\
\hline$\# \#$ & & & & \\
\hline$\# \#$ & & & & \\
\hline$\# \#$ & & & & \\
\hline$\# \#$ & & & & \\
\hline$\# \#$ & & & & \\
\hline$\# \#$ & & & & \\
\hline$\# \#$ & & & & \\
\hline$\# \#$ & & & & \\
\hline$\# \#$ & & & & \\
\hline$\# \#$ & & & & \\
\hline$\# \#$ & & & & \\
\hline$\# \#$ & & & & \\
\hline$\# \#$ & & & & \\
\hline$\# \#$ & & & & \\
\hline$\# \#$ & & & & \\
\hline$\# \#$ & & & & \\
\hline$\# \#$ & & & & \\
\hline$\# \#$ & & & & \\
\hline
\end{tabular}

Target Irradiation Conditions

Table 4: Key Irradiation Parameters

\begin{tabular}{|c|c|}
\hline Parameter & Value \\
\hline Coolant Velocity & \\
\hline Peak Local Heat Flux & \\
\hline Peak Plate Surface Temp & \\
\hline Peak Fuel Meat Centerline Temp & \\
\hline $\begin{array}{c}\text { Target Fission Density (total fissions from all } \\
\text { isotopes) }\end{array}$ & \\
\hline
\end{tabular}

Fuel plate 2D heat flux maps for the peak case were obtained. For the hottest plate, results can be seen in Table 5. In order to give refined results each fuel meat was analyzed with \#\# and \#\# cells in the transverse and axial directions, respectively. 


\section{Appendix A (Draft F\&OR)}

\begin{tabular}{|l|lll|}
\hline DDE-MURR IRRADIATION IN THE BR2 & Identifier: & FOR- 118 \\
Revision: & 0 (DRAFT) \\
& Effective Date: & XX/XX/XX $\quad$ Page: 12 of 12 \\
\hline
\end{tabular}

Table 5: Fuel Plate Heat Flux (W/cm2)

Plate Number \#\#

\begin{tabular}{|c|c|c|c|c|c|c|c|c|c|c|c|}
\hline & \multicolumn{10}{|c|}{ Cell Transverse Location (from edge of fuel meat) } \\
\hline & & \#\# & \#\# & \#\# & \#\# & \#\# & \#\# & \#\# & \#\# & \#\# & \#\# \\
\hline \multirow{20}{*}{$\widehat{\vec{E}}$} & \#\# & \#\# & \#\# & \#\# & \#\# & \#\# & \#\# & \#\# & \#\# & \#\# & \#\# \\
\hline & \#\# & \#\# & \#\# & \#\# & \#\# & \#\# & \#\# & \#\# & \#\# & \#\# & \#\# \\
\hline & \#\# & \#\# & \#\# & \#\# & \#\# & \#\# & \#\# & \#\# & \#\# & \#\# & \#\# \\
\hline & \#\# & \#\# & \#\# & \#\# & \#\# & \#\# & \#\# & \#\# & \#\# & \#\# & \#\# \\
\hline & \#\# & \#\# & \#\# & \#\# & \#\# & \#\# & \#\# & \#\# & \#\# & \#\# & \#\# \\
\hline & \#\# & \#\# & \#\# & \#\# & \#\# & \#\# & \#\# & \#\# & \#\# & \#\# & \#\# \\
\hline & \#\# & \#\# & \#\# & \#\# & \#\# & \#\# & \#\# & \#\# & \#\# & \#\# & \#\# \\
\hline & \#\# & \#\# & \#\# & \#\# & \#\# & \#\# & \#\# & \#\# & \#\# & \#\# & \#\# \\
\hline & \#\# & \#\# & \#\# & \#\# & \#\# & \#\# & \#\# & \#\# & \#\# & \#\# & \#\# \\
\hline & \#\# & \#\# & \#\# & \#\# & \#\# & \#\# & \#\# & \#\# & \#\# & \#\# & \#\# \\
\hline & \#\# & \#\# & \#\# & \#\# & \#\# & \#\# & \#\# & \#\# & \#\# & \#\# & \#\# \\
\hline & \#\# & \#\# & \#\# & \#\# & \#\# & \#\# & \#\# & \#\# & \#\# & \#\# & \#\# \\
\hline & \#\# & \#\# & \#\# & \#\# & \#\# & \#\# & \#\# & \#\# & \#\# & \#\# & \#\# \\
\hline & \#\# & \#\# & \#\# & \#\# & \#\# & \#\# & \#\# & \#\# & \#\# & \#\# & \#\# \\
\hline & \#\# & \#\# & \#\# & \#\# & \#\# & \#\# & \#\# & \#\# & \#\# & \#\# & \#\# \\
\hline & \#\# & \#\# & \#\# & \#\# & \#\# & \#\# & \#\# & \#\# & \#\# & \#\# & \#\# \\
\hline & \#\# & \#\# & \#\# & \#\# & \#\# & \#\# & \#\# & \#\# & \#\# & \#\# & \#\# \\
\hline & \#\# & \#\# & \#\# & \#\# & \#\# & \#\# & \#\# & \#\# & \#\# & \#\# & \#\# \\
\hline & \#\# & \#\# & \#\# & \#\# & \#\# & \#\# & \#\# & \#\# & \#\# & \#\# & \#\# \\
\hline & \#\# & \#\# & \#\# & \#\# & \#\# & \#\# & \#\# & \#\# & \#\# & \#\# & \#\# \\
\hline
\end{tabular}

The normal NBSR LEU fuel cycle is expected to consist of \#\# cycles of approximately \#\# full power days each. The peak conditions noted above are expected to occur at \#\#. Beginning and end of life heat fluxes are expected to be \#\# and \#\#, respectively. More detailed 2D heat flux maps for time steps of interest can be seen

\section{$\underline{\text { Discussion }}$}

It is acknowledged that the above Critical Characteristics were produced as part of a suite of ongoing analyses, design, and development activities lead by the RC pillar. While these Critical Characteristics may be subject to change, they represent the best known data at this time and are the most appropriate design inputs for proceeding with the conceptual design of DDE-NBSR. Any future changes to the Critical Characteristics will be communicated in follow-on submittals. 


\title{
Appendix B (Draft Coupon Specification)
}

Document ID: SPC-1568

Revision ID: 0 (Draft)

Effective Date: TBD

\author{
Specification
}

\section{Specification for U-Mo Coupons for DDE-MURR}

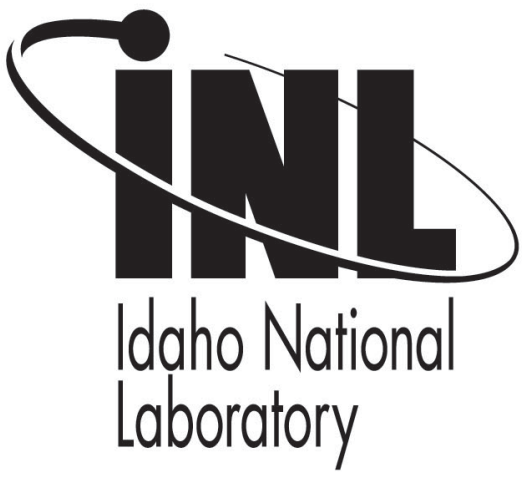

The INL is a U.S. Department of Energy National Laboratory operated by Battelle Energy Alliance. 
Appendix B (Draft Coupon Specification)

Idaho National Laboratory

\begin{tabular}{|l|l|l|l|}
\hline $\begin{array}{l}\text { SPECIFICATION FOR U-MO COUPONS } \\
\text { FOR DDE-MURR }\end{array}$ & $\begin{array}{l}\text { Identifier: } \\
\text { Revision: } \\
\text { Effective Date: }\end{array}$ & $\begin{array}{l}\text { SPC-1568 } \\
0 \text { (Draft) }\end{array}$ & Page: 2 of 9 \\
\hline
\end{tabular}

Manual: Nuclear Nonproliferation

\section{REVISION LOG}

\begin{tabular}{|c|c|c|l|}
\hline Rev. & Date & Affected Pages & \multicolumn{1}{|c|}{ Revision Description } \\
\hline 0 & TBD & All & New Issue. \\
\hline & & & \\
\hline & & & \\
\hline & & & \\
\hline & & & \\
\hline & & & \\
\hline & & & \\
\hline & & & \\
\hline & & & \\
\hline & & & \\
\hline & & & \\
\hline & & & \\
\hline
\end{tabular}


Appendix B (Draft Coupon Specification)

\begin{tabular}{|c|lll|}
\hline $\begin{array}{c}\text { SPECIFICATION FOR U-MO COUPONS } \\
\text { FOR DDE-MURR }\end{array}$ & Identifier: & SPC-1568 \\
& Revision: & 0 (Draft) & \\
& Effective Date: & TBD & Page: 3 of 9 \\
\hline
\end{tabular}

\section{CONTENTS}

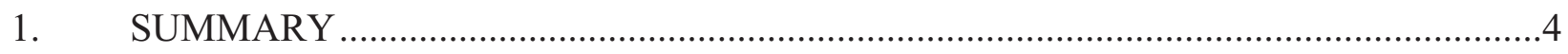

2. APPLICABLE CODES, PROCEDURES, AND REFERENCES …………....................

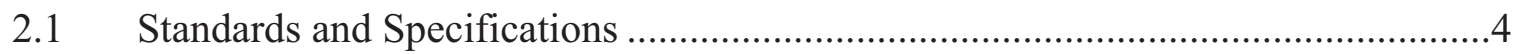

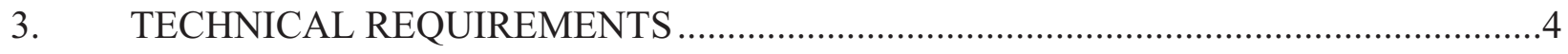

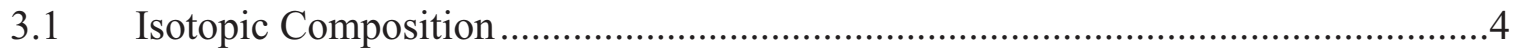

3.2 Chemical Composition.....................................................................................

3.3 Equivalent Boron Content.................................................................................

3.4 Out-of-Limits Condition ..............................................................................

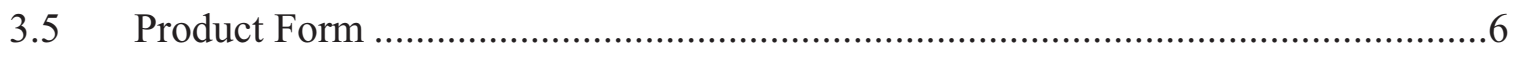

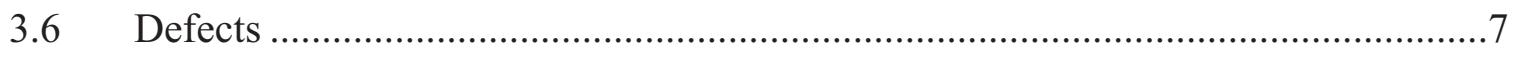

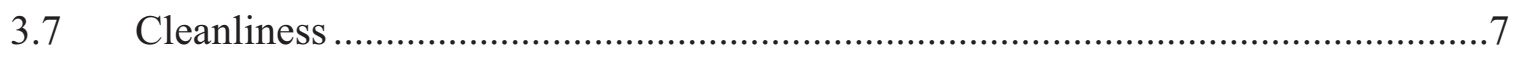

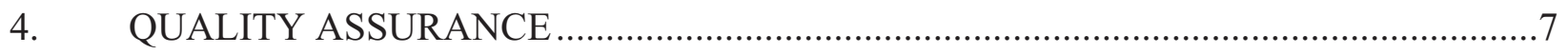

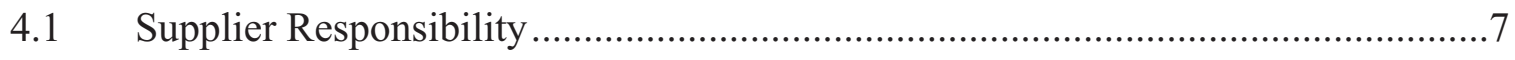

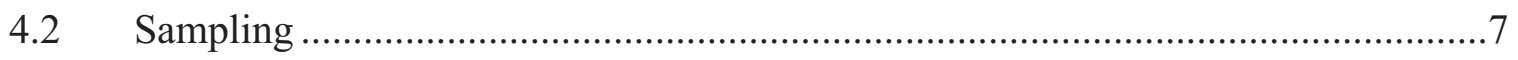

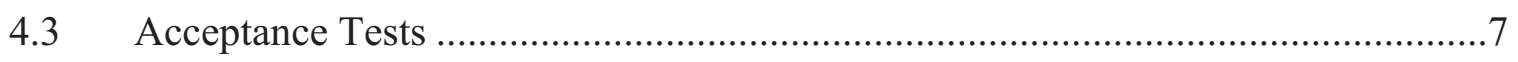

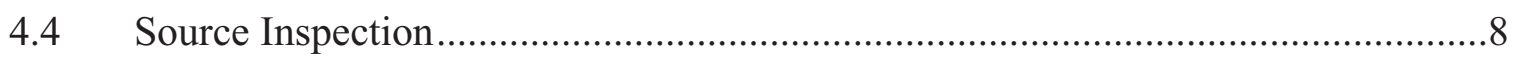

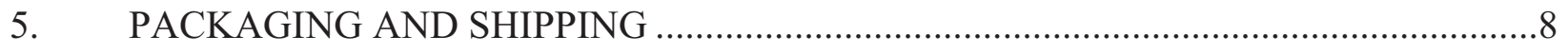

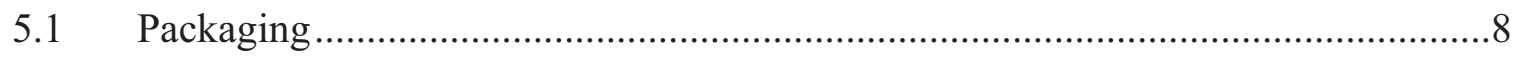

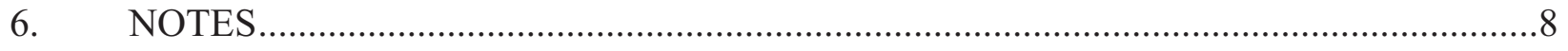

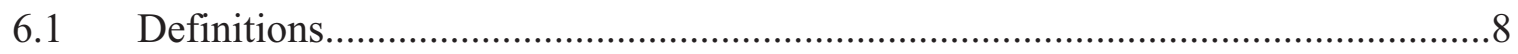

6.2 Quality Verification Test Results..................................................................... 
Appendix B (Draft Coupon Specification)

\begin{tabular}{|c|c|c|c|}
\hline $\begin{array}{c}\text { SPECIFICATION FOR U-MO COUPONS } \\
\text { FOR DDE-MURR }\end{array}$ & $\begin{array}{l}\text { Identifier: } \\
\text { Revision: } \\
\text { Effective Date: }\end{array}$ & $\begin{array}{l}\text { SPC-1568 } \\
0 \text { (Draft) } \\
\text { TBD }\end{array}$ & Page: 4 of 9 \\
\hline
\end{tabular}

\section{SUMMARY}

This specification defines the requirements for $U-M o$ (see def.) Coupons for use in production of fuel plates for the Design Demonstration Experiment (DDE) for the Missouri University Research Reactor (MURR).

\section{APPLICABLE CODES, PROCEDURES, AND REFERENCES}

Applicable portions of the following documents as defined herein, form a part of this specification. Where there is a conflict between the document cited and its latest revision, the supplier shall notify the Purchaser of the conflict and use the latest revision in effect unless otherwise directed by the Purchaser.

\subsection{Standards and Specifications}

ASTM C1233-03 Standard Practice for Determining Equivalent Boron Content of Nuclear Materials

SPC-1314 Specification for DDE-MURR Fuel Elements

\section{TECHNICAL REQUIREMENTS}

\subsection{Isotopic Composition}

The uranium isotopic composition shall be within the limits shown in Table 1.

Table 1: Isotopic Composition

\begin{tabular}{|c|c|c|c|}
\hline Element & Symbol & Units & Limit \\
\hline $\mathrm{U}-232$ & $\mathrm{U}-232$ & $\mu \mathrm{g} / \mathrm{gU}$ & $\leq 0.002$ \\
\hline $\mathrm{U}-234$ & $\mathrm{U}-234$ & $\mathrm{wt} \% \mathrm{OU}$ & $\leq 0.260 \%$ \\
\hline $\mathrm{U}-235$ & $\mathrm{U}-235$ & $\mathrm{wt} \% \mathrm{OU}$ & $19.75 \%+0.20 \%-0.30 \%$ \\
\hline $\mathrm{U}-236$ & $\mathrm{U}-236$ & $\mu \mathrm{g} / \mathrm{gU}$ & $\leq 4600$ \\
\hline Trans-U (Alpha) & $\mathrm{TRU}$ & $\mathrm{Bq} / \mathrm{gU}-\mathrm{Mo}$ & $\leq 250.0$ \\
\hline Fission Products & ${ }^{2}$ & $\mathrm{~Bq} / \mathrm{gU}-\mathrm{Mo}$ & $\leq 600.0$ \\
\hline
\end{tabular}

${ }^{1}$ The "Alpha activity" reflects measured transuranium elements to include: Americium 241, Curium 243/244, Neptunium 237, Plutonium 238, and Plutonium 239/240.

${ }^{2}$ Only those isotopes with a mass number less than 200 shall be considered fission products. Fission product activity levels which are false positive due to gamma photopeak interference may be excluded.

\subsection{Chemical Composition}

The composition of the LEU-Mo material shall be uranium alloyed with molybdenum (nominally $10 \mathrm{wt} \% \mathrm{Mo}$ ). Molybdenum content shall be no less than $9.00 \%$ and no greater than $11.00 \%$ by weight. Total weight percent uranium shall be reported. Chemical composition and impurities shall be determined on each Lot of material and shall be within the limits in Table 2 . 
Appendix B (Draft Coupon Specification)

Idaho National Laboratory

\begin{tabular}{|c|c|c|c|}
\hline $\begin{array}{c}\text { SPECIFICATION FOR U-MO COUPONS } \\
\text { FOR DDE-MURR }\end{array}$ & $\begin{array}{l}\text { Identifier: } \\
\text { Revision: } \\
\text { Effective Date: }\end{array}$ & $\begin{array}{l}\text { SPC-1568 } \\
0 \text { (Draft) } \\
\text { TBD }\end{array}$ & Page: 5 of 9 \\
\hline
\end{tabular}

Table 2: Chemical composition and impurities of the alloyed material

\begin{tabular}{|c|c|c|c|c|}
\hline Element & Symbol & Units & Limit & EBC Factor \\
\hline Aluminum & $\mathrm{Al}$ & $\mu \mathrm{g} / \mathrm{gU}-\mathrm{Mo}$ & $\leq 150$ & 0.0000 \\
\hline Beryllium & $\mathrm{Be}$ & $\mu \mathrm{g} / \mathrm{gU}-\mathrm{Mo}$ & $\leq 10.0$ & 0.0000 \\
\hline Boron & $\mathrm{B}$ & $\mu \mathrm{g} / \mathrm{gU}-\mathrm{Mo}$ & $\leq 3.0$ & 1.0000 \\
\hline Cadmium & $\mathrm{Cd}$ & $\mu \mathrm{g} / \mathrm{gU}-\mathrm{Mo}$ & $\leq 5.0$ & 0.3172 \\
\hline Calcium & $\mathrm{Ca}$ & $\mu \mathrm{g} / \mathrm{gU}-\mathrm{Mo}$ & $\leq 100.0$ & 0.0002 \\
\hline Carbon & $\mathrm{C}$ & $\mu \mathrm{g} / \mathrm{gU}-\mathrm{Mo}$ & $\leq 725.0$ & 0.0000 \\
\hline Chromium & $\mathrm{Cr}$ & $\mu \mathrm{g} / \mathrm{gU}-\mathrm{Mo}$ & $\leq 50.0$ & 0.0008 \\
\hline Cobalt & $\mathrm{Co}$ & $\mu \mathrm{g} / \mathrm{gU}-\mathrm{Mo}$ & $\leq 10.0$ & 0.0089 \\
\hline Copper & $\mathrm{Cu}$ & $\mu \mathrm{g} / \mathrm{gU}-\mathrm{Mo}$ & $\leq 50.0$ & 0.0008 \\
\hline Dysprosium & Dy & $\mu \mathrm{g} / \mathrm{gU}-\mathrm{Mo}$ & $\leq 5.0$ & 0.0818 \\
\hline Erbium & $\mathrm{Er}$ & $\mu \mathrm{g} / \mathrm{gU}-\mathrm{Mo}$ & $\leq 100.0$ & 0.0135 \\
\hline Europium & $\mathrm{Eu}$ & $\mu \mathrm{g} / \mathrm{gU}-\mathrm{Mo}$ & $\leq 2.0$ & 0.4250 \\
\hline Gadolinium & $\mathrm{Gd}$ & $\mu \mathrm{g} / \mathrm{gU}-\mathrm{Mo}$ & $\leq 1.0$ & 4.3991 \\
\hline Iron & $\mathrm{Fe}$ & $\mu \mathrm{g} / \mathrm{gU}-\mathrm{Mo}$ & $\leq 250.0$ & 0.0006 \\
\hline Lead & $\mathrm{Pb}$ & $\mu \mathrm{g} / \mathrm{gU}-\mathrm{Mo}$ & $\leq 10.0$ & 0.0000 \\
\hline Lithium & $\mathrm{Li}$ & $\mu \mathrm{g} / \mathrm{gU}-\mathrm{Mo}$ & $\leq 10.0$ & 0.1439 \\
\hline Magnesium & $\mathrm{Mg}$ & $\mu \mathrm{g} / \mathrm{gU}-\mathrm{Mo}$ & $\leq 50.0$ & 0.0000 \\
\hline Manganese & $\mathrm{Mn}$ & $\mu \mathrm{g} / \mathrm{gU}-\mathrm{Mo}$ & $\leq 50.0$ & 0.0034 \\
\hline Nickel & $\mathrm{Ni}$ & $\mu \mathrm{g} / \mathrm{gU}-\mathrm{Mo}$ & $\leq 100.0$ & 0.0011 \\
\hline Phosphorus & $\mathrm{P}$ & $\mu \mathrm{g} / \mathrm{gU}-\mathrm{Mo}$ & $\leq 100.0$ & 0.0000 \\
\hline Samarium & $\mathrm{Sm}$ & $\mu \mathrm{g} / \mathrm{gU}-\mathrm{Mo}$ & $\leq 3.0$ & 0.5336 \\
\hline Silicon & $\mathrm{Si}$ & $\mu \mathrm{g} / \mathrm{gU}-\mathrm{Mo}$ & $\leq 250.0$ & 0.0000 \\
\hline Sodium & $\mathrm{Na}$ & $\mu \mathrm{g} / \mathrm{gU}-\mathrm{Mo}$ & $\leq 25.0$ & 0.0003 \\
\hline Tin & Sn & $\mu \mathrm{g} / \mathrm{gU}-\mathrm{Mo}$ & $\leq 100.0$ & 0.0000 \\
\hline Tungsten & $\mathrm{W}$ & $\mu \mathrm{g} / \mathrm{gU}-\mathrm{Mo}$ & $\leq 100.0$ & 0.0014 \\
\hline Vanadium & $\mathrm{V}$ & $\mu \mathrm{g} / \mathrm{gU}-\mathrm{Mo}$ & $\leq 30.0$ & 0.0014 \\
\hline Zirconium & $\mathrm{Zr}$ & $\mu \mathrm{g} / \mathrm{gU}-\mathrm{Mo}$ & $\leq 250.0$ & 0.0000 \\
\hline \multicolumn{2}{|l|}{ Total Impurities ${ }^{1}$} & $\mu \mathrm{g} / \mathrm{gU}-\mathrm{Mo}$ & $\leq 1500$ & \\
\hline \multicolumn{2}{|c|}{ Equivalent Boron Content ${ }^{2,3}$} & $\mu \mathrm{g} / \mathrm{gU}-\mathrm{Mo}$ & $\leq 10.0$ & \\
\hline
\end{tabular}

\subsection{Equivalent Boron Content}

The EBC shall be calculated in accordance with ASTM C1233, "Standard Practice for Determining Equivalent Boron Contents of Nuclear Materials". The individual $\mu \mathrm{g} / \mathrm{gU}-M o$ impurity limits shall not be exceeded except as allowed in Section 3.4. The total impurities ( $\mu \mathrm{g} / \mathrm{gU}-\mathrm{Mo})$ and EBC shall not exceed the limits shown in Table 2. 
Appendix B (Draft Coupon Specification)

\begin{tabular}{|c|lll|}
\hline $\begin{array}{c}\text { SPECIFICATION FOR U-MO COUPONS } \\
\text { FOR DDE-MURR }\end{array}$ & Identifier: & SPC-1568 & \\
& Revision: & 0 (Draft) & \\
& Effective Date: & TBD & Page: 6 of 9 \\
\hline
\end{tabular}

\subsection{Out-of-Limits Condition}

An out-of-limits condition for Table 2 elements is acceptable for a maximum of two elements not to exceed $10 \%$ of the limit established in Table 2 provided the EBC and total impurities limits are not exceeded.

\subsection{Product Form}

U-Mo shall be provided in the form of a Coupon meeting the dimensional requirements of Figure 1 . The dimensions L, W, and T as well as quantity of Coupons will be specified by the Purchaser in a purchase order or similar contractual document.
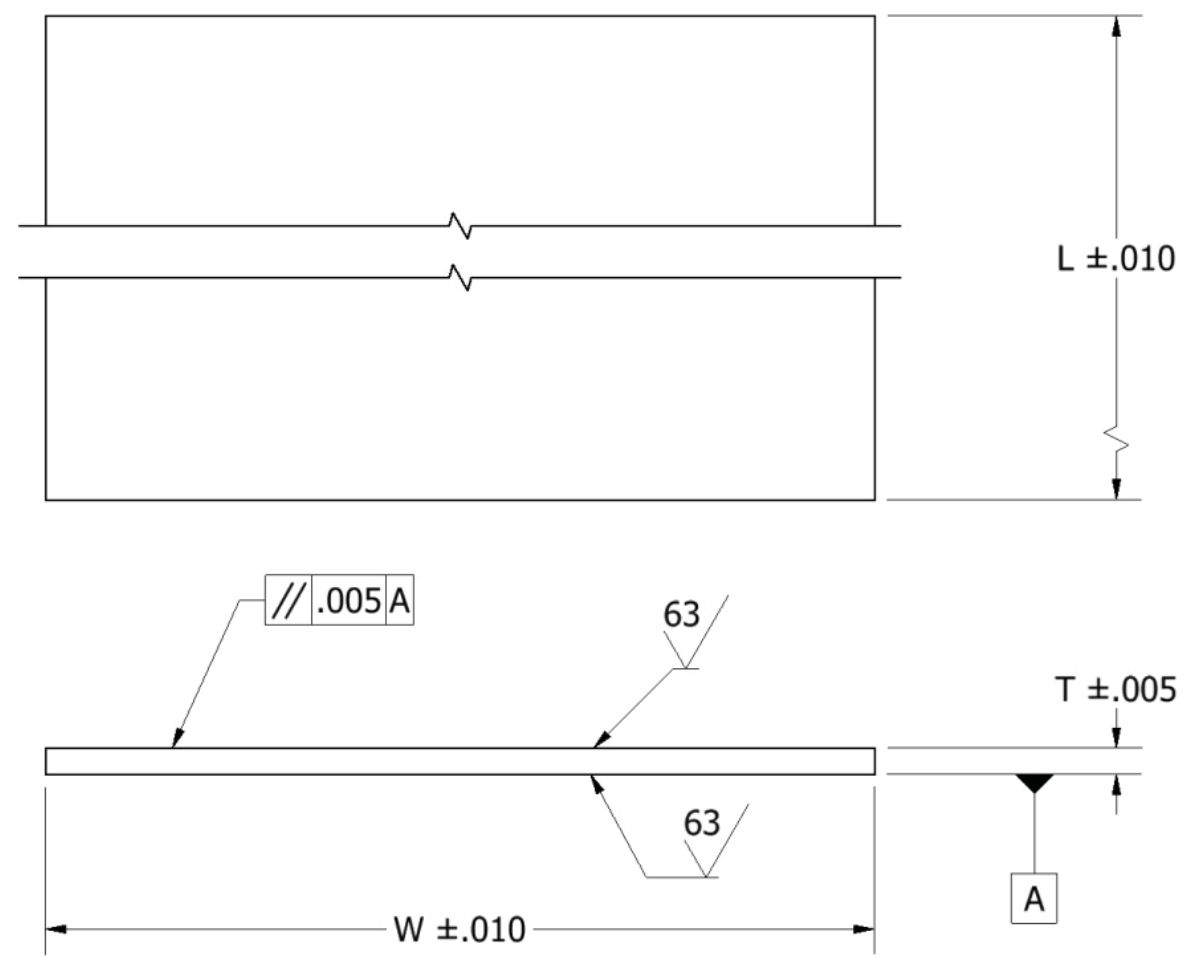

Figure 1: Coupon Dimensional Tolerances 
Appendix B (Draft Coupon Specification)

\begin{tabular}{|c|lll|}
\hline $\begin{array}{c}\text { SPECIFICATION FOR U-MO COUPONS } \\
\text { FOR DDE-MURR }\end{array}$ & Identifier: & SPC-1568 & \\
& Revision: & 0 (Draft) & \\
& Effective Date: & TBD & Page: 7 of 9 \\
\hline
\end{tabular}

\subsection{Defects}

Every Coupon shall be visually examined for surface defects. Each coupon surface shall be found free the following:

- Visible inclusions greater than 0.063 in any dimension

- Surface scratches and cracks greater than 0.003 in. in depth or 0.25 in. in length

- Surface pores greater than 0.063 in. in any dimension, except depth, which shall not exceed 0.031 in.

One randomly selected Coupon per Lot shall be examined by radiography and evaluated against the above criteria. Radiography parameters shall produce images of sufficient quality to identify the types of defects and rejection criteria as above.

\subsection{Cleanliness}

There shall be no volatiles, oil, grease, particulate, or other foreign materials on the surfaces of finished Coupons.

\section{QUALITY ASSURANCE}

The supplier shall document, implement, and maintain a quality program in compliance with Title 10, Code of Federal Regulations, Part 830.120, "Quality Assurance”.

\subsection{Supplier Responsibility}

The supplier shall be responsible for performing all tests and inspections required for the product form provided prior to shipment of the material. The results of all tests shall be recorded as quantitative data and furnished to the Fabricator as stipulated by Section 6.1.1.

\subsection{Sampling}

Each Lot of U-Mo shall be sampled and tested in accordance with the requirements of this specification and a purchaser approved sampling plan.

\subsection{Acceptance Tests}

The following tests shall be conducted on all Lots of U-Mo.

\subsection{1 $\quad$ Isotopic Composition}

The isotopic composition of each Lot of uranium alloy shall be determined by mass spectrographic analysis or equivalent method. The 
Appendix B (Draft Coupon Specification)

\begin{tabular}{|c|lll|}
\hline $\begin{array}{c}\text { SPECIFICATION FOR U-MO COUPONS } \\
\text { FOR DDE-MURR }\end{array}$ & Identifier: & SPC-1568 & \\
& Revision: & 0 (Draft) & \\
& Effective Date: & TBD & Page: 8 of 9 \\
\hline
\end{tabular}

isotopic concentration shall be in conformance with Section 3.1. Isotopic composition of total uranium content shall be calculated by difference or equivalent method.

\subsubsection{Chemical Composition}

The chemical composition and impurities shall be determined on each Lot of material. The results shall be in conformance with Section 0 .

\subsection{Source Inspection}

The supplier shall facilitate access to Purchaser-assigned quality assurance and/or technical representative(s) sufficient to provide the information necessary to verify and accept the product per the requirements of this specification.

\section{PACKAGING AND SHIPPING}

\subsection{Packaging}

Packaging and shipping containers shall comply with DOE and NRC Regulations in effect at the time of delivery.

\section{NOTES}

\subsection{Definitions}

6.1.1 Certification Package. A written and signed document from the supplier which certifies that the material described thereon complies with this specification and provides results of tests performed

6.1.2 Coupon. A thick rectangular product form intended to be reduced to final foil thickness by rolling

6.1.3 Fabricator. The primary entity selected by the Purchaser to use the UMo coupons to fabricate fuel plates

6.1.4 Lot. A group of pieces handled as a unit or material traceable to a common processing step

6.1.5 Purchaser. Idaho National Laboratory

6.1.6 Supplier. The primary entity selected by the Purchaser to supply the UMo coupons

6.1.7 U-Mo. A binary alloy comprised of uranium and molybdenum 


\section{Appendix B (Draft Coupon Specification)}

\begin{tabular}{|c|lll|}
\hline $\begin{array}{c}\text { SPECIFICATION FOR U-MO COUPONS } \\
\text { FOR DDE-MURR }\end{array}$ & Identifier: & SPC-1568 & \\
& Revision: & 0 (Draft) & \\
& Effective Date: & TBD & Page: 9 of 9 \\
\hline
\end{tabular}

\subsection{Quality Verification Test Results}

A Certification Package shall be provided for each shipment or group of shipments. Certifications shall be signed by project quality engineer or equivalent. Three (3) copies of the Certified Test Results (see Section 4.1) and certification as required above shall be provided to the fuel plate fabricator and one (1) copy to the Purchaser at time of shipment. Also one (1) copy should accompany the shipment or be provided to the receiver at time of shipment. The Certification Package shall include the following:

6.2.1 A statement that the material meets the requirements contained in this specification

6.2.2 A list of Coupon identification numbers and total Coupon, U-Mo alloy, uranium, and isotope masses 


\section{Appendix C (Draft Element Specification)}

Document ID: SPC-1314

Revision ID: 0

Effective Date: TBD

Specification

\section{Specification for DDE- MURR Fuel Elements}

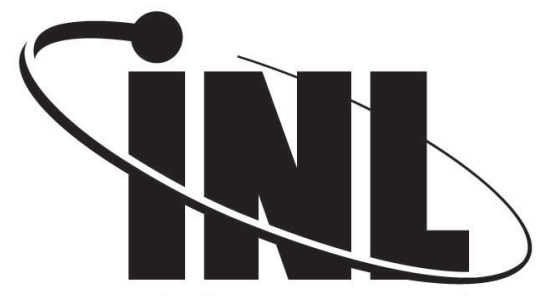

Idaho National Laboratory

The INL is a U.S. Department of Energy National Laboratory operated by Battelle Energy Alliance. 


\section{Appendix C (Draft Element Specification)}

Idaho National Laboratory

\begin{tabular}{|c|lll|}
\hline $\begin{array}{c}\text { SPECIFICATION FOR DDE-MURR FUEL } \\
\text { ELEMENTS }\end{array}$ & \begin{tabular}{lll} 
Identifier: & SPC-1314 & \\
Revision: & 0 & Page: 2 of 21 \\
\hline
\end{tabular} \\
\hline
\end{tabular}

\begin{tabular}{|l|l|l|l|}
\hline & Specification & & eCR Number: \#\#\#\#\# \\
\hline
\end{tabular}

Manual: Nuclear Nonproliferation

\section{REVISION LOG}

\begin{tabular}{|c|c|c|l|}
\hline Rev. & Date & Affected Pages & \multicolumn{1}{|c|}{ Revision Description } \\
\hline 0 & TBD & All & New Issue \\
\hline & & & \\
\hline & & & \\
\hline & & & \\
\hline & & & \\
\hline & & & \\
\hline & & & \\
\hline & & & \\
\hline & & & \\
\hline
\end{tabular}




\section{Appendix C (Draft Element Specification)}

Idaho National Laboratory

\begin{tabular}{|c|c|c|c|}
\hline $\begin{array}{l}\text { SPECIFICATION FOR DDE-MURR FUEL } \\
\text { ELEMENTS }\end{array}$ & $\begin{array}{l}\text { Identifier: } \\
\text { Revision: } \\
\text { Effective Date: }\end{array}$ & $\begin{array}{l}\text { SPC-1314 } \\
0 \\
\text { TBD }\end{array}$ & Page: 3 of 21 \\
\hline
\end{tabular}

\section{CONTENTS}

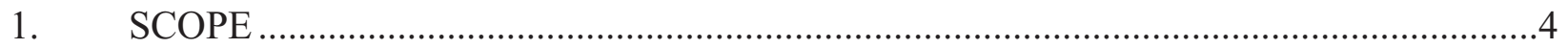

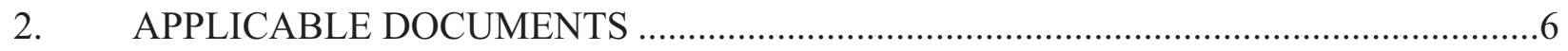

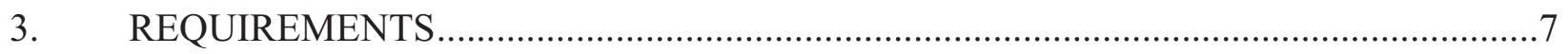

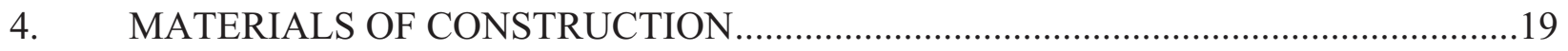

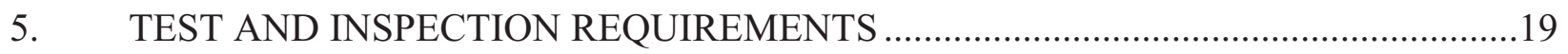

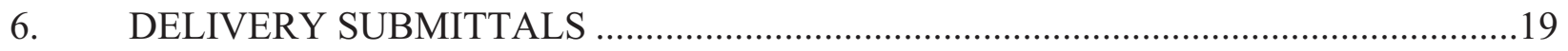

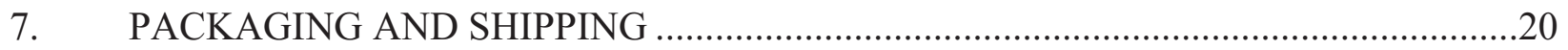

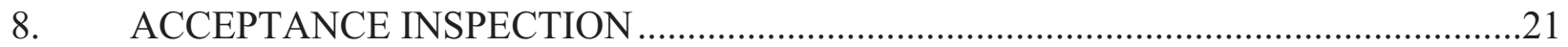




\section{Appendix C (Draft Element Specification)}

\begin{tabular}{|c|c|c|c|}
\hline $\begin{array}{l}\text { SPECIFICATION FOR DDE-MURR FUEL } \\
\text { ELEMENTS }\end{array}$ & $\begin{array}{l}\text { Identifier: } \\
\text { Revision: } \\
\text { Effective Date: }\end{array}$ & $\begin{array}{l}\text { SPC-1314 } \\
0 \\
\text { TBD }\end{array}$ & Page: 4 of 21 \\
\hline
\end{tabular}

\section{SCOPE}

\section{$1.1 \quad$ Introduction}

This Specification details the materials, components, testing, inspection, and Quality Control requirements for the fabrication of Fuel Elements for the Design Demonstration Experiment (DDE) representing the Missouri University Research Reactor (MURR) low enriched uranium fuel design. DDE-MURR Fuel Elements are designed for irradiation in the Belgium Reactor 2 (BR-2) in Mol, Belgium. If there appears to be any conflict between parts of this Specification, such as its referenced drawings and standards, the Purchaser and Stakeholder shall be notified for resolution.

\subsection{Definitions}

For the purpose of this Specification, the following terms are identified:

1.2.1 Cladding. The aluminum bonded to the Fuel Meat

1.2.2 Controlled Work Area. A work area to which access of personnel, tools, and materials is limited and physically controlled. Temporary enclosures may be used where adjacent activities produce contamination which is detrimental to the job

1.2.3 Coupon. A thick rectangular product form intended to be reduced to final foil thickness by rolling

1.2.4 Development. A determination of processes, equipment, and parameters required to produce a product in compliance with this Specification

1.2.5 Failure. A condition where the Manufacturing Process appears to be out of control or damage to Fuel Plates or Fuel Elements or breakdown of equipment causes delays and/or excessive cost

1.2.6 Fuel Meat. The uranium bearing region of each Fuel Plate

1.2.7 Fuel Element. An assembly of Fuel Plates and hardware components

1.2.8 Fuel Plate. The Fuel Meat complete with aluminum Cladding

1.2.9 Hot Isostatic Press (HIP). Fabrication process which bonds Cladding to Monolithic foils by subjecting un-bonded Fuel Plate materials to a high pressure and temperature 


\section{Appendix C (Draft Element Specification)}

\begin{tabular}{|c|c|c|c|}
\hline $\begin{array}{l}\text { SPECIFICATION FOR DDE-MURR FUEL } \\
\text { ELEMENTS }\end{array}$ & $\begin{array}{l}\text { Identifier: } \\
\text { Revision: } \\
\text { Effective Date: }\end{array}$ & $\begin{array}{l}\text { SPC-1314 } \\
0 \\
\text { TBD }\end{array}$ & Page: 5 of 21 \\
\hline
\end{tabular}

1.2.10 In-Process Controls. Inspection and tests made during Production to ensure that the Manufacturing processes, equipment, and personnel are producing a product meeting specified requirements

1.2.11 Interlayer. Thin zirconium layer applied to the surface of Monolithic foils

1.2.12 Lot. A group of pieces handled as a unit or material traceable to a common processing step

1.2.13 Manufacturing. All fabrication, assembly, test, inspection, and Quality Control processes

1.2.14 Monolithic. Fuel type composed of a metallic alloy in the form of a foil.

1.2.15 Production. That phase of the program, following Qualification, during which the product is in Manufacture

\subsubsection{Purchaser. Idaho National Laboratory}

1.2.17 Qualification. A documented demonstration approved by the Purchaser that the Manufacturing processes, equipment, and personnel can produce a product in compliance with this Specification

1.2.18 Quality Control. The sampling plans, inspections, and tests required during Production to assure that the product is in compliance with this Specification

1.2.19 Rejection. Refusal of acceptance of materials, parts, components, or assembly products as part of the contract requirements of this program because of noncompliance with this Specification

1.2.20 Requalification. A demonstration that a single, or group of Manufacturing processes, equipment, and personnel can produce a product in compliance with this Specification after the original Qualification has been completed and becomes invalid

1.2.21 Specification. All parts and attachments of this document, its references, drawings, and standards, as may be modified from time to time by contractual document

\subsubsection{Stakeholder. Missouri University Research Reactor}

1.2.23 Subtier Supplier. Any vendor selected by the Supplier to furnish materials, services, or manufactured parts to the Supplier 
Appendix C (Draft Element Specification)

Idaho National Laboratory

\begin{tabular}{|c|c|c|c|}
\hline $\begin{array}{l}\text { SPECIFICATION FOR DDE-MURR FUEL } \\
\text { ELEMENTS }\end{array}$ & $\begin{array}{l}\text { Identifier: } \\
\text { Revision: } \\
\text { Effective Date: }\end{array}$ & $\begin{array}{l}\text { SPC-1314 } \\
0 \\
\text { TBD }\end{array}$ & Page: 6 of 21 \\
\hline
\end{tabular}

1.2.24 Supplier. The primary vendor selected by INL to Manufacture the product

1.2.25 U-Mo. A binary alloy comprised of uranium and molybdenum

\section{APPLICABLE DOCUMENTS}

\subsection{Applicable Standards}

The applicable portions of the following documents, as defined herein, form a part of this Specification. Where there is a conflict between the documents cited and the latest revision, thereof, the Supplier shall notify the Purchaser of the conflict and use the latest revision unless otherwise directed by the Purchaser.

2.1.1 National Codes and Standards

MIL-C-45662 Calibration System Requirements

2.1.2 American Society for Testing and Materials (ASTM)

ASTM E 1742

ASTM E 8

ASTM E 29-93a
Standard Practice for Radiograph Examination

Methods of Tension Testing of Metallic Materials

Recommended Practice for Indicating Which Places of Figures are to be Considered Significant in Specified Limiting Values

2.1.3 American National Standards Institute (ANSI)

ANSI B46.1

ANSI Y14.5
Surface Texture

Dimensioning and Tolerancing for Engineering Drawings

2.1.4 American Society of Mechanical Engineers (ASME) 
Appendix C (Draft Element Specification)

\begin{tabular}{|c|c|c|c|}
\hline $\begin{array}{l}\text { SPECIFICATION FOR DDE-MURR FUEL } \\
\text { ELEMENTS }\end{array}$ & $\begin{array}{l}\text { Identifier: } \\
\text { Revision: } \\
\text { Effective Date: }\end{array}$ & $\begin{array}{l}\text { SPC-1314 } \\
0 \\
\text { TBD }\end{array}$ & Page: 7 of 21 \\
\hline
\end{tabular}

ASME

ASME NQA-1

Boiler and Pressure Vessel Code Section $\mathrm{V}$

Quality Assurance Requirements for Nuclear Facility Applications

2.1.5 Idaho National Laboratory

STD-7022A

SPC-1568

Cleanliness Acceptance Levels for Nuclear or Non-Nuclear Service Components Specification for U-Mo Coupons for DDE-MURR

2.1.6 American Society for Nondestructive Test (ASNT)

SNT-TC-1A American Society For Nondestructive Testing (ASNT) Recommended Practice

\subsubsection{Drawings (INL)}

603455

MURR LEU Fuel Element Assembly

\section{REQUIREMENTS}

\subsection{Records and Reports}

3.1.1 Two (2) copies of the following data and records shall be supplied to the Purchaser for review and approval prior to fabrication of Fuel Elements. One (1) information copy shall be supplied to the Stakeholder by the Supplier.

3.1.1.1 All shop drawings of Fuel Element components and assemblies to be used in the fabrication of Fuel Elements

3.1.1.2 Integrated Manufacturing and Inspection Test Plan, submittal of Supplier route cards, operation procedures, drawings, and flow sheets may fulfill this requirement 


\begin{tabular}{|c|c|c|c|}
\hline $\begin{array}{l}\text { SPECIFICATION FOR DDE-MURR FUEL } \\
\text { ELEMENTS }\end{array}$ & $\begin{array}{l}\text { Identifier: } \\
\text { Revision: } \\
\text { Effective Date: }\end{array}$ & $\begin{array}{l}\text { SPC-1314 } \\
0 \\
\text { TBD }\end{array}$ & Page: 8 of 21 \\
\hline
\end{tabular}

3.1.1.3 A detailed description as to the manner by which the Supplier proposes to assign Fuel Plate U-235 content, included in the description shall be sampling, analytical, and Quality Control procedures; a statement as to the estimated absolute accuracy of the assigned Fuel Plate and Fuel Element U-235 content

\subsubsection{Qualification Package for Fuel Plate fabrication}

3.1.2 Concurrent with or prior to the shipment of each Fuel Element the Supplier shall provide the Purchaser with the items in Section 6 of this Specification.

3.1.3 Two (2) copies of the following reports are required by this Specification:

3.1.3.1 Monthly Reports: A monthly report using Line of Balance, Program Evaluation and Review Technique (PERT), or similar reporting techniques which details program progress against a previously submitted schedule shall be provided by the Supplier to the Purchaser and Stakeholder by the fifteenth $\left(15^{\text {th }}\right)$ working day of each month.

3.1.3.2 Failure Notification: During Production, complete records shall be kept by the Supplier. In the event of a Failure, the time, nature, description, corrective action taken, and proposed further corrective action shall be reported to the Purchaser within five (5) working days after such Failure. An information copy shall be sent to the Stakeholder when process Failures are involved.

\subsection{Manufacturing Procedures}

All changes and modifications to programs, processes, procedures to be used to Manufacture the product shall be submitted to the Purchaser for review and approval prior to use. Information copies shall be provided to the Stakeholder. These shall include:

\subsubsection{Supplier's Specifications for all materials used}

\subsubsection{Identification of Subtier Suppliers}

3.2.3 Complete Development program, including material, process, equipment, and test procedures, Supplier submittal of the Qualification data package may fulfill this requirement 


\section{Appendix C (Draft Element Specification)}

\begin{tabular}{|c|c|c|c|}
\hline $\begin{array}{l}\text { SPECIFICATION FOR DDE-MURR FUEL } \\
\text { ELEMENTS }\end{array}$ & $\begin{array}{l}\text { Identifier: } \\
\text { Revision: } \\
\text { Effective Date: }\end{array}$ & $\begin{array}{l}\text { SPC-1314 } \\
0 \\
\text { TBD }\end{array}$ & Page: 9 of 21 \\
\hline
\end{tabular}

3.2.4 All fabrication, assembly, cleaning, surface treating, handling, and demonstration procedures

3.2.5 All test, inspection, Production, and Quality Control procedures, including all nondestructive tests and standards

3.2.6 In-Process Controls, sampling programs, and procedures

3.2.7 Quality Control sampling program and procedures

3.2.8 All rework or repair programs and procedures

3.2.9 All final inspection, washing, packaging, storage, and shipping procedures

3.2.10 Manufacturing plan and inspection procedure for Fuel Plate and Fuel Element fabrication

3.2.11 The Supplier shall prepare and maintain written procedures also for radiograph test, ultrasonic test, visual examination, and personnel certification

\subsection{Quality Assurance}

The Supplier shall document, implement, and maintain a quality system in compliance with ASME NQA-1. Measurement equipment used for tests and inspection required in this section and in Section 5 shall be calibrated in conformance with Mil-C-45652. A description of the Quality Assurance Program and the procedures to maintain adequate control and quality shall be furnished to the Purchaser.

The Supplier shall permit the Purchaser to conduct pre-award and continuing evaluation of the Supplier's quality system. The Supplier shall be subject to Source Inspection by the Purchaser at the Supplier's facility and also at the Subtier Supplier's facility if deemed necessary. The Purchaser will identify hold points to the Supplier to be witnessed by the Purchaser's representative. The Purchaser's source inspection does not constitute final acceptance of the items. A Quality Supplier Release, which is approved by the source inspector, shall be required before shipment to the facility designated by the Purchaser.

Personnel performing NDE examinations, specifically radiographic, ultrasonic, and visual shall be certified to American Society for Nondestructive Testing (ASNT) Number SNT-TC-1A and certification documentation shall be made available to the purchaser. 


\section{Appendix C (Draft Element Specification)}

\begin{tabular}{|c|c|c|c|}
\hline $\begin{array}{l}\text { SPECIFICATION FOR DDE-MURR FUEL } \\
\text { ELEMENTS }\end{array}$ & $\begin{array}{l}\text { Identifier: } \\
\text { Revision: } \\
\text { Effective Date: }\end{array}$ & $\begin{array}{l}\text { SPC-1314 } \\
0 \\
\text { TBD }\end{array}$ & Page: 10 of 21 \\
\hline
\end{tabular}

The Supplier is required to qualify the processes or portions of the process, or be exempt from same by written approval of the Purchaser. Only materials which comply with this Specification shall be used. Fuel Plate Qualification shall be satisfied by the fabrication of at least one Lot of consecutively produced Fuel Plates of each size having a yield of at least $65 \%$ acceptable Fuel Plates which meet the requirements of this Specification. The Lot size shall be determined by an agreement between the Purchaser and Supplier.

Fuel plates made prior to and during qualification runs that fail to meet the $65 \%$ yield requirements shall not be used in fabricating Fuel Elements without prior approval of the purchaser.

3.3.1 Operator Qualification: Operator Qualification shall be accomplished via an approved Supplier Internal Qualification program for the following operations:

\subsubsection{Swaging}

\subsubsection{Final machining}

In addition to the operations specified above, the Supplier shall also show evidence of the training and competency of those individuals who perform any of the following Fuel Element fabrication and inspection activities:

\subsubsection{HIP pack assembly and preparation}

3.3.1.4 Fuel Plate, Fuel Element, and component cleaning

3.3.1.5 Dimensional inspection of Fuel Plates, Fuel Elements, and subcomponents

3.3.1.6 Visual inspection of the Fuel Plates, Fuel Elements, subcomponents, and bend test specimens

3.3.1.7 Coolant channel gap dimensioning or probing

3.3.1.8 Radiography and inspection of Fuel Plate radiographs

\subsubsection{Ultrasonic testing}

\subsubsection{Eddy current testing}

The individuals performing these operations shall have specific requirements imposed on them that will demonstrate their knowledge 


\section{Appendix C (Draft Element Specification)}

\begin{tabular}{|c|c|c|c|}
\hline $\begin{array}{l}\text { SPECIFICATION FOR DDE-MURR FUEL } \\
\text { ELEMENTS }\end{array}$ & $\begin{array}{l}\text { Identifier: } \\
\text { Revision: } \\
\text { Effective Date: }\end{array}$ & $\begin{array}{l}\text { SPC-1314 } \\
0 \\
\text { TBD }\end{array}$ & Page: 11 of 21 \\
\hline
\end{tabular}

and ability to perform their respective assignments. Documented evidence of the training of those individuals shall be maintained and shall be made available to the Purchaser upon request.

3.3.2 In-Process Controls: The Supplier shall establish a process control program whereby checks are made on the Fuel Plate Manufacturing processes, operational procedures, intermediate product characteristics, and equipment to demonstrate process stability during Production is at least equal to that demonstrated during Qualification. These In-Process Controls shall monitor, as a minimum, the following fuel plate characteristics:

\subsubsection{Fuel Homogeneity}

\subsubsection{Fuel Configuration}

\subsubsection{Cladding Thickness}

3.3.2.4 Internal defects and bond integrity

\subsubsection{Surface finish and defects}

\subsubsection{Cleanliness}

\subsubsection{Dimensional}

\subsubsection{Swage joint pull tests}

3.3.3 Requalification: The Supplier shall notify the Purchaser of any proposed process change. A changed process may not be used in Production until the Supplier has submitted the results and data of the Requalification effort to the Purchaser and received written approval to use the changed process in Production. The Supplier may be exempt from Requalification if the Supplier can demonstrate to the Purchaser by proof test or engineering explanation, and receives written approval from the Purchaser, that the proposed process change will not degrade the quality of the product.

\subsection{Product Requirements}

3.4.1 Fuel Meat: Fuel Meats shall be U-Mo Monolithic foils fabricated from U-Mo Coupons furnished per SPC-1567. U-Mo Monolithic foils shall have zirconium Interlayers bonded to the largest surfaces for which the nominal thickness is 0.001 inch each. Zirconium materials shall be at least $99.5 \%$ pure (metals basis excluding hafnium) with no greater than 


\section{Appendix C (Draft Element Specification)}

\begin{tabular}{|c|c|}
\hline $\begin{array}{l}\text { SPECIFICATION FOR DDE-MURR FUEL } \\
\text { ELEMENTS }\end{array}$ & $\begin{array}{ll}\text { Identifier: } & \text { SPC-1314 } \\
\text { Revision: } & 0 \\
\text { Effective Date: } & \text { TBD }\end{array}$ \\
\hline
\end{tabular}

100ppm hafnium impurities. Zirconium materials shall be purchased with vendor certifications and shall be verified by independent laboratory analysis. During Qualification a minimum of one (1) randomly selected Monolithic foils of each thickness type shall be examined for Interlayer thickness per section 3.4.1.1. During Production a minimum of one (1) randomly selected Monolithic foil per 100 of each thickness type shall be examined for Interlayer thickness per section 3.4.1.1.

\subsubsection{Interlayer Thickness: At least four (4) microscopic} examinations per foil shall be evaluated for Interlayer thickness. Each side of the foil shall be represented by at least one (1) sample as in Figure 1. Samples shall be taken from those portions of the foil that are removed during final sizing. Each sample shall be sectioned, polished, and dimensional measurements shall be obtained at 50X minimum magnification. At least ten (10) thickness measurements shall be obtained for each of the two (2) Interlayers on each of the four (4) samples. The average of each set of ten (10) readings shall not be less than 0.0005 inch.

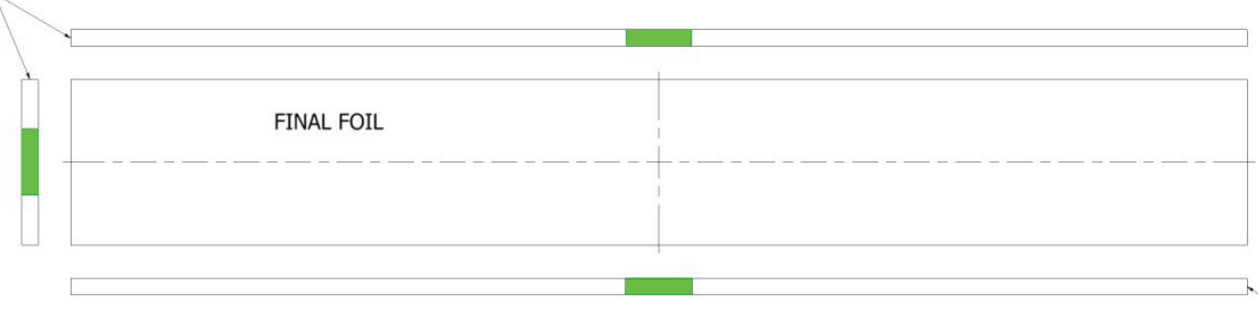

Figure 1: Foil Sample Locations

\subsubsection{Fuel Plates}

Fuel Loading: Each Fuel Plate shall be loaded to U-235 content limits per Table 1. Requirements for fuel loading shall be established in accordance with Section 3.1.1.3 by the Supplier subject to the approval of the Purchaser.

Table 1: Fuel Plate U-235 Loading

\begin{tabular}{|c|c|c|c|c|}
\hline $\begin{array}{c}\text { Fuel } \\
\text { Plate }\end{array}$ & $\begin{array}{c}\mathrm{U}-235 \\
\text { Nominal }(\mathrm{g})\end{array}$ & $\begin{array}{c}\text { Tolerance } \\
( \pm \%)\end{array}$ & $\begin{array}{c}\mathrm{U}-235 \\
\text { Minimum }(\mathrm{g})\end{array}$ & $\begin{array}{c}\mathrm{U}-235 \\
\text { Maximum }(\mathrm{g})\end{array}$ \\
\hline 1 & 18.10 & $11 \%$ & 16.09 & 20.11 \\
\hline 2 & 25.66 & $8.3 \%$ & 23.52 & 27.80 \\
\hline
\end{tabular}


Appendix C (Draft Element Specification)

\begin{tabular}{|c|c|c|c|}
\hline $\begin{array}{l}\text { SPECIFICATION FOR DDE-MURR FUEL } \\
\text { ELEMENTS }\end{array}$ & $\begin{array}{l}\text { Identifier: } \\
\text { Revision: } \\
\text { Effective Date: }\end{array}$ & $\begin{array}{l}\text { SPC-1314 } \\
0 \\
\text { TBD }\end{array}$ & Page: 13 of 21 \\
\hline
\end{tabular}

\begin{tabular}{|c|c|c|c|c|}
3 & 36.27 & $6.3 \%$ & 34.00 & 38.53 \\
\hline 4 & 47.88 & $5.0 \%$ & 45.48 & 50.27 \\
\hline 5 & 50.45 & $5.0 \%$ & 47.93 & 52.97 \\
\hline 6 & 52.99 & $5.0 \%$ & 50.34 & 55.64 \\
\hline 7 & 55.54 & $5.0 \%$ & 52.76 & 58.32 \\
\hline 8 & 58.06 & $5.0 \%$ & 55.16 & 60.97 \\
\hline 9 & 60.61 & $5.0 \%$ & 57.58 & 63.64 \\
\hline 10 & 63.16 & $5.0 \%$ & 60.00 & 66.31 \\
\hline 11 & 65.70 & $5.0 \%$ & 62.42 & 68.99 \\
\hline 12 & 68.25 & $5.0 \%$ & 64.84 & 71.66 \\
\hline 13 & 70.77 & $5.0 \%$ & 67.23 & 74.31 \\
\hline 14 & 73.32 & $5.0 \%$ & 69.65 & 76.98 \\
\hline 15 & 75.86 & $5.0 \%$ & 72.07 & 79.66 \\
\hline 16 & 78.41 & $5.0 \%$ & 74.49 & 82.33 \\
\hline 17 & 80.96 & $5.0 \%$ & 76.91 & 85.00 \\
\hline 18 & 83.48 & $5.0 \%$ & 79.30 & 87.65 \\
\hline 19 & 86.02 & $5.0 \%$ & 81.72 & 90.33 \\
\hline 20 & 88.59 & $5.0 \%$ & 84.16 & 93.02 \\
\hline 21 & 91.14 & $5.0 \%$ & 86.58 & 95.70 \\
\hline 22 & 93.71 & $5.0 \%$ & 89.02 & 98.40 \\
\hline 23 & 81.88 & $5.9 \%$ & 77.06 & 86.70 \\
\hline
\end{tabular}

3.4.2.1 Requirements for Radiography of Fuel Plates: A procedure shall be written by the Supplier to specify the details for achieving acceptable Fuel Plate radiographs. The procedure shall include the requirements given in this Specification and shall be approved by the Purchaser.

The voltage shall be at least 100 k.v.p with focal spot size of $5 \mathrm{~mm}$ maximum. The distance between the focal point and the Fuel Plate shall be at least twice the length of the Fuel Plate. The focal point shall be centered laterally and longitudinally over the Fuel Plate or group of Fuel Plates. Any method(s) used to mitigate and/or correct for undercutting effects at Fuel Meat edges shall be documented in the procedure.

The image outline shall be clear and sharp; the film shall be free of runs, streaks, scratches, blurs, and cassette defects that will affect the area covered by the Fuel Plates.

Film density for fuel homogeneity radiographs, as read over the Fuel Meat region, shall provide densitometer readings of between 1.0 and 4.0 . 


\section{Appendix C (Draft Element Specification)}

\begin{tabular}{|c|c|c|c|}
\hline $\begin{array}{l}\text { SPECIFICATION FOR DDE-MURR FUEL } \\
\text { ELEMENTS }\end{array}$ & $\begin{array}{l}\text { Identifier: } \\
\text { Revision: } \\
\text { Effective Date: }\end{array}$ & $\begin{array}{l}\text { SPC-1314 } \\
0 \\
\text { TBD }\end{array}$ & Page: 14 of 21 \\
\hline
\end{tabular}

Density standard(s) shall be exposed simultaneously with each Fuel Plate.

The film shall be an extreme sensitivity, extra fine grain, high contrast, double emulsion, industrial X-ray type, (Kodak type $\mathrm{M}$ or equal) which is acceptable to the Purchaser. Development of the film shall be in accordance with the manufacturer's recommendation.

A system of identification of the film shall be provided by the Supplier which shall show as a minimum:

3.4.2.1.1 Fuel Plate Lot number

3.4.2.1.2 Fuel Plate serial number

3.4.2.1.3 Orientation of density standard

3.4.2.1.4 Density standard identification

\subsection{Date of radiography}

Fuel Homogeneity: Any one half (1/2) inch diameter area, at any location in the Fuel Meat shall not exceed the limit of a $\pm 15 \%$ density standard.

Between the minimum and maximum permissible Fuel Meat length boundary, fuel underload condition shall not be evaluated.

3.4.2.2 Fuel Configuration: The outline of the Fuel Meat shall be within the largest and smallest areas as defined by dwg 603455 dimensions and their respective tolerances.

Compliance with Fuel Meat configuration requirements shall be by visual inspection of Fuel Plate radiographs of all Fuel Plates. Visual radiograph inspections shall be performed on a light table having a light range of 450-600 footcandles at the table surface and the area darkened to give a light range of 5-15 footcandles 18 inches above the light table with radiographic film in place on the table.

3.4.2.3 Cladding Thicknesses: All Fuel Plates shall be evaluated for Cladding thickness by UT and shall have a minimum Cladding thickness of 0.008 inches. 


\section{Appendix C (Draft Element Specification)}

\begin{tabular}{|c|c|c|c|}
\hline $\begin{array}{l}\text { SPECIFICATION FOR DDE-MURR FUEL } \\
\text { ELEMENTS }\end{array}$ & $\begin{array}{l}\text { Identifier: } \\
\text { Revision: } \\
\text { Effective Date: }\end{array}$ & $\begin{array}{l}\text { SPC-1314 } \\
0 \\
\text { TBD }\end{array}$ & Page: 15 of 21 \\
\hline
\end{tabular}

3.4.2.4 Internal Defects and Bond Integrity: During Qualification all

Fuel Plates shall be evaluated for bond integrity by UT and bend testing. During Production all Fuel Plates shall be evaluated for bond integrity by UT and one (1) Fuel Plate per Lot shall be evaluated by bend testing.

Any UT indications of debond, voids, blisters, or delaminations larger than 0.060 inches over the Fuel Meat or 0.120 inches outside the Fuel Meat area shall be cause for Rejection. A maximum of two (2) indications less than 0.060 inches in diameter are allowed in the Fuel Meat area provided they are more than 0.250 inches apart. A maximum of two (2) indications less than 0.120 inches in diameter are allowed in any edge or end clad area, outside the Fuel Meat area, provided they are not any closer than 0.050 inches to the edge or end of the Fuel Plate and no closer together than the major dimension of the largest indication.

Bend test samples shall be the portions of the Fuel Plate assembly adjacent to the final Fuel Plate which are removed from the assembly during final sizing of the Fuel Plate. Each sample shall be bent around a mandrel 90 degrees in one direction, returned to 0 degrees, then bent 90 degrees in the other direction, and returned to 0 degrees. The edges of the bend test specimen adjacent to the Fuel Plate shall then be visually examined, without magnification, for delamination. Any edge adjacent to the Fuel Plate showing visual delamination of the Cladding layers shall be cause for Rejection of the associated Fuel Plate. At least six (6) bend samples per Fuel Plate, including two (2) along each long side and one (1) along each short side, shall be tested and visually inspected to verify bonding.

3.4.2.5 Surface Finish and Defects: The finished Fuel Plates shall be free from pits, dents, scratches, and other areas of Cladding removed in excess of 0.003 inch deep.

Compliance with surface finish and defect requirements shall be established by $100 \%$ visual inspection without magnification of all Fuel Plates. An optical depth gage shall be used to evaluate questionable defects.

3.4.2.6 Dimensional: Fuel Plate outer dimensions shall be verified by inspection of three (3) Fuel Plates per Lot. If any of these three 


\begin{tabular}{|c|c|c|c|}
\hline $\begin{array}{l}\text { SPECIFICATION FOR DDE-MURR FUEL } \\
\text { ELEMENTS }\end{array}$ & $\begin{array}{l}\text { Identifier: } \\
\text { Revision: } \\
\text { Effective Date: }\end{array}$ & $\begin{array}{l}\text { SPC-1314 } \\
0 \\
\text { TBD }\end{array}$ & Page: 16 of 21 \\
\hline
\end{tabular}

(3) is discrepant, the entire Lot shall be dimensionally inspected. All Dimensions shall apply at a temperature of $75^{\circ} \mathrm{F}$ $\pm 5^{\circ} \mathrm{F}$.

3.4.2.7 Identification: Each finished Fuel Plate shall be identified by a marking method approved by the Purchaser over the nonfueled region per dwg 603455 and shall not be in excess of 0.010 inch deep. Positive identification shall be maintained relative to the complete fabrication history including the Fuel Plate Lot, Monolithic foils, basic material Lots, U-Mo coupons, Manufacturing cycle, and Quality Control phases.

3.4.2.8 Storage: All Fuel Plates that have received final cleaning shall be contained in clean polyethylene containers or other containers approved by the Purchaser while awaiting final assembly, being transferred into storage, and being maintained in storage. Any material exposed to contamination shall be reinspected to the requirements of Section 3.4.3.6.

\subsubsection{Fuel Elements}

3.4.3.1 Fuel Loading: Each Fuel Element shall contain $1439 \mathrm{~g} \pm 14.4 \mathrm{~g}$ U-235.

3.4.3.2 Mechanical Integrity: The Supplier shall assemble fuel plates to side plates by swaging. Mechanical integrity of swage joints shall be established by performing pull tests with care equivalent to performing tension tests as prescribed in ASTM E 8. Swaged joints between the Fuel Plates and side plates shall be able to withstand a load of not less than 150 pounds per linear inch of swage joint.

Pull test samples shall have matching geometry compared to the Fuel Elements except that they shall be $3.0 \pm 0.1$ inch long and that the plate portions may be made from "blank" aluminum stock in lieu of fueled plates. Swaging of test specimens shall be interspersed in the normal Fuel Element swaging process without adjustment of the swaging parameters. The swage test specimen quantity, placement, type, and sequencing shall be sufficient to comprehensively represent each Fuel Element's swaging operation in all of the following parameters: 


\section{Appendix C (Draft Element Specification)}

\begin{tabular}{|c|c|c|c|}
\hline $\begin{array}{l}\text { SPECIFICATION FOR DDE-MURR FUEL } \\
\text { ELEMENTS }\end{array}$ & $\begin{array}{l}\text { Identifier: } \\
\text { Revision: } \\
\text { Effective Date: }\end{array}$ & $\begin{array}{l}\text { SPC-1314 } \\
0 \\
\text { TBD }\end{array}$ & Page: 17 of 21 \\
\hline
\end{tabular}

3.4.3.2.1 Fuel plate type including a sample plate 1, plate 23, and one plate each selected from each of the ranges plates 2-8, plates 9-15, and plates $16-22$

3.4.3.2.2 Each side plate (left and right)

3.4.3.2.3 Three locations in the swage bed direction of travel (fore, middle, and aft)

\subsection{Swaging sequence (both prior to and following} swaging of the Fuel Element)

3.4.3.3 Identification: The side plate of each Fuel Element shall be identified as DDE-MURR as shown in drawing 603455.

3.4.3.4 Dimensional: Verification of all external dimensions of the Fuel Elements and all coolant channel gaps shall be by $100 \%$ inspection in accordance with INL drawing 603455. Final coolant channel gap dimensions shall be taken after the final Fuel Element assembly. The coolant channel gap dimensions shall be taken within the full length of each channel as measured half way between the combs and the side plates and by a procedure that provides digital dimensions. All dimensions of this Specification shall apply at a temperature of $75^{\circ} \mathrm{F} \pm 5^{\circ} \mathrm{F}$. Results of this inspection shall be submitted to the Purchaser and the User.

3.4.3.5 Surface Finish and Defects: Fuel Elements surfaces, which are not Fuel Plate surfaces, shall be free from pits, dents, scratches, and other removal of metal in excess of 0.015 inches deep and 0.180 inches in diameter.

3.4.3.6 Cleanliness and Surface Contamination: The Supplier's fabrication, assembly, and storage areas used for the Production of Fuel Elements and/or components shall conform to the requirements of a "Controlled Work Area" as defined in Paragraph 1.3.6 of STD-7022A. Cleanliness shall be in compliance with STD-7022A, paragraphs 1.1, 1.2.3, 3.1, 3.2-b, $-\mathrm{d},-1,3.3-\mathrm{d},-\mathrm{e}, 4.1 .3,4.2$, and 4.3. Freon shall not be used to clean Fuel Elements or components.

There shall be no foreign materials on the surfaces of the finished Fuel Plates or Fuel Elements. Use of graphite or organics for marking purposes is prohibited. The use of 


\section{Appendix C (Draft Element Specification)}

\begin{tabular}{|c|c|c|c|}
\hline $\begin{array}{l}\text { SPECIFICATION FOR DDE-MURR FUEL } \\
\text { ELEMENTS }\end{array}$ & $\begin{array}{l}\text { Identifier: } \\
\text { Revision: } \\
\text { Effective Date: }\end{array}$ & $\begin{array}{l}\text { SPC-1314 } \\
0 \\
\text { TBD }\end{array}$ & Page: 18 of 21 \\
\hline
\end{tabular}

abrasives for cleaning the Fuel Plates or for any other purpose is prohibited, as is any procedure which removes aluminum from the surface of the finished Fuel Plates. Any corrosion products, dirt, scale, graphite, oil products, metal chips, finger prints, etc., shall be removed without violating minimum Cladding thickness. Degreasing agents shall be approved by the Purchaser. After degreasing, all surfaces, including all crevices shall be thoroughly rinsed with distilled water. Water marks that do not affect the mechanical integrity of the swage joints are allowed.

Fuel Plate and Fuel Element cleanliness requirements of shall be verified by visual inspection of $100 \%$ of the Fuel Plates and Fuel Elements and by In-Process Controls. The surfaces of each Fuel Plate and the completed Fuel Element shall be smeared and the smear counted for radioactive contamination. The alpha count shall be less than five (5) dpm per $100 \mathrm{~cm}^{2}$ and the beta-gamma count shall be less than two hundred (200) dpm per $100 \mathrm{~cm}^{2}$.

3.4.3.7 Fuel Element Surface Treatment: After Fuel Elements are final machined and inspected they shall be subjected to an environment that will cause an evenly distributed boehmite layer to form on all surfaces of the entire assembly. The treatment process shall be performed under controlled conditions, which shall require the Supplier to maintain a record of the thermal history of the autoclave. The records shall include heat charts of recorded time and temperature. The Supplier shall maintain documented evidence of the controls placed on the autoclave.

Each Fuel Element shall have a corresponding aluminum plate cropping, made from Fuel Plate end crops, placed near the Fuel Element during the boehmite formation process. The aluminum plate croppings shall be subjected to the same environment as the Fuel Elements and each aluminum plate cropping measured for boehmite thickness via Eddy current instrumentation. The average of these measurements shall not be less than less than 0.00006 inch or more than 0.0003 inch thickness.

Fuel Elements and aluminum plate croppings subjected to the boehmite formation process shall be carefully handled to preclude scratches, dents, and gouges that would cause removal of boehmite. 


\section{Appendix C (Draft Element Specification)}

\begin{tabular}{|c|c|c|c|}
\hline $\begin{array}{l}\text { SPECIFICATION FOR DDE-MURR FUEL } \\
\text { ELEMENTS }\end{array}$ & $\begin{array}{l}\text { Identifier: } \\
\text { Revision: } \\
\text { Effective Date: }\end{array}$ & $\begin{array}{l}\text { SPC-1314 } \\
0 \\
\text { TBD }\end{array}$ & Page: 19 of 21 \\
\hline
\end{tabular}

3.4.3.8 Storage: All Fuel Elements that have received boehmite treatment shall be sealed in clean polyethylene containers or other containers approved by the Purchaser while being transferred into storage, maintained in storage, and prepared for packaging and shipment. Any material exposed to contamination shall be re-inspected according to the requirements of Section 3.4.3.6.

\section{MATERIALS OF CONSTRUCTION}

4.1 All items prepared for Fuel Element assembly shall be traceable to the raw material from which they were fabricated.

4.2 Prior to fabrication of Fuel Plates and Fuel Elements, the Supplier or an independent laboratory shall perform chemical analysis, and mechanical tests where applicable, on U-Mo alloys, zirconium Interlayer, side plates, end box, and Fuel Plate Cladding materials.

\section{TEST AND INSPECTION REQUIREMENTS}

\section{$5.1 \quad$ Responsibility}

Unless otherwise specified, the Supplier shall be responsible for the performance of all tests and inspections required prior to submission to the Purchaser of any Fuel Element for acceptance. The following tests and inspections, in addition to the ones listed in the various sections of the Specification, shall be performed by the Supplier to assure that the product quality is in accordance with the requirements of this Specification.

5.1.1 Materials: Compliance with material requirements shall be established by Supplier certification. A certification of chemical analysis or a certified Mill Test Report shall be supplied to the Purchaser for each Lot of material used in the fabrication of Fuel Elements. All materials shall be traceable to the Fuel Elements fabricated from these materials.

\section{DELIVERY SUBMITTALS}

6.1 Two (2) copies (except as noted) of the following data and records shall be sent previous to or concurrent with shipments to the Purchaser and one (1) copy shall be sent to the Stakeholder.

6.1.1 Certification of product compliance to the requirements of this Specification to include any test data pertaining thereto 


\section{Appendix C (Draft Element Specification)}

\begin{tabular}{|c|c|c|c|}
\hline $\begin{array}{l}\text { SPECIFICATION FOR DDE-MURR FUEL } \\
\text { ELEMENTS }\end{array}$ & $\begin{array}{l}\text { Identifier: } \\
\text { Revision: } \\
\text { Effective Date: }\end{array}$ & $\begin{array}{l}\text { SPC-1314 } \\
0 \\
\text { TBD }\end{array}$ & Page: 20 of 21 \\
\hline
\end{tabular}

6.1.2 Certification of material compliance to the requirement of this

Specification to include any chemical and physical test results pertaining thereto

6.1.3 Dimensional Data as required by Section 3.4.2.6 and Section 3.4.3.4

6.1.4 Individual Fuel Plate uranium data including:

6.1.4.1 Serial number with foil identification

6.1.4.2 Foil weight

6.1.4.3 Uranium content

6.1.4.4 Total U-235 content

6.1.4.5 Alpha contamination results

6.1.5 Individual Fuel Element Composition data including:

6.1.5.1 Serial number of the Fuel Element

6.1.5.2 Uranium content

6.1.5.3 U-235 content

6.1.5.4 Serial number of each Fuel Plate in the Fuel Element and the stacking order

6.1.6 Radiation smear count from Fuel Plate and Fuel Element exterior, as required by Section 3.4.3.6

6.1.7 Results of swage joint pull tests specified in Section 3.4.3.2

6.1.8 List of all applicable waivers and deviations and related Fuel Plates or Fuel Elements

6.1.9 Radiographs as specified in Section 0 and UT data as specified in Section 3.4.2.4 to be sent to the Purchaser

\section{PACKAGING AND SHIPPING}

7.1 Purchaser shall provide shipping containers which will protect the Fuel Elements from damage during shipment and which conform in all respects to the applicable regulations of the U.S. Department of Energy, of the U.S. Department of 


\section{Appendix C (Draft Element Specification)}

\begin{tabular}{|c|c|c|c|}
\hline $\begin{array}{l}\text { SPECIFICATION FOR DDE-MURR FUEL } \\
\text { ELEMENTS }\end{array}$ & $\begin{array}{l}\text { Identifier: } \\
\text { Revision: } \\
\text { Effective Date: }\end{array}$ & $\begin{array}{l}\text { SPC-1314 } \\
0 \\
\text { TBD }\end{array}$ & Page: 21 of 21 \\
\hline
\end{tabular}

Transportation, and of any other agencies having jurisdiction over the shipment of radioactive materials.

7.2 The Supplier shall load the Fuel Elements into the shipping containers in a sealed polyethylene bag in a clean and dry condition free of extraneous materials.

7.3 The Supplier shall take all necessary precautions during packing to prevent damage to the Fuel Elements during shipment. Each container shall be provided with a tamper-proof seal. The container's loading and shipping documents shall be prepared in accordance with all applicable regulations.

7.4 The Supplier shall make arrangements for shipment to the facility designated by the Purchaser. Approval of shipping date shall be obtained from Purchaser prior to any shipment. The Supplier shall make the shipment per a prepared and maintained handling, packaging, and shipping procedure.

\section{ACCEPTANCE INSPECTION}

\subsection{Acceptance Inspection}

All materials, workmanship, and procedures shall be subject to inspection, examination, test, and Rejection by the Purchaser for noncompliance with the Specifications at any and all times during Manufacture, and at any and all places where such Manufacture is carried on. Final inspection and acceptance or Rejection will be made by the Purchaser at the Supplier's plant. The Purchaser shall have the right to reject any finished products for defects in workmanship, or defects in any of the materials comprising the finished product which otherwise fail to meet the Specification.

\subsection{Deviation from Specifications}

Notwithstanding other provisions of these Specifications, the Purchaser may, when requested in writing, waive certain minor deviations from requirements of the Specifications and drawings where the Failure to meet any specific requirement either alone or in combination with other Failures will not significantly reduce the efficiency or performance of the assembly. Acceptance of a Fuel Element by the Purchaser with deviations from the Specifications shall not be construed to mean the Purchaser approves or will approve similar deviations in Fuel Elements not yet delivered under the contract.

Deviations from design documents shall be documented on a change request form One (1) copy is to be sent to the Stakeholder concurrent to transmittal to the Purchaser. 


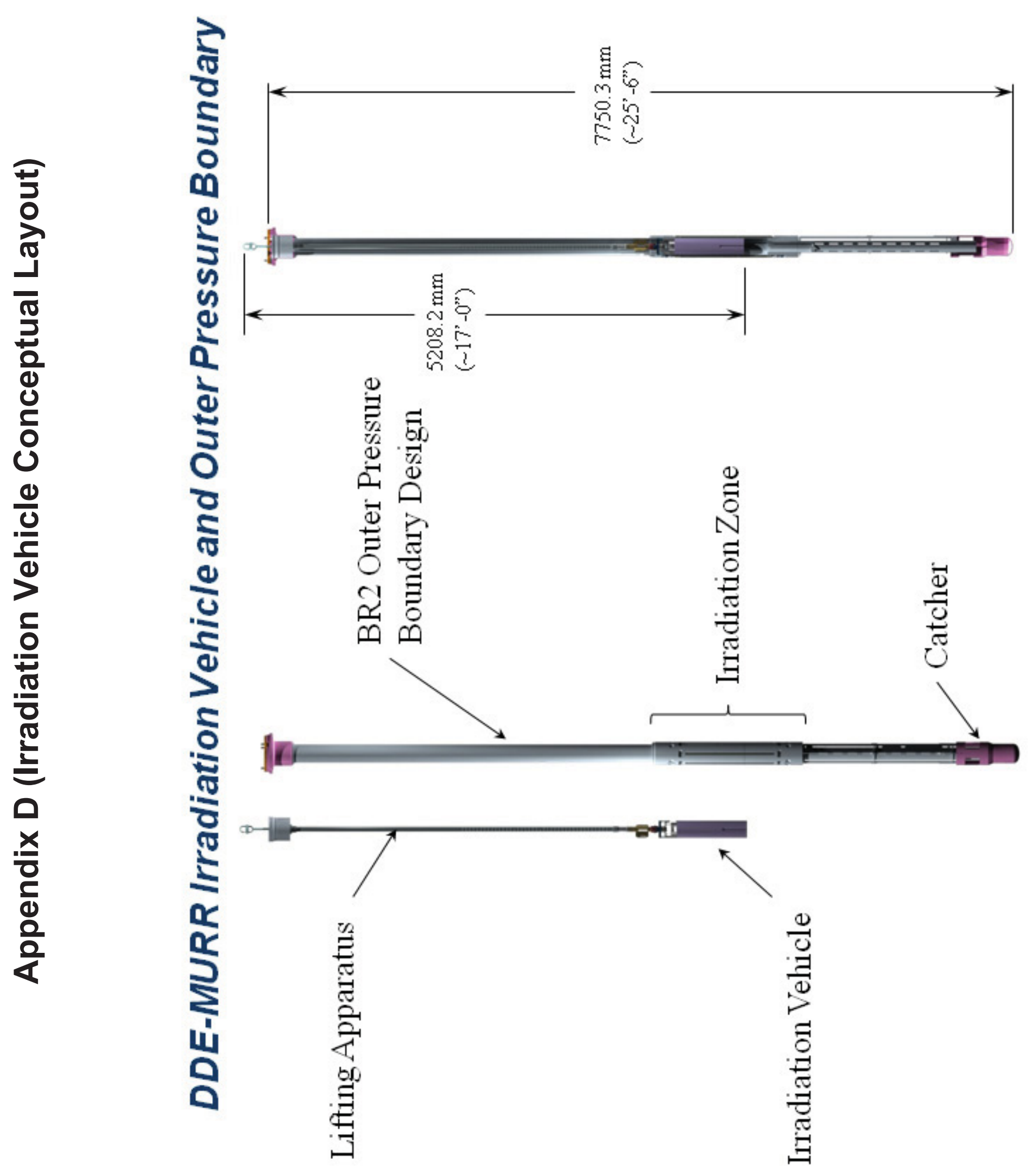




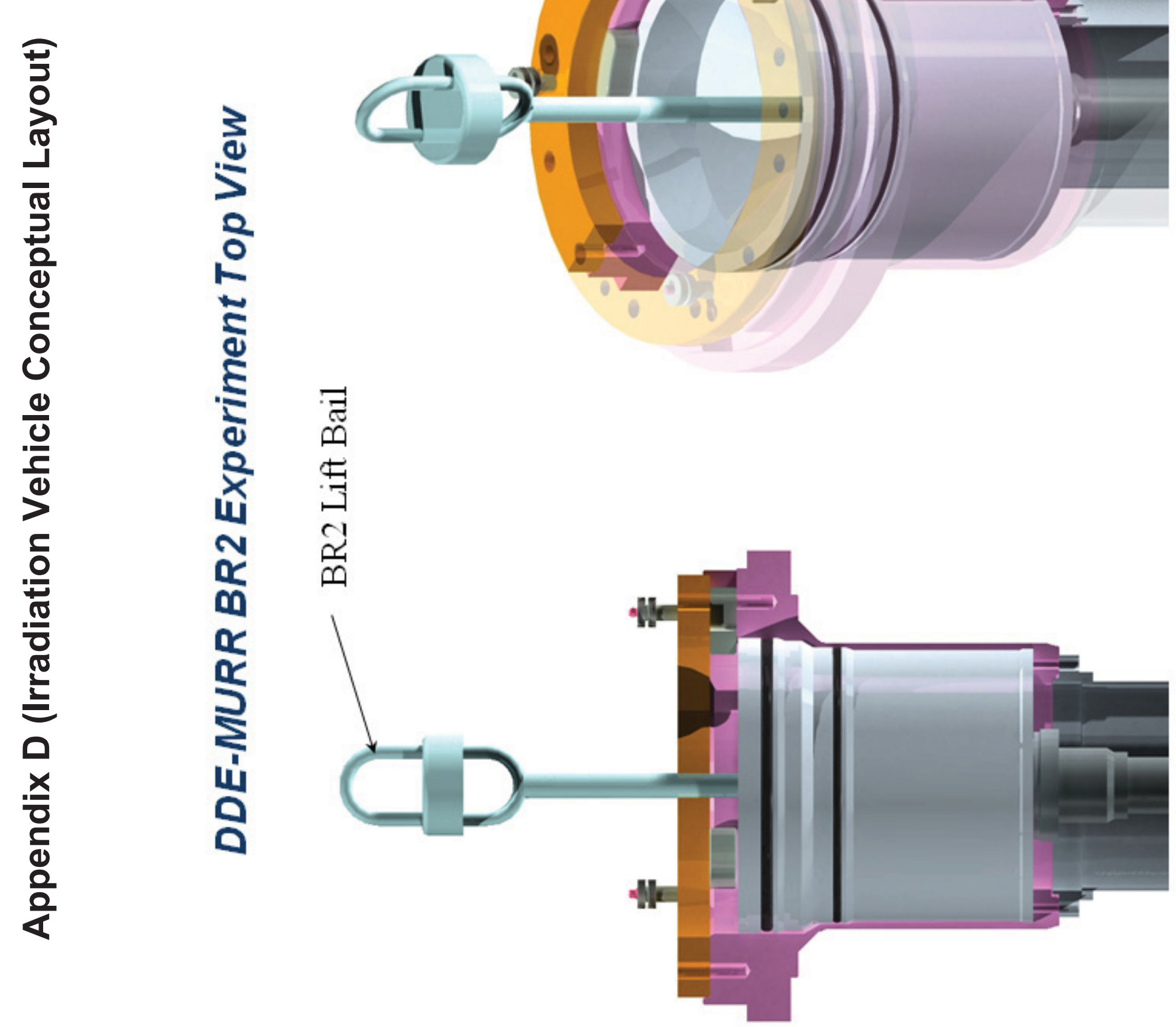



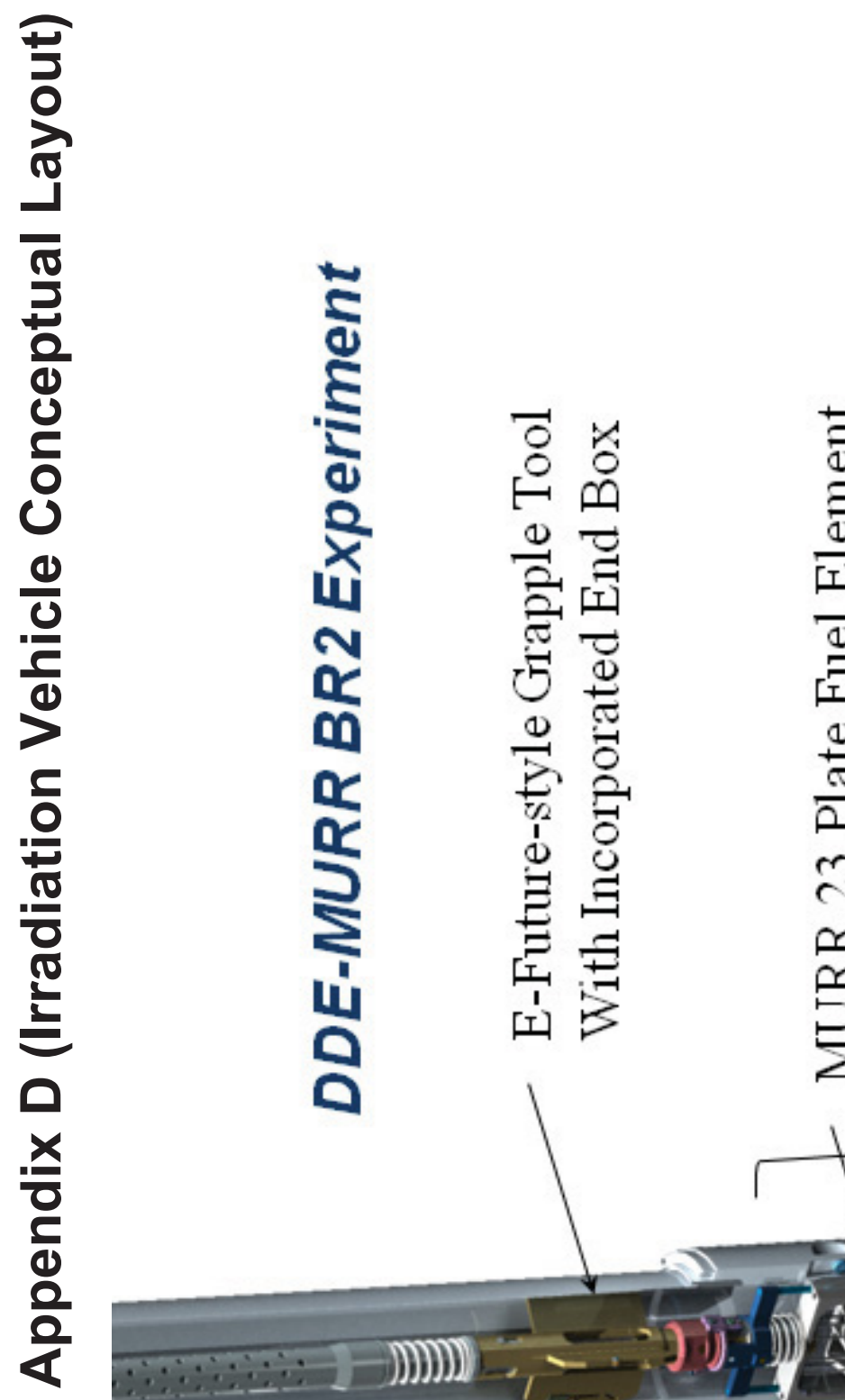

范

$\vec{\Phi}$

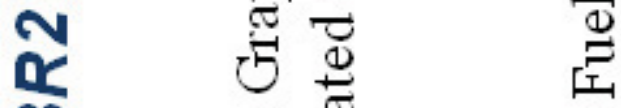

$\infty$

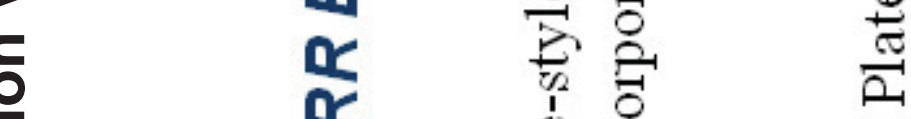

\%

0

恶声

m

$\frac{\sim}{p^{\prime}}$

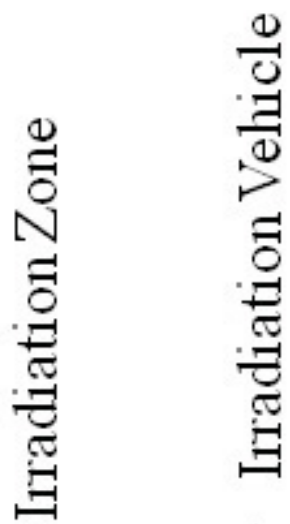

41

Q

$=$
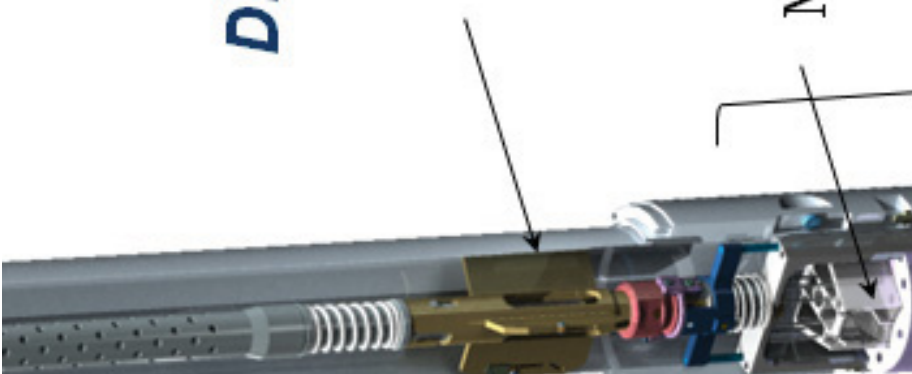

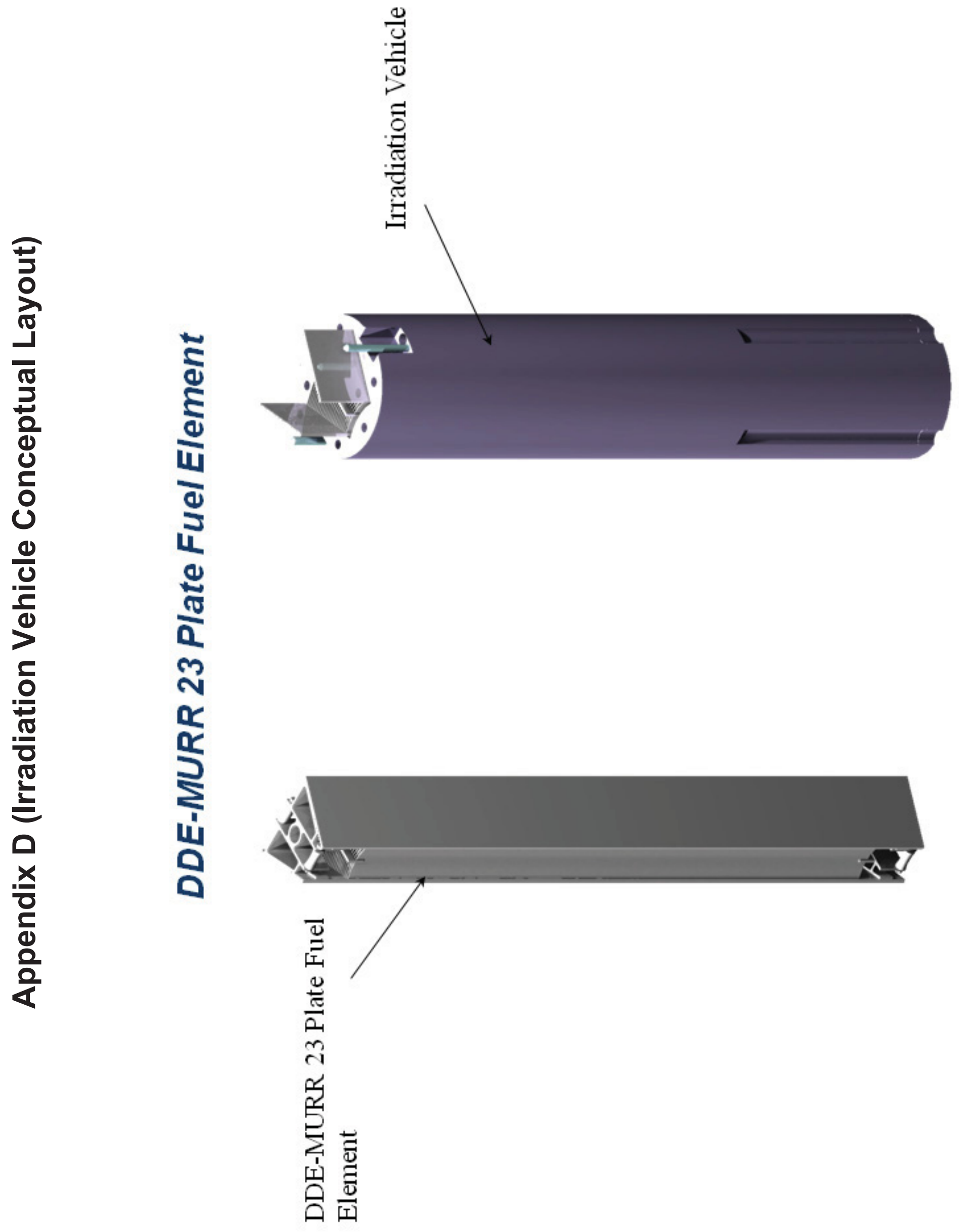


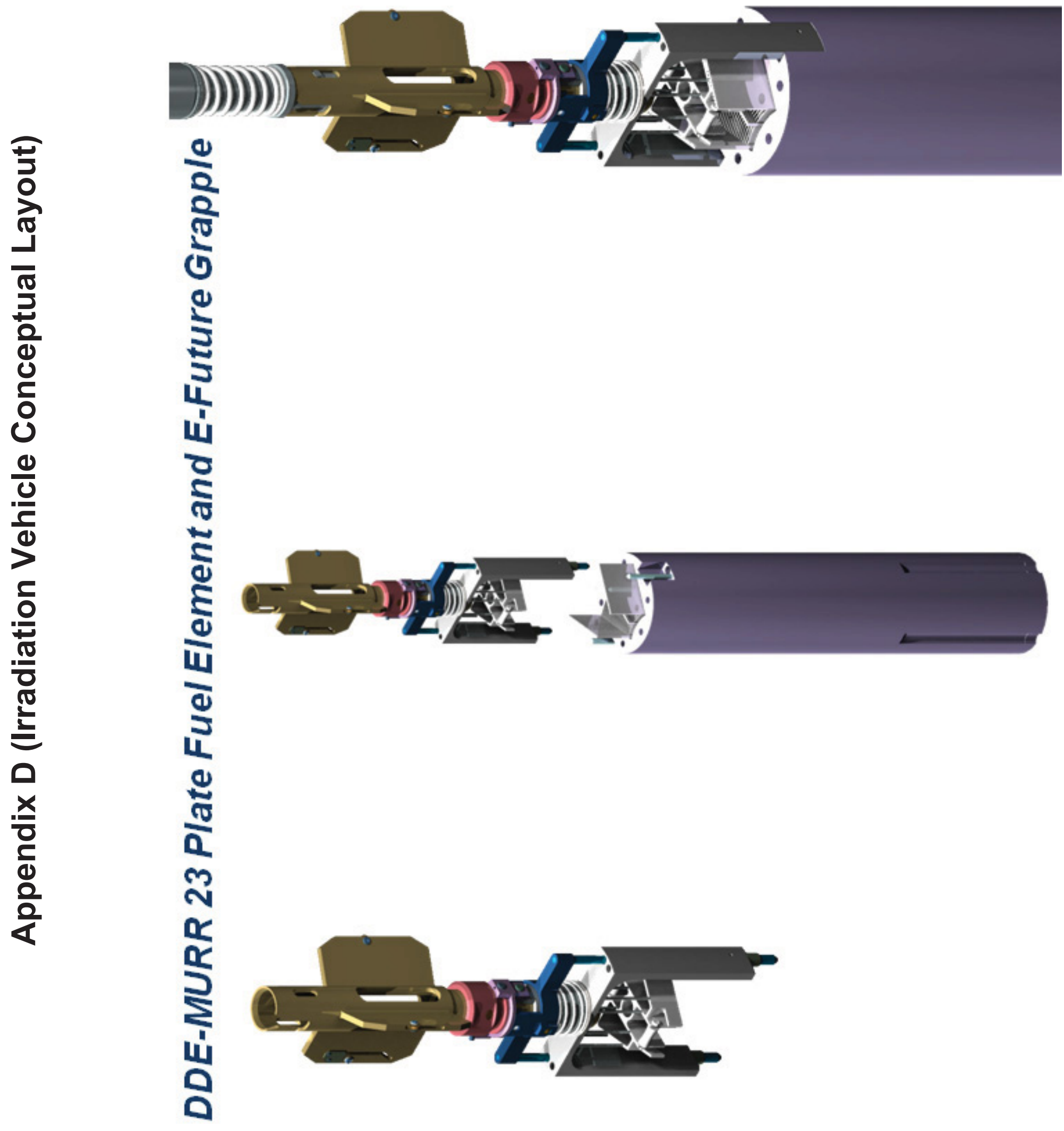




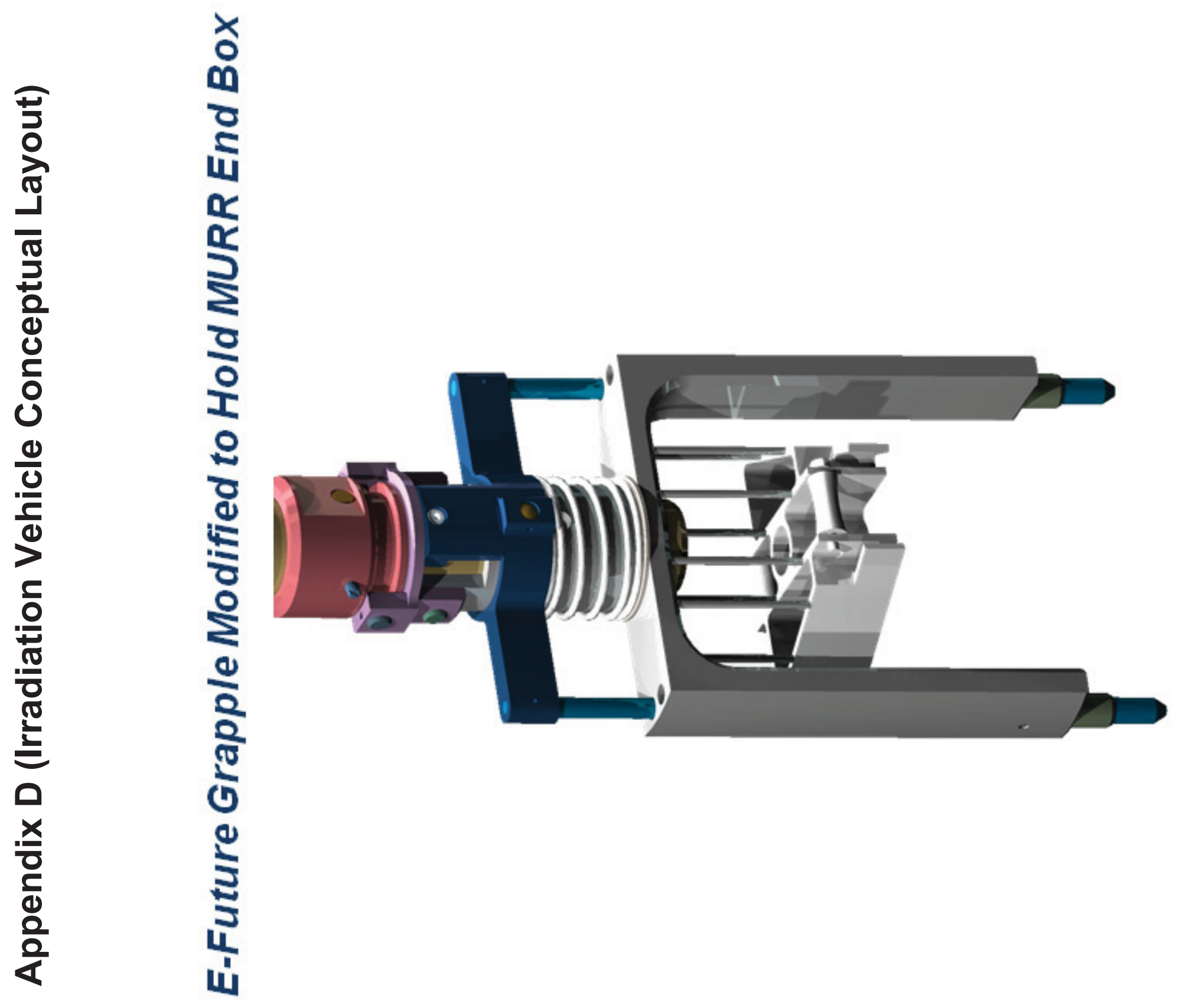




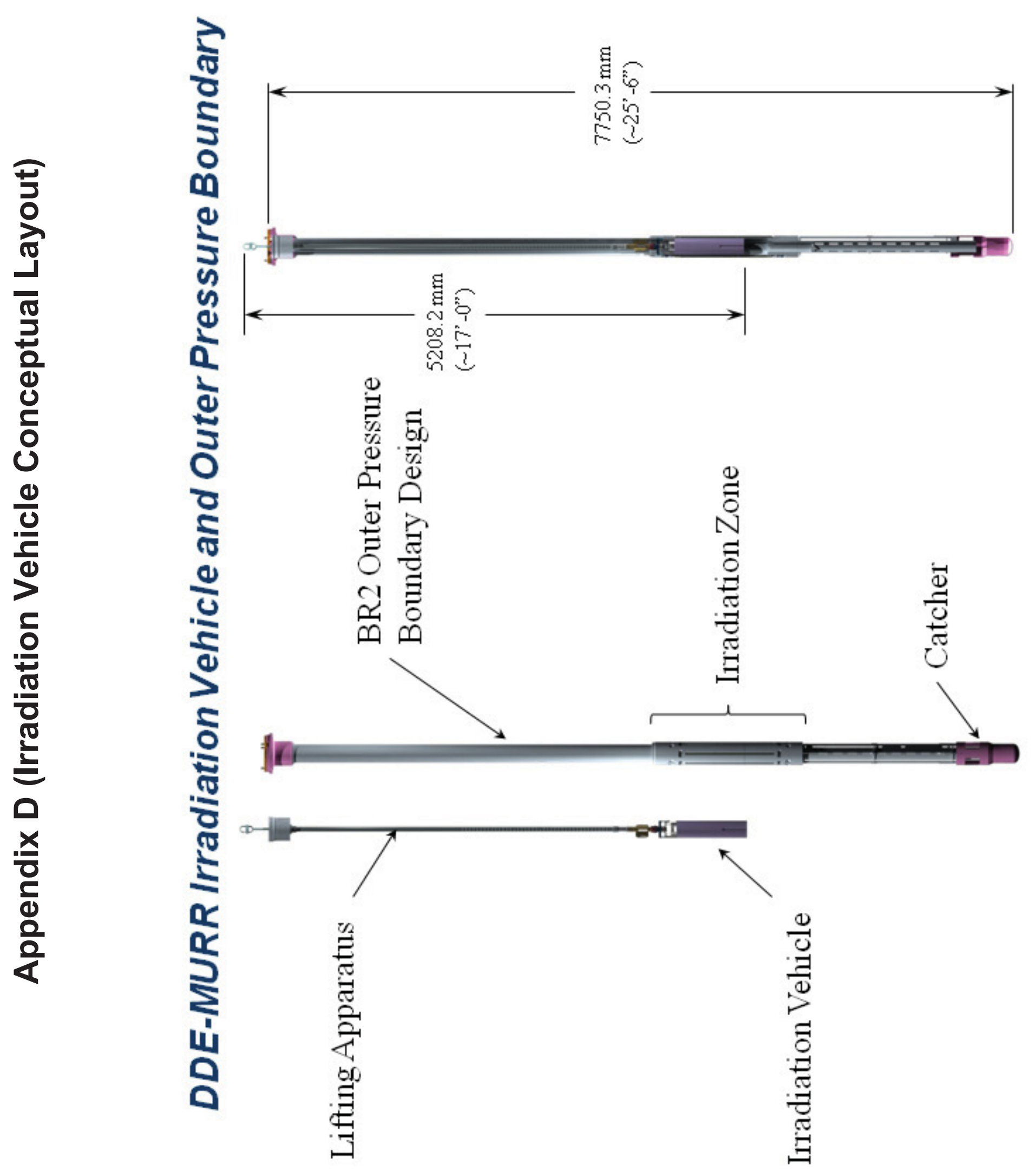




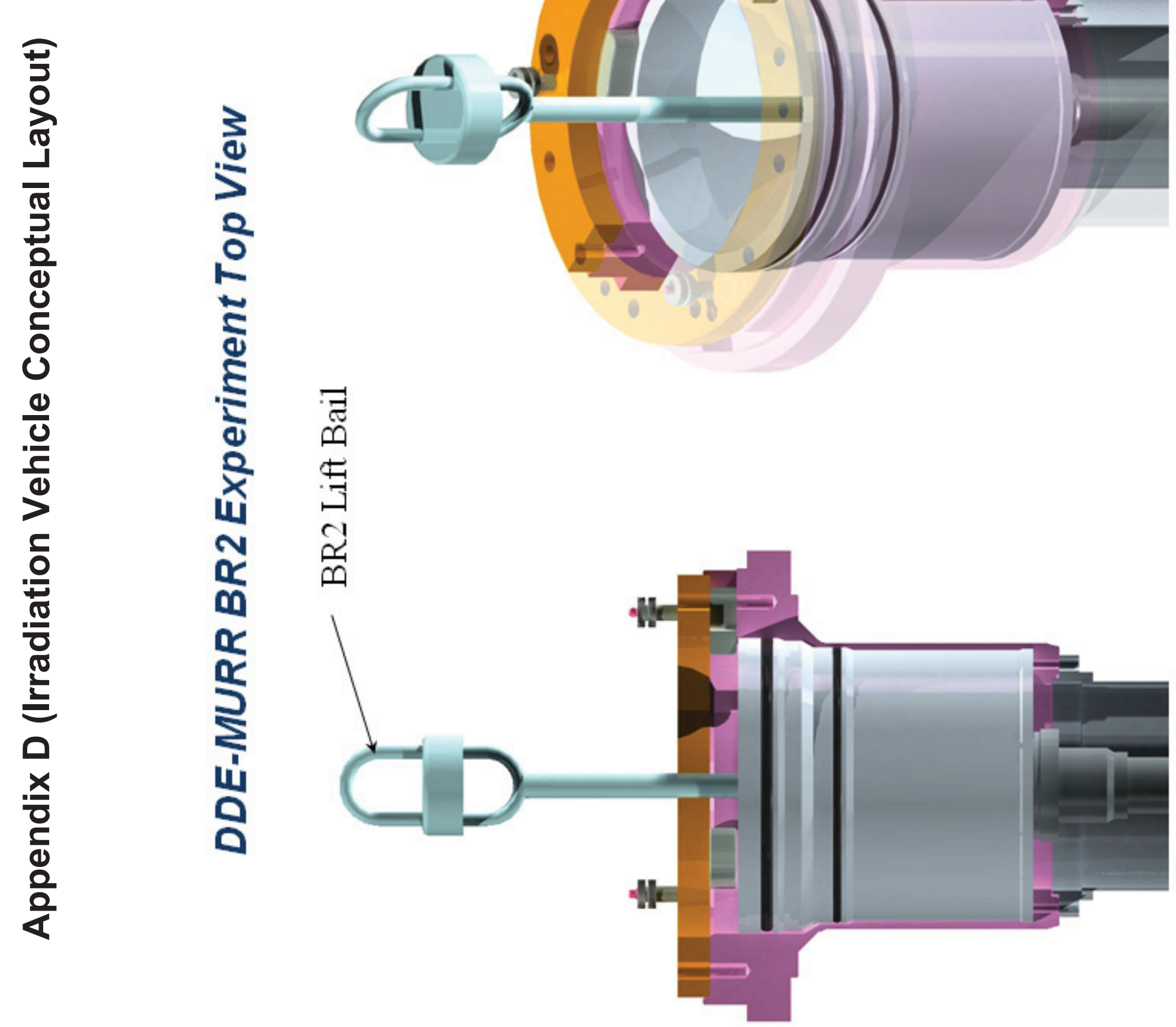



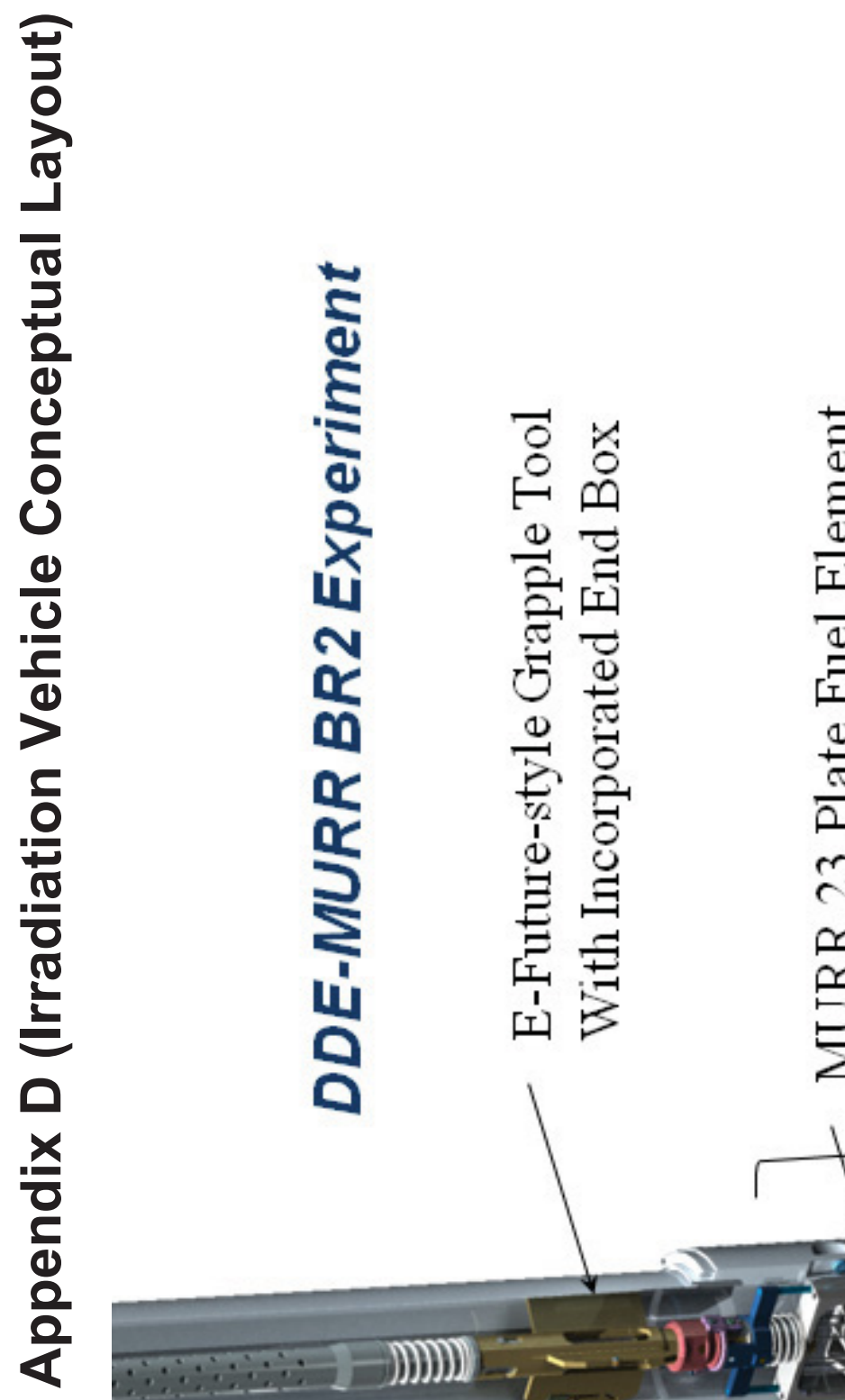

范

$\vec{\Phi}$

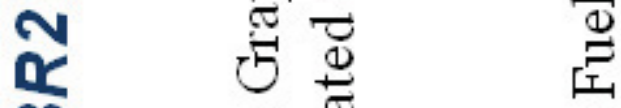

$\infty$

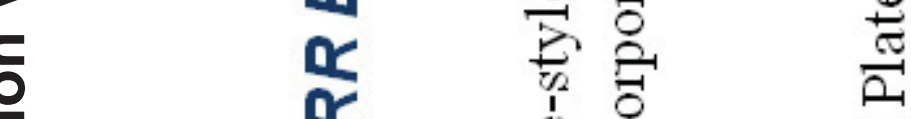

\%

0

恶声

m

$\frac{\sim}{p^{\prime}}$

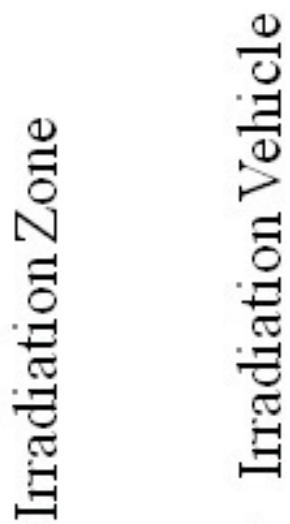

41

Q

$=$
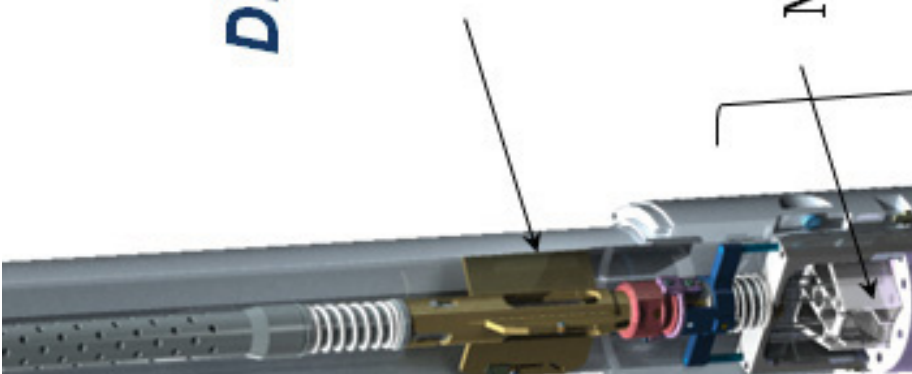

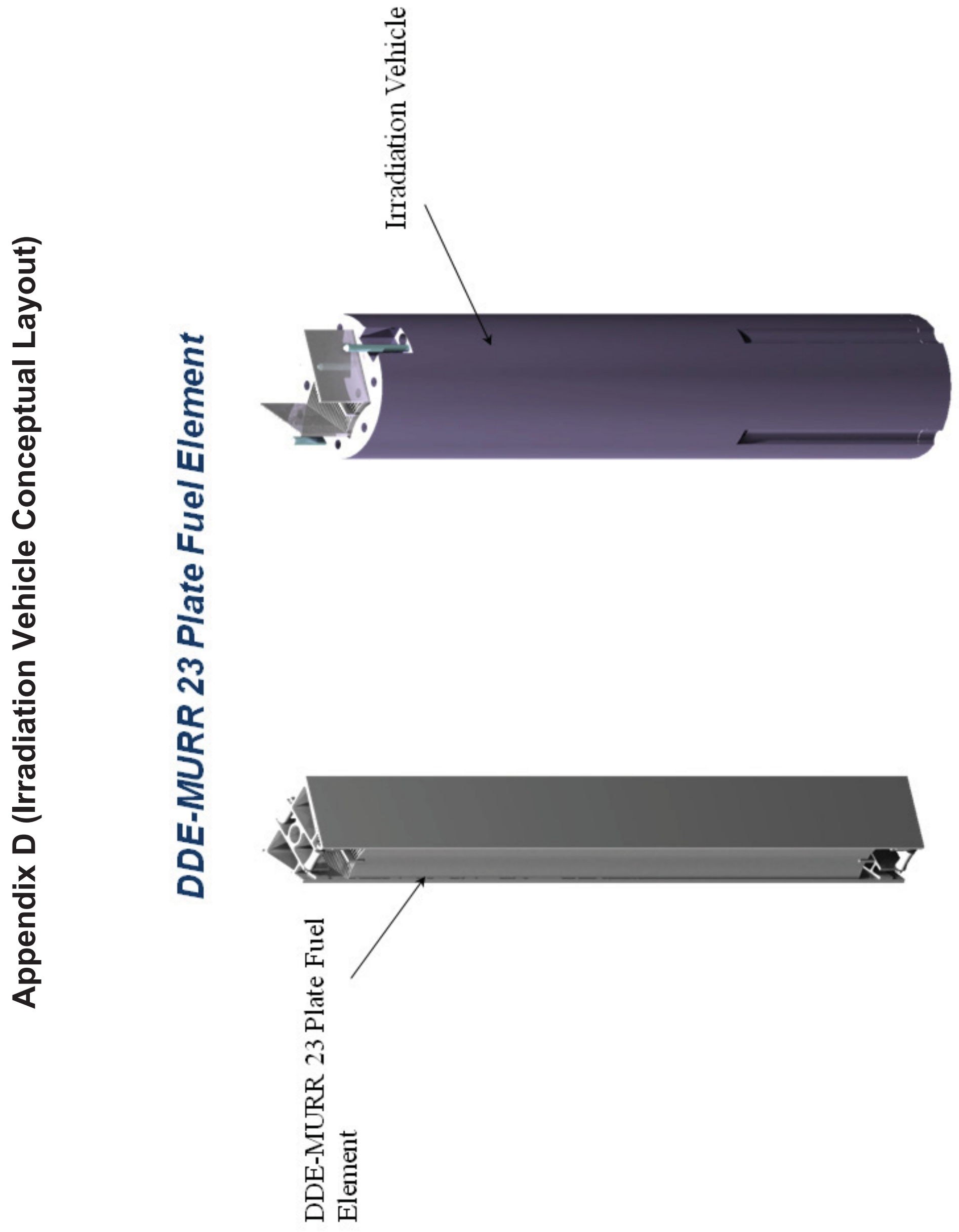


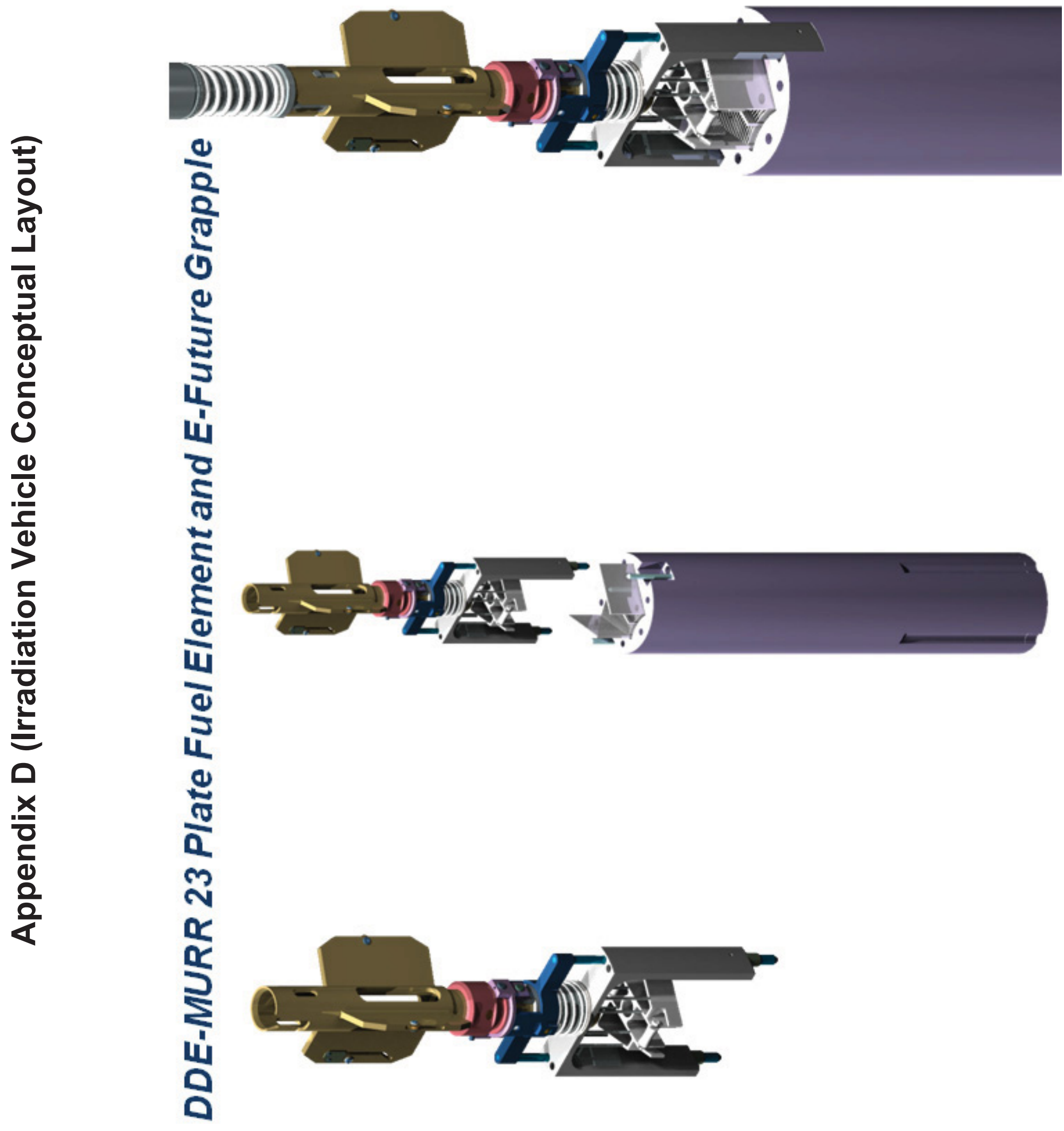




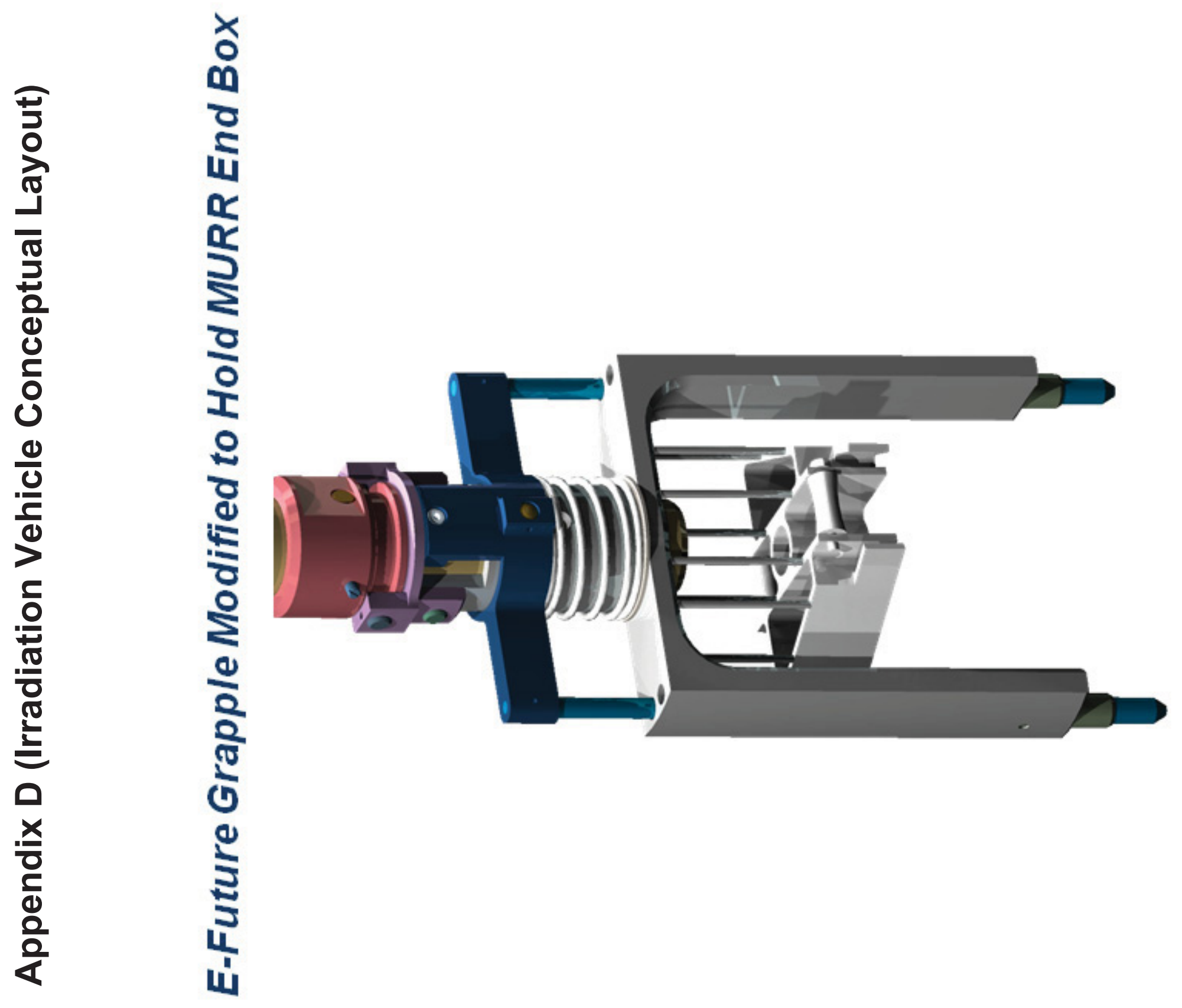




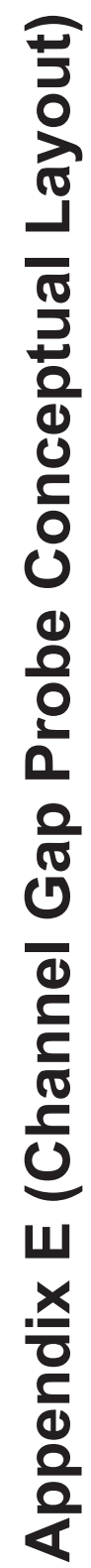

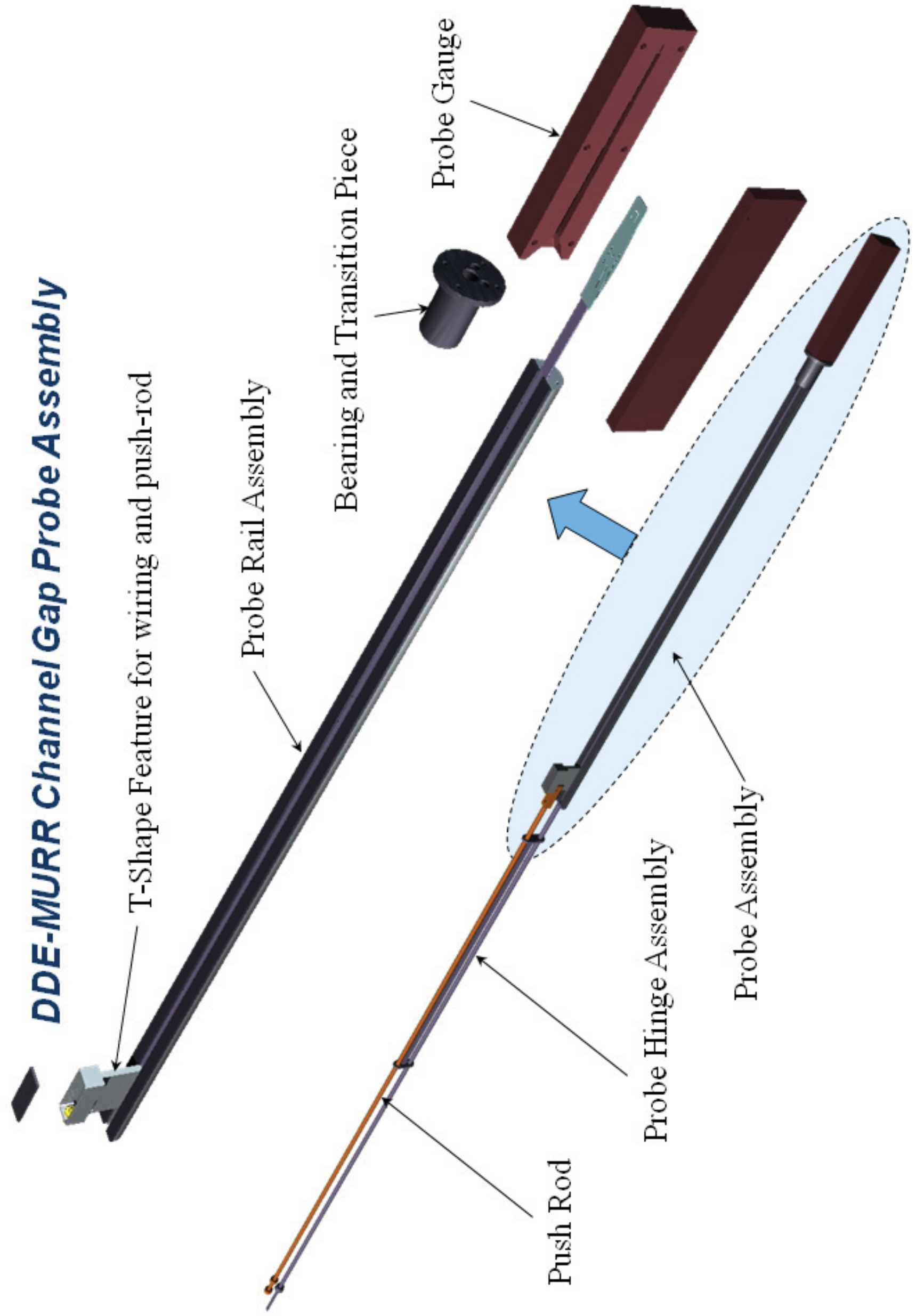



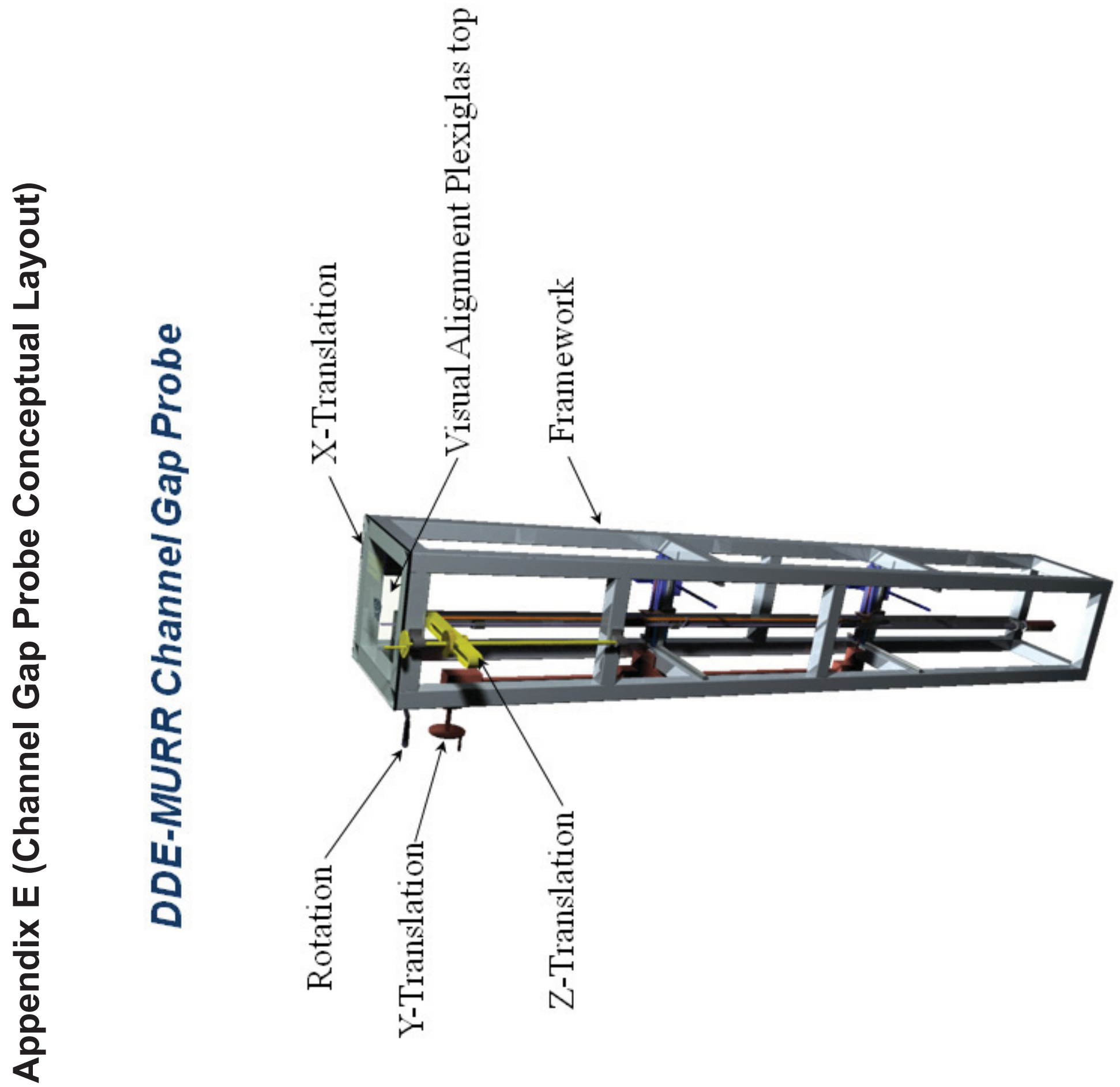


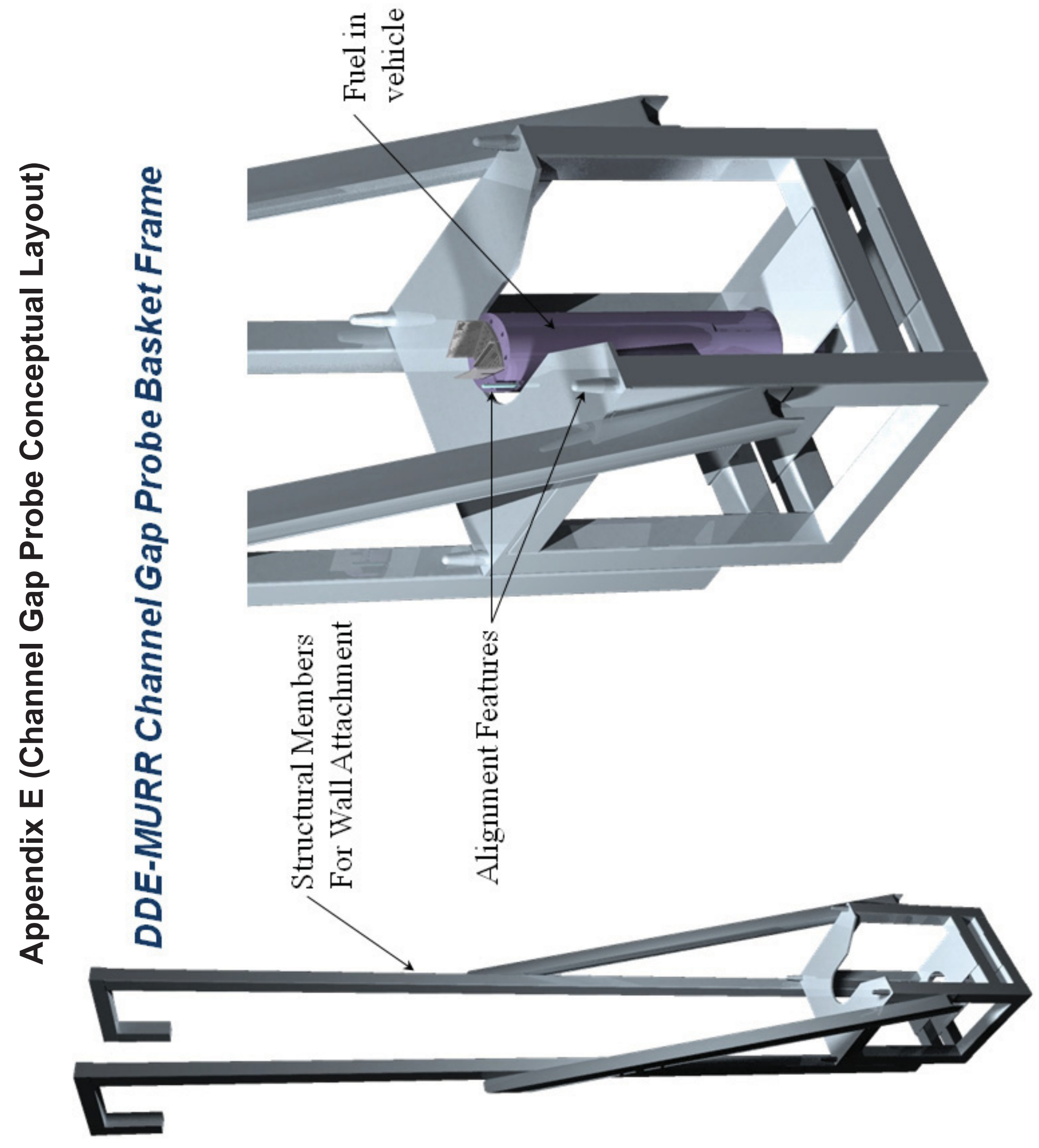



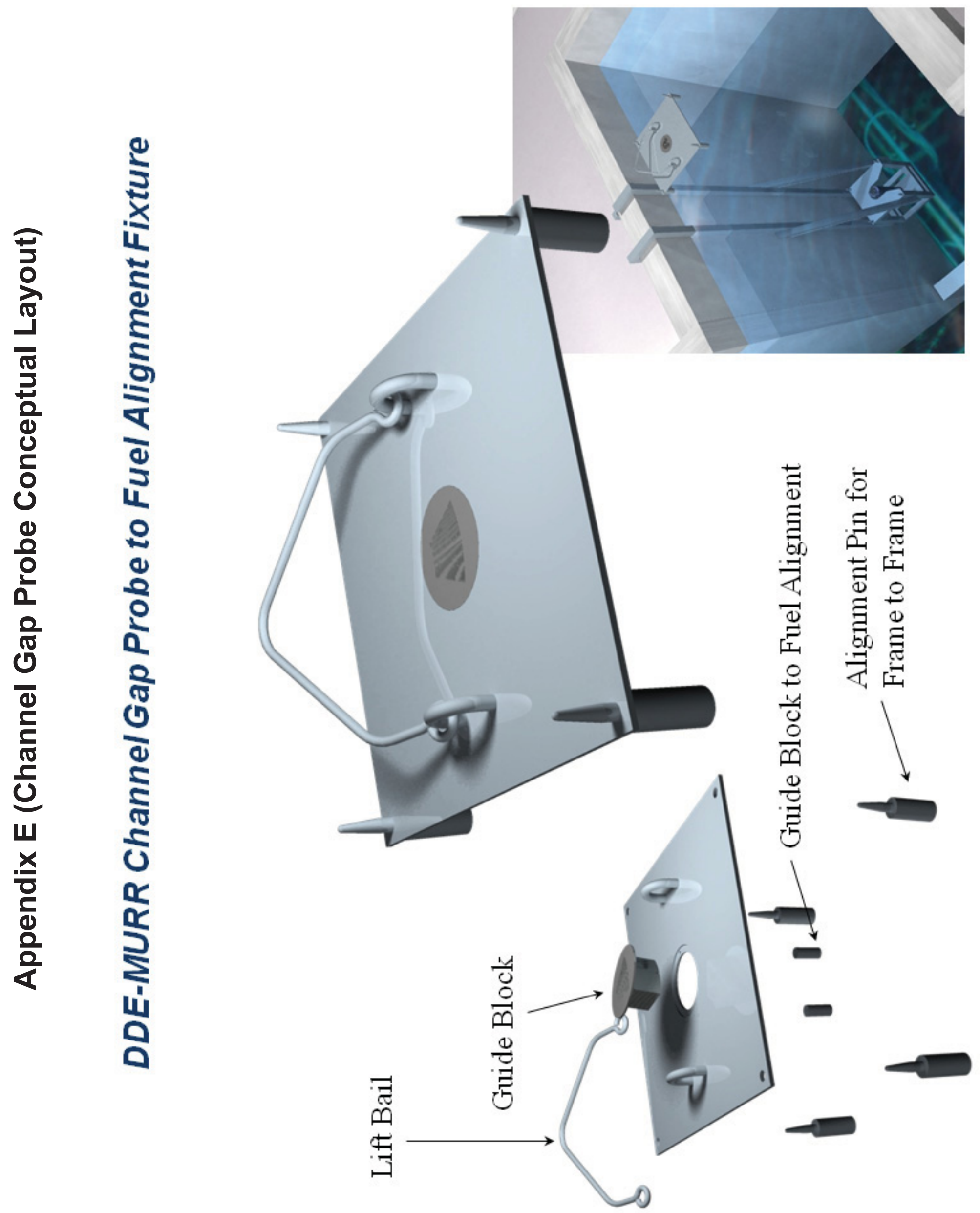

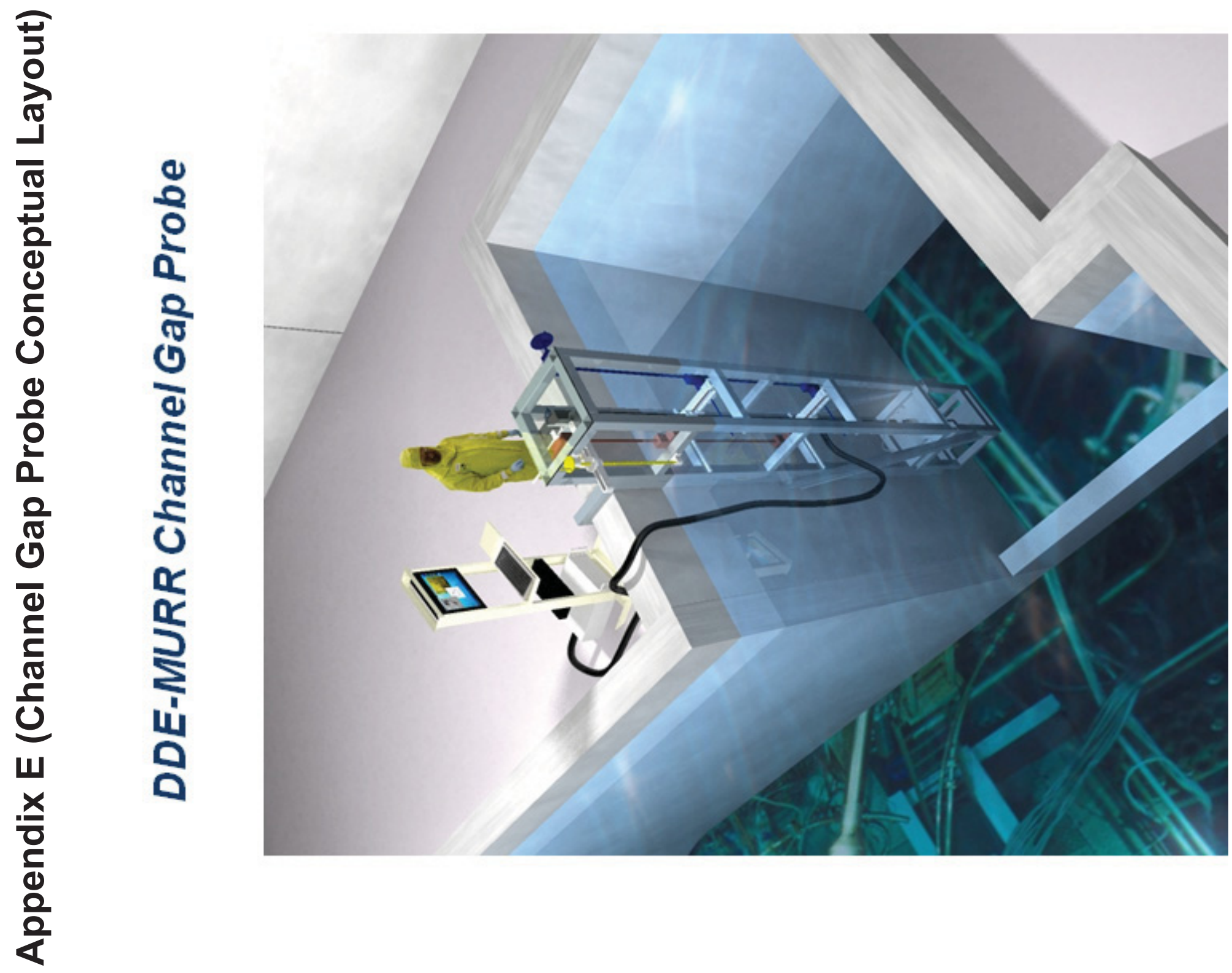

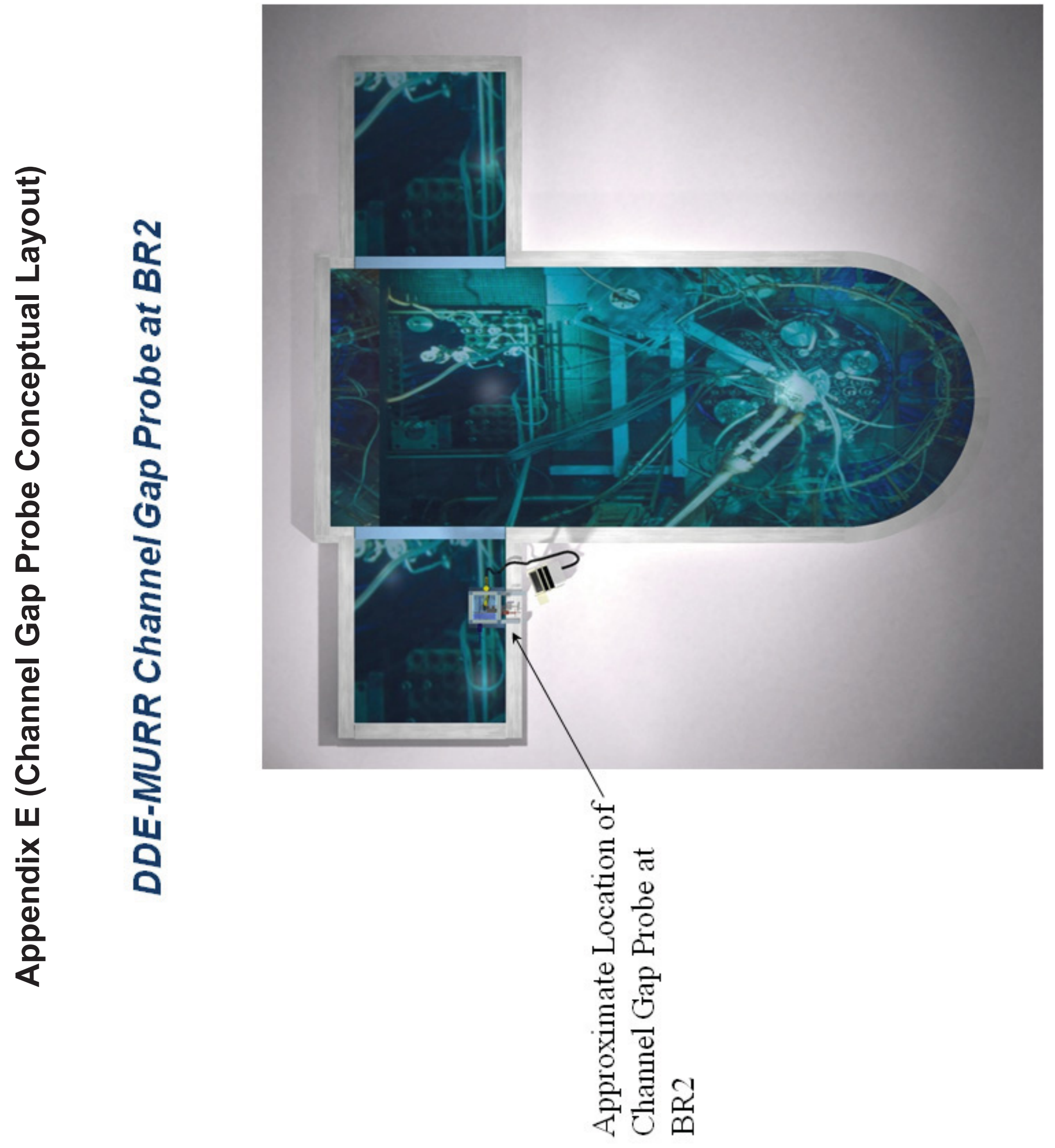


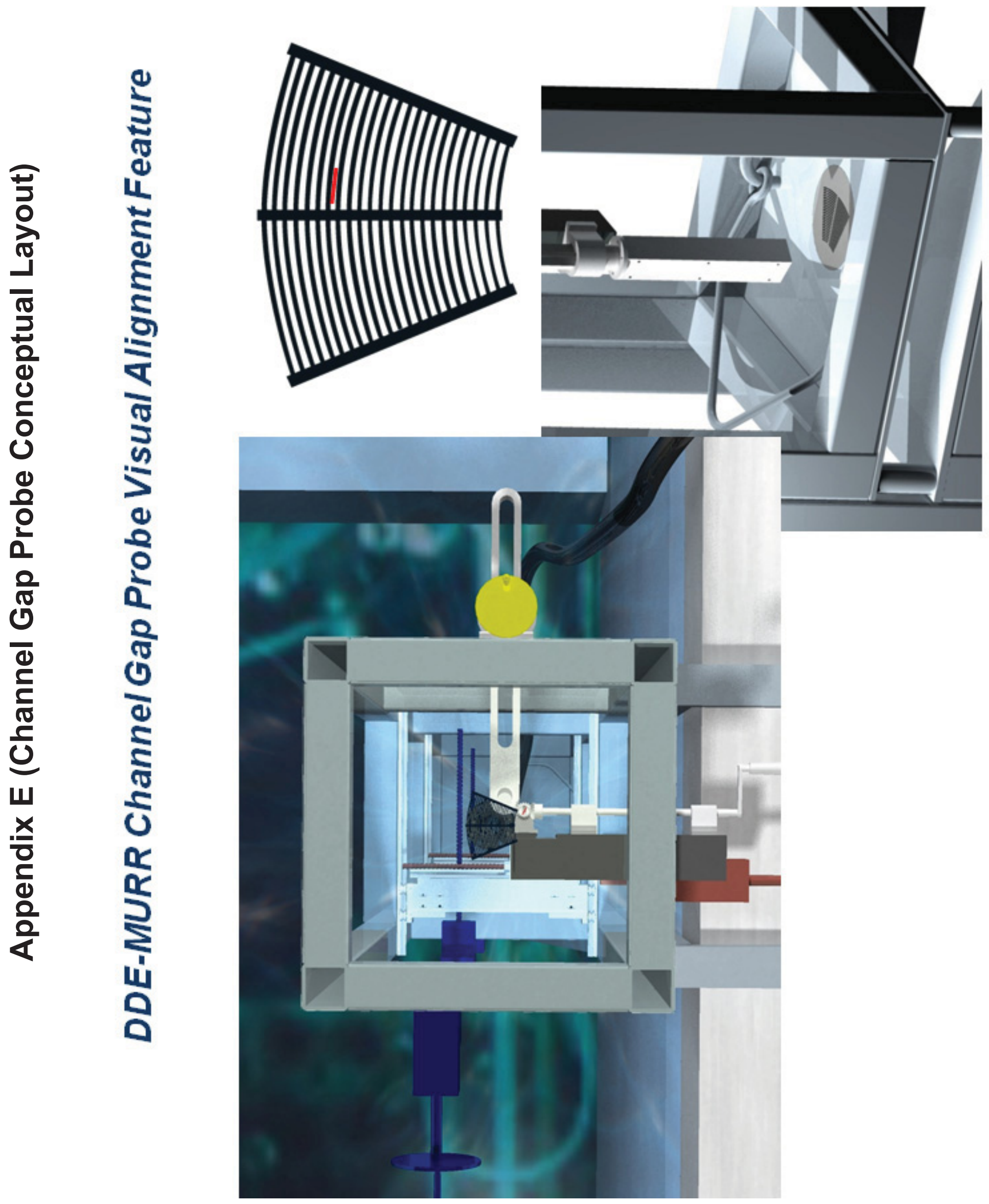




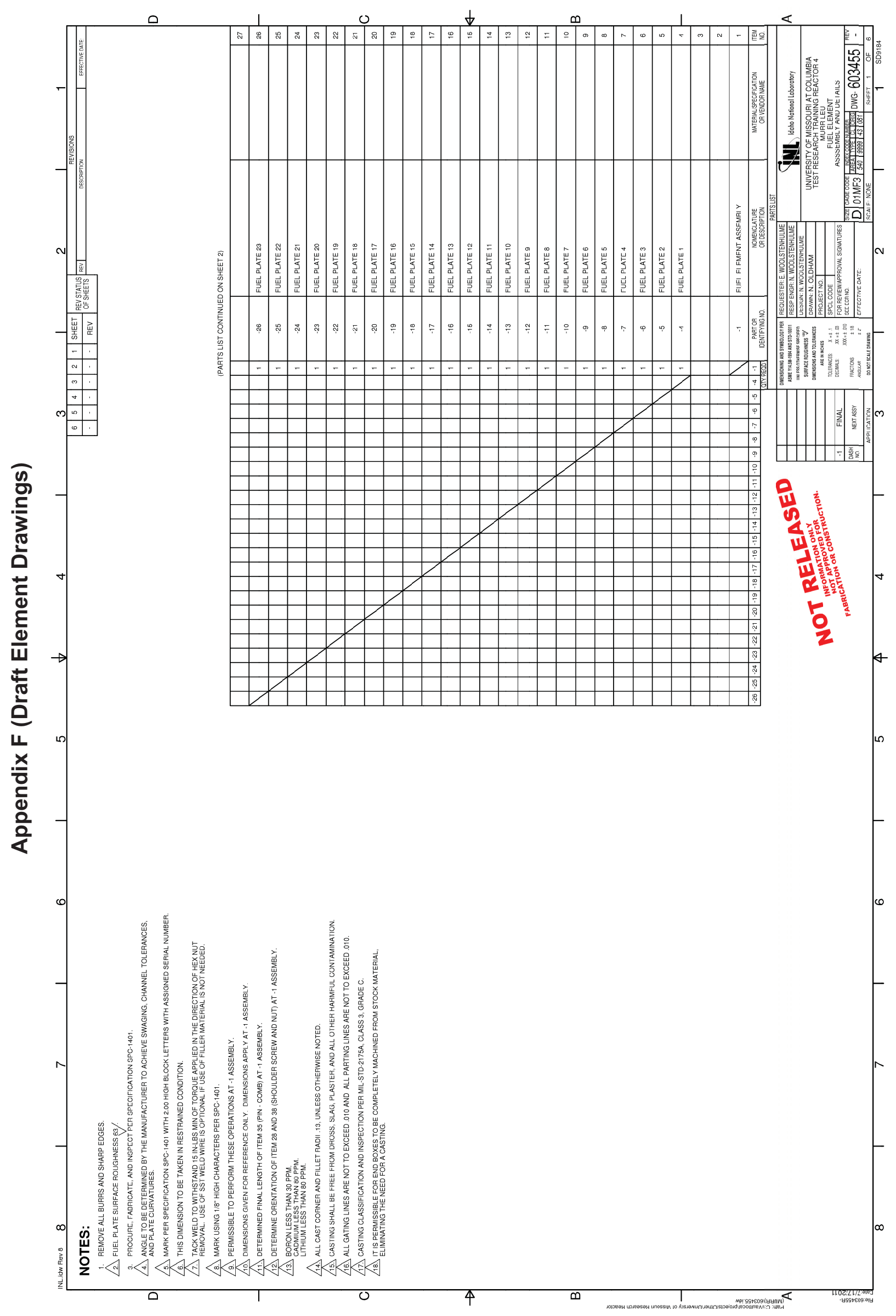




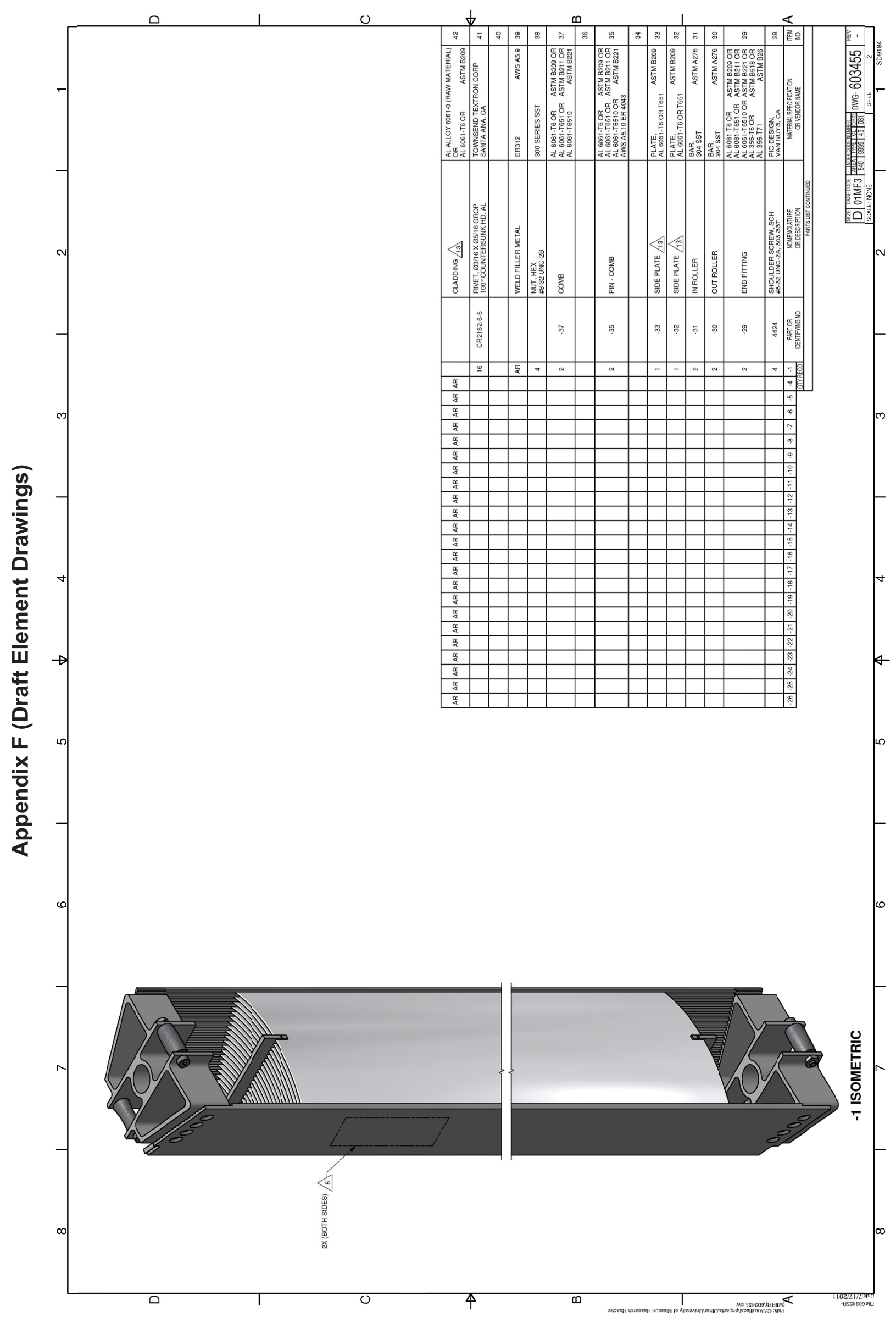




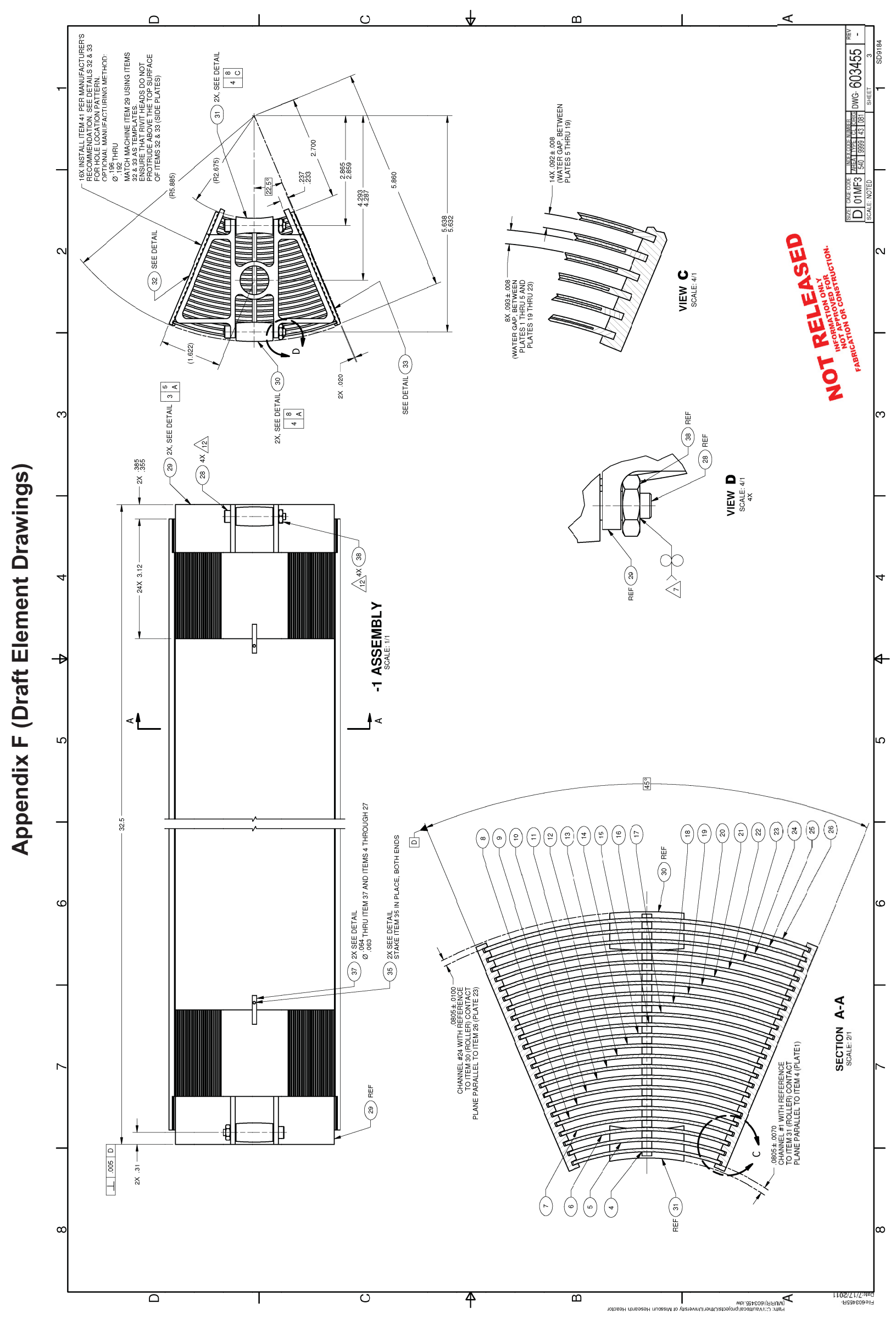




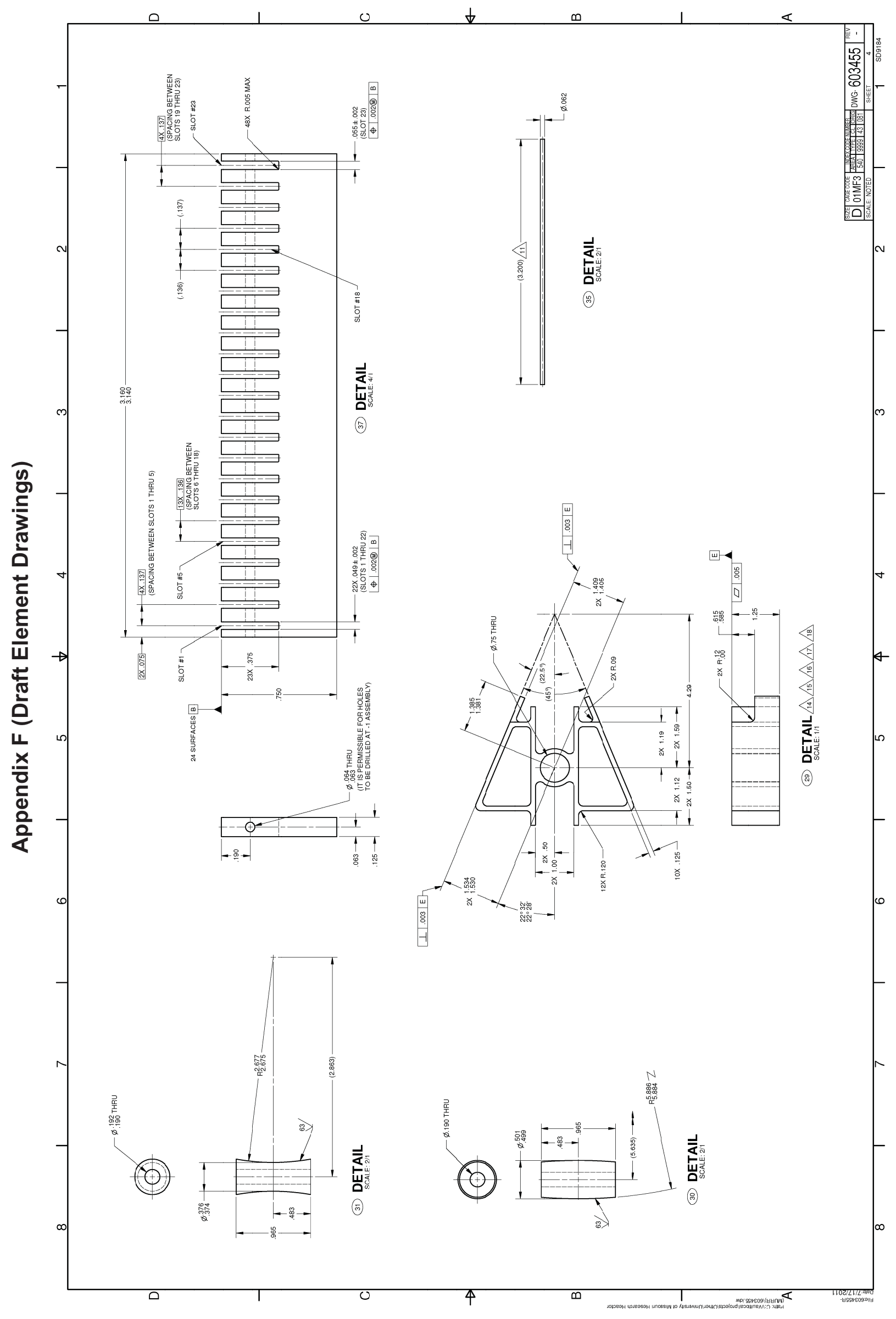




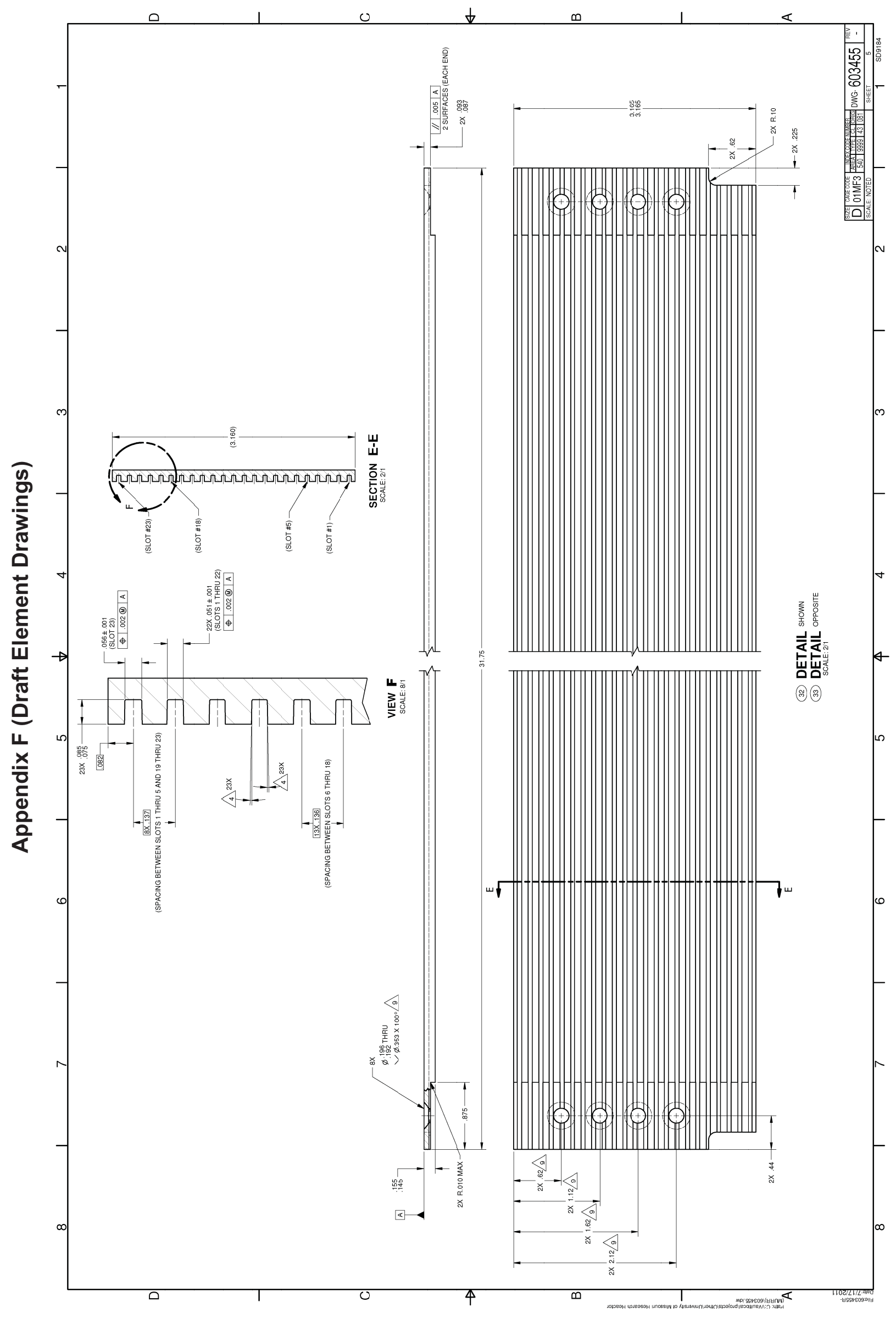




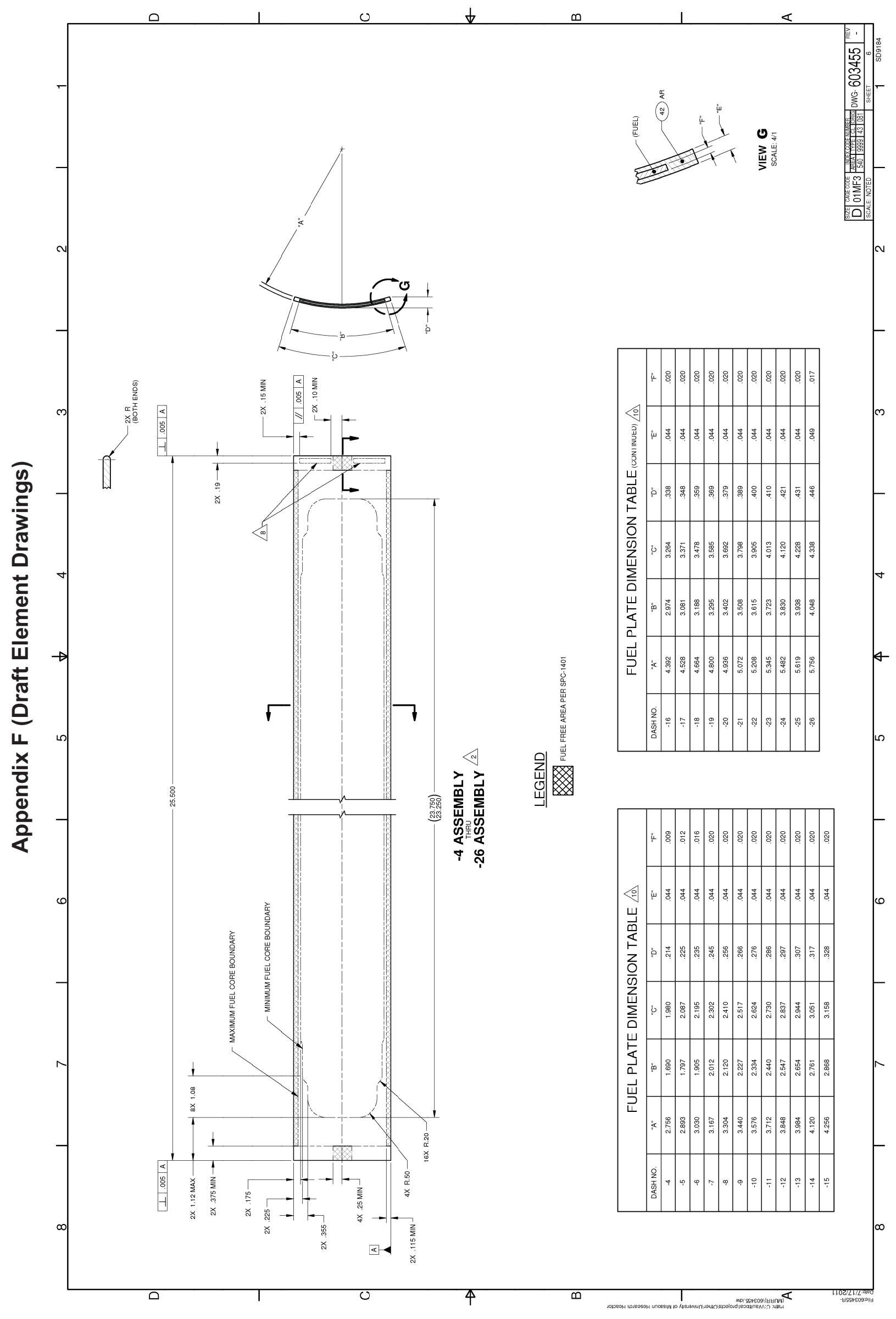

